\title{
Treatment adherence in hypertension : methodological aspects and new strategies
}

Citation for published version (APA):

van Onzenoort, H. A. W. (2012). Treatment adherence in hypertension : methodological aspects and new strategies. [Doctoral Thesis, Maastricht University]. Maastricht University. https://doi.org/10.26481/dis.20120627ho

Document status and date:

Published: 01/01/2012

DOI:

10.26481/dis.20120627ho

Document Version:

Publisher's PDF, also known as Version of record

\section{Please check the document version of this publication:}

- A submitted manuscript is the version of the article upon submission and before peer-review. There can be important differences between the submitted version and the official published version of record.

People interested in the research are advised to contact the author for the final version of the publication, or visit the DOI to the publisher's website.

- The final author version and the galley proof are versions of the publication after peer review.

- The final published version features the final layout of the paper including the volume, issue and page numbers.

Link to publication

\footnotetext{
General rights rights.

- You may freely distribute the URL identifying the publication in the public portal. please follow below link for the End User Agreement:

www.umlib.nl/taverne-license

Take down policy

If you believe that this document breaches copyright please contact us at:

repository@maastrichtuniversity.nl

providing details and we will investigate your claim.
}

Copyright and moral rights for the publications made accessible in the public portal are retained by the authors and/or other copyright owners and it is a condition of accessing publications that users recognise and abide by the legal requirements associated with these

- Users may download and print one copy of any publication from the public portal for the purpose of private study or research.

- You may not further distribute the material or use it for any profit-making activity or commercial gain

If the publication is distributed under the terms of Article $25 \mathrm{fa}$ of the Dutch Copyright Act, indicated by the "Taverne" license above, 


\section{Treatment adherence in hypertension}

methodological aspects and new strategies 
(C) Hein van Onzenoort, Nijmegen 2012

Layout: Tiny Wouters

Cover: Multisign2 belettering \& vormgeving

Production: Ipskamp

ISBN: 978-90-9026643-4 


\title{
Treatment adherence in hypertension
}

\author{
methodological aspects and new strategies
}

\section{PROEFSCHRIFT}

Ter verkrijging van de graad van doctor

aan de Universiteit Maastricht, op gezag van de Rector Magnificus,

Prof. mr. G.P.M.F. Mols,

volgens het besluit van het College van Decanen,

in het openbaar te verdedigen

op woensdag 27 juni 2012 om 12.00 uur

door

H.A.W. van Onzenoort 


\section{Promotores}

Prof.dr. P.W. de Leeuw

Prof.dr. C. Neef

\section{Co-Promotores}

Dr. PH.M. van der Kuy (Orbis MC, Sittard)

Dr. W.J. Verberk (Microlife Corporation, Taiwan)

\section{Beoordelingscommissie}

Prof.dr. H.A.J. Struijker Boudier (voorzitter)

Prof.dr. H.J.G.M. Crijns

Prof.dr. H.G. Leufkens (Universiteit Utrecht)

Dr. P.J. Nelemans

Prof.dr. M.C.J.M. Sturkenboom (Erasmus MC, Rotterdam) 


\section{Contents}

$\begin{array}{lll}\text { Chapter } 1 & \text { General introduction } & 7\end{array}$

Chapter 2 Effectiveness of interventions to improve adherence to treatment in patients with hypertension: A systematic review

Chapter 3 Electronic monitoring of adherence, treatment of hypertension and 55 blood pressure control American Journal of Hypertension 2012;25:54-59

Chapter 4 Effect of self-measurement of blood pressure on adherence to treatment in patients with mild to moderate hypertension Journal of Hypertension 2010;28:622-627

Chapter 5 Assessing medication adherence simultaneously by electronic monitoring and pill count in patients with mild to moderate hypertension American Journal of Hypertension 2010;23:149-154

Chapter 6 Participation in a clinical trial enhances adherence and persistence to treatment: A retrospective cohort study Hypertension 2011;58:573-578

Chapter 7 Objective adherence measurement with a smart blister:

A feasibility study in primary care Accepted by American Journal of Health-System Pharmacy

Chapter 8 The importance of adherence data for the approval of antihypertensive drugs by regulatory authorities:

A review of marketing authorization applications

Chapter 9 General discussion

Summary

Samenvatting

Dankwoord 

Chapter 1

General introduction 
8 $\mid$ Chapter 1 


\section{Introduction}

Hypertension is a major risk factor for the development of cardiovascular morbidity and mortality, and continues to be a major health problem since its prevalence is increasing worldwide ${ }^{1,2}$. Hypertension affects approximately 1 billion adults, a number that is expected to have increased by $60 \%$ in the year $2025^{2}$. High blood pressure is the third cause of global diseases, next to childhood and maternal underweight and unsafe sex, and is estimated to be responsible for $62 \%$ of cerebrovascular disease and $49 \%$ of coronary heart disease $\mathrm{e}^{3,4}$. An estimated 7.1 million deaths per year may be attributable to high blood pressure ${ }^{4}$.

In the past decades, considerable success has been achieved in the treatment of high blood pressure with the availability of effective antihypertensive drugs. In the late 1940s and early 1950s development and testing of alkaloids, ganglionic blocking drugs, and hydralazine were the first initiatives on treatment of high blood pressure with pharmacologic substances. Thiazide diuretics were discovered in the late 1950s and have been recommended for lowering blood pressure since. In later years many other classes of antihypertensive drugs have been approved, of which, next to diuretics, beta-receptor blockers, angiotensin-converting-enzyme inhibitors, angiotensin-receptor blockers, and calcium-channel blockers represent the primary treatment options ${ }^{1,5}$. Recent treatment strategies for hypertension have mainly focused on combining different classes of drugs in fixed-dose combinations ${ }^{5}$, whereas the discovery of new pharmacologic agents has been limited to the registration of the renin inhibitor aliskiren. All classes of drugs which are now considered to be first line treatment for hypertension have shown a comparable reduction in cardiovascular complications 5 . A meta-analysis performed by Law and colleagues suggested that lowering systolic blood pressure by $10 \mathrm{mmHg}$ or diastolic blood pressure by $5 \mathrm{mmHg}$ reduces cardiovascular events (fatal and non-fatal) by approximately $25 \%$ and cerebrovascular events by $30 \%{ }^{6}$.

New therapies for hypertension are subject to clinical research and may be approved within a few years. The endothelin receptor type A antagonist darusentan may be the first one to become available for the treatment of resistant hypertension ${ }^{7}$. Other potential targets that are being explored are the cannabinoid-1-receptors and crosslinkages of collagen and elastin ${ }^{8,9}$.

The recommended algorithm for the management of hypertension uses a stepwise approach. The expected reduction in blood pressure when initiating treatment depends on the initial blood pressure; the expected risk reduction in cardiovascular events and strokes also depends on patient's age ${ }^{9}$. For patients with a blood pressure of 140-159/90-99 $\mathrm{mmHg}$ and no other cardiovascular risk factors lifestyle modifications are initially the most important interventions. When blood pressure remains uncontrolled or when total cardiovascular risk is high or very high, pharmacologic treatment should be initiated ${ }^{5}$. 
Nowadays, hypertension is considered to be one of the most preventable diseases. However, data indicate that $30 \%$ of the Americans with hypertension are unaware of their condition ${ }^{1}$, and of those who are being treated for hypertension only $34-50 \%$ reach a controlled blood pressure below $140 / 90 \mathrm{mmHg}^{1,10}$. It is therefore paradoxical that despite the availability of effective antihypertensive drugs and the progress that has been made in the treatment of hypertension, the number of people whose blood pressure is controlled is disappointingly low ${ }^{11}$.

\section{An introduction to adherence to treatment}

An important aspect in the treatment of hypertension is that patients who start with treatment should be prepared to take antihypertensive drugs for a life-long period. Imperfect execution of the dosing regimen or discontinuation of treatment because of, for example, side-effects of drugs will lead to a less effective treatment. Execution of the dosing regimen reflects the extent to which a patient takes his medication as prescribed $^{12}$ and can be expressed by the term adherence or compliance. There is however a difference between the terms adherence and compliance. Where compliance refers to 'the extent to which patient's behaviour matches the prescriber's recommendations ${ }^{13}$, adherence emphasises the need for agreement between prescriber and patient in the treatment of the disease ${ }^{14,15}$ and, consequently, focuses on patient's ability and willingness to accept a therapeutic regimen ${ }^{16}$. It is therefore that the term adherence has been adopted by many as an alternative to compliance.

Missing drug doses, whether or not intentionally, can occur for varying lengths of time. Short periods in which patients consciously do not take medication, and restart after a while are referred to as drug holidays. For patients with hypertension it appears to be very difficult to maintain daily dosing. Vrijens and colleagues showed that only $5 \%$ of the patients fully adhered to treatment throughout a period of one year and that $8-10 \%$ of the patients missed a dose on any given day ${ }^{17}$. Depending on the pharmacological characteristics of the prescribed drug, these omissions may have consequences for blood pressure reduction and cardiovascular risk. Forgiveness refers to 'the ability of a pharmaceutical to maintain therapeutic drug action in the face of occasional, variably long lapses in dosing ${ }^{18,19}$. The longer a drug's plasma half-life, the longer the pharmacodynamic effect of that drug may persist when a patient misses a dose. For antihypertensive drugs with plasma half-lives ranging between 9 and 50 hours a once-daily dosing regimen can be applied ${ }^{20}$. Recent data indicate that patients who are prescribed short-acting antihypertensive drugs such as captopril and quinapril and who have an average adherence of $75 \%$ may gain the least in cardiovascular disease risk reductions, whereas the effect of missing doses of amlodipine may not contribute at all to loss of effectiveness ${ }^{21}$. 
Besides an imperfect execution of the dosing regimen, discontinuation of treatment is a major determinant of uncontrolled blood pressure. Generally referred to as nonpersistence, discontinuation of treatment is a barrier in the treatment of hypertension especially in the first year after initiating antihypertensive treatment: discontinuation rates vary from $22 \%$ to almost $50 \%$ during the first year ${ }^{17,22-24}$.

For the interpretation of adherence data it is important to distinguish adherence from persistence (Figure 1.1). Both components determine the effectiveness of antihypertensive drugs, but the effect of non-adherence on blood pressure reduction and cardiovascular risk differs from that of short persistence. In the available literature this distinction is lacking. Despite that, estimated adherence rates in patients with hypertension range from $20 \%$ to over $90 \%{ }^{25-32}$. Differences in study design, method of adherence measurement, follow-up period, drug regimens used, and patient groups may explain this large variance in adherence results, but these data also underscore the complexity of this topic.

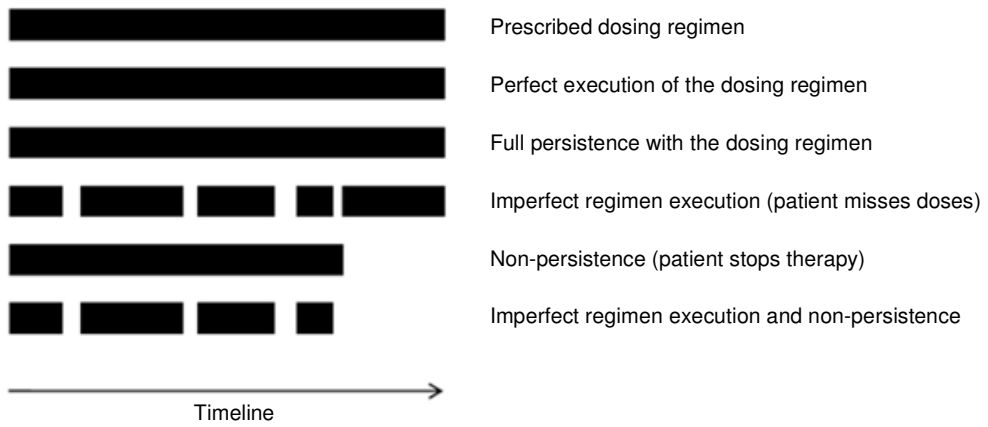

Figure 1.1 Differences between adherence and persistence.

Figure depicted from Lowy $A$, et al. ${ }^{21}$

\section{Factors related to non-adherence}

Many studies have addressed the complexity of adherence to treatment and tried to identify factors related to adherence and non-adherence ${ }^{14}$. Studies investigating whether non-adherence could be explained by patients' socio-demographic characteristics, such as gender, ethnicity, socio-economic status or education, showed that the effect of these variables are weak and inconsistent ${ }^{33}$. Recent literature suggests that the complexity of non-adherence could be explained better by applying the conceptual distinction of 'unintentional' and 'intentional' non-adherence ${ }^{14}$. Unintentional non-adherence refers to barriers to patients taking medicines as prescribed; intentional adherence refers to deliberate decisions patients may take to adjust their medication use. In the latter case, patients may modify the prescribed 
drug regimen by altering the dose or frequency of the medication or only take treatment when having symptoms of the disease, or discontinue treatment at all. These reasoned actions, or behavioural intentions, are influenced by attitudes and subjective norms ${ }^{34}$ and may be reliable predictors for non-adherence. Barriers to patients taking medicines resulting in unintentional non-adherence arise from capacity and resource limitations of the patient, such as memory, knowledge or dexterity deficiencies ${ }^{14}$.

\section{Methods for measuring adherence}

At present there are numerous methods available for measuring adherence to treatment. Table 1.1 shows methods that have been used for adherence measurement, with their advantages and disadvantages. In 1979, Rudd described the criteria that an ideal method for adherence measurement should meet: it should be unobtrusive, objective, and practical ${ }^{35}$. Though electronic monitors are often considered as the gold standard, no single instrument is available that possesses all these criteria. Consequently, the interpretation and comparability of adherence data are complicated by the method of measurement.

\section{Objectives of the thesis}

The objectives of this thesis were to assess the methodological aspects and consequences of (non-)adherence in patients with hypertension and to provide suggestions for new strategies in adherence measurement and for interventions aimed at improving adherence. 
Table 1.1 Methods for measuring adherence.

\begin{tabular}{|c|c|c|}
\hline Method for measuring adherence & Advantages & Disadvantages \\
\hline \multicolumn{3}{|l|}{ Direct methods } \\
\hline Directly Observed Therapy & Most accurate & $\begin{array}{l}\text { Patients can hide pills in the } \\
\text { mouth and then discard them; } \\
\text { impractical for routine use }\end{array}$ \\
\hline $\begin{array}{l}\text { Measurement of the level of } \\
\text { medicine or metabolite in blood }\end{array}$ & Objective & $\begin{array}{l}\text { Variations in metabolism and } \\
\text { 'white-coat adherence' can give a } \\
\text { false impression of adherence; } \\
\text { expensive }\end{array}$ \\
\hline $\begin{array}{l}\text { Measurement of the biologic } \\
\text { marker in blood }\end{array}$ & $\begin{array}{l}\text { Objective; in clinical trials can also } \\
\text { be used to measure placebo }\end{array}$ & $\begin{array}{l}\text { Requires expensive quantitative } \\
\text { assays and collection of bodily } \\
\text { fluids }\end{array}$ \\
\hline \multicolumn{3}{|l|}{ Indirect methods } \\
\hline Patient questionnaires/self-reports & $\begin{array}{l}\text { Simple, inexpensive; the most } \\
\text { useful method in the clinical } \\
\text { setting }\end{array}$ & $\begin{array}{l}\text { Susceptible to error with increases } \\
\text { in time between visits; results are } \\
\text { easily distorted by the patient }\end{array}$ \\
\hline Pill count & $\begin{array}{l}\text { Objective; quantifiable, and easy } \\
\text { to perform }\end{array}$ & $\begin{array}{l}\text { Data easily altered by the patient } \\
\text { (e.g., pill dumping) }\end{array}$ \\
\hline Rates of prescription refills & Objective; easy to obtain data & $\begin{array}{l}\text { A prescription refill is not } \\
\text { equivalent to ingestion of } \\
\text { medication; requires a closed } \\
\text { pharmacy system }\end{array}$ \\
\hline $\begin{array}{l}\text { Assessment of patient's clinical } \\
\text { response }\end{array}$ & Simple; generally easy to perform & $\begin{array}{l}\text { Factors other than medication } \\
\text { adherence can affect clinical } \\
\text { response }\end{array}$ \\
\hline Electronic medication monitors & $\begin{array}{l}\text { Precise; results are easily } \\
\text { quantified; track patterns of taking } \\
\text { adherence }\end{array}$ & $\begin{array}{l}\text { Expensive; requires return visits } \\
\text { and downloading data from } \\
\text { medication vials }\end{array}$ \\
\hline $\begin{array}{l}\text { Measurement of physiologic } \\
\text { markers (e.g. heart rate in patients } \\
\text { taking beta-blockers) }\end{array}$ & Often easy to perform & $\begin{array}{l}\text { Marker may be absent for other } \\
\text { reasons (e.g., increased } \\
\text { metabolism, } \\
\text { poor absorption, lack of } \\
\text { response) }\end{array}$ \\
\hline Patient diaries & Help to correct for poor adherence & Easily altered by the patient \\
\hline $\begin{array}{l}\text { When the patient is a child, } \\
\text { questionnaire for caregiver or } \\
\text { teacher }\end{array}$ & Simple; objective & Susceptible to distortion \\
\hline
\end{tabular}

Table depicted from Osterberg L, et al. ${ }^{36}$ 


\section{Outline of the thesis}

In Chapter 2, a literature review is presented on various interventions performed by healthcare workers to improve adherence to antihypertensive treatment. The aim of this systematic review was to identify successful intervention strategies for improving adherence to treatment that could be used in non-adherent patients with hypertension.

A possible intervention strategy for improving adherence to treatment, and consequently blood pressure control may be electronic monitoring of adherence. Several trials suggest that electronic monitoring by means of Medication Event Monitoring System (MEMS), a pillbox that records every opening of the bottle, results into increased blood pressure control. Whether this effect sustains is not known. In Chapter 3, an observational study is described in which the effect of electronic monitoring on blood pressure control has been investigated.

Several reports suggest that self-measurement of blood pressure may increase adherence to prescribed drugs. Implementation of self-measurements in the routine diagnostic and therapeutic follow-up could be of great value in the management of hypertension. In Chapter 4, a randomised controlled trial is described in which the effect of self-measurement of blood pressure on adherence to treatment has been investigated.

The interpretation of adherence data is complicated by the method of measurement. Each method could trigger deviant drug intake behaviour. In Chapter 5, an observational study is described in which different drug intake behavioural patterns on blood pressure are investigated. In this chapter, data from two methods for adherence measurement are matched and investigated.

Generalizibility of adherence results may be limited by differences between a 'real life setting' and clinical practice under experimental conditions. The specific design of a clinical trial and selection of patients into this trial may affect patient's adherence to treatment. In Chapter 6, a retrospective cohort study is described in which the effect of participation in a clinical trial on adherence to treatment has been investigated.

At present, electronic monitoring by MEMS is considered to be the most reliable method to evaluate patient adherence. However, an opening of the MEMS bottle does not necessarily mean a single removal of a tablet. A novel method is the 'smart blister'. This blister can be attached to a commercially, available standard blister package and records each removal of a tablet. In Chapter 7, a feasibility study is described in which the first clinical experiences of the smart blister have been investigated. 
Randomised controlled trials (RCTs) are crucial to the scientific evaluation of therapies, and are mandatory for drug approvals by Medicines Evaluation Boards (MEBs). In such trials, poor adherence can be a major threat for obtaining statistical power to detect intervention effects. Several statistical approaches are available to minimize the influence of non-adherence in the analysis of data from RCTs. However, these approaches do not answer why and to which extent patients are non-adherent, which is important for MEBs when reviewing a new drug for its efficacy and safety. In Chapter 8, a review of registration files of new drugs is described in which the prevalence of adherence data in clinical trials has been addressed.

Finally, the topic itself, the results, conclusions, and recommendations are discussed in a broader perspective in Chapter $\mathbf{9}$. 


\section{References}

1. Chobanian AV, Bakris GL, Black HR, Cushman WC, Green LA, Izzo JL Jr, Jones DW, Materson BJ, Oparil S, Wright JT Jr, Roccella EJ; National Heart, Lung, and Blood Institute Joint National Committee on Prevention, Detection, Evaluation, and Treatment of High Blood Pressure; National High Blood Pressure Education Program Coordinating Committee. The seventh report of the joint national committee on prevention, detection, evaluation, and treatment of high blood pressure: the JNC 7 report. JAMA 2003;289:2560-72.

2. Kearney PM, Whelton M, Reynolds K, Muntner P, Whelton PK, He J. Global burden of hypertension: analysis of worldwide data. Lancet 2005;365:217-23.

3. Ezzati M, Lopez AD, Rodgers A, Van der Hoorn S, Murray CJL, and the Comparative Risk Assessment Collaborating Group. Selected major risk factors and global and regional burden of disease. Lancet 2002;360:1347-60.

4. World Health Report 2002: Reducing risks, promoting healthy life. Geneva, Switzerland:World Health Organization, 2002. http://www.who.int/whr/2002/.

5. Mancia G, De Backer G, Dominiczak A, Cifkova R, Fagard R, Germano G, Grassi G, Heagerty AM, Kjeldsen SE, Laurent S, Narkiewicz K, Ruilope L, Rynkiewicz A, Schmieder RE, Boudier HA, Zanchetti A, Vahanian A, Camm J, De Caterina R, Dean V, Dickstein K, Filippatos G, Funck-Brentano C, Hellemans I, Kristensen SD, McGregor K, Sechtem U, Silber S, Tendera M, Widimsky P, Zamorano JL, Erdine S, Kiowski W, Agabiti-Rosei E, Ambrosioni E, Lindholm LH, Viigimaa M, Adamopoulos S, Agabiti-Rosei E, Ambrosioni E, Bertomeu V, Clement D, Erdine S, Farsang C, Gaita D, Lip G, Mallion JM, Manolis AJ, Nilsson PM, O'Brien E, Ponikowski P, Redon J, Ruschitzka F, Tamargo J, van Zwieten P, Waeber B, Williams B; Management of Arterial Hypertension of the European Society of Hypertension; European Society of Cardiology. 2007 Guidelines for the Management of Arterial Hypertension: The Task Force for the Management of Arterial Hypertension of the European Society of Hypertension (ESH) and of the European Society of Cardiology (ESC). J Hypertens 2007;25:1105-87.

6. Law MR, Morris JK, Wald NJ. Use of blood pressure lowering drugs in the prevention of cardiovascular disease: meta-analysis of 147 randomised trials in the context op expectations from prospective epidemiological trials. BMJ 2009;338:b1665.

7. Black HR, Bakris GL, Weber MA, Weiss R, Shahawy ME, Marple R, Tannoury G, Linas S, Wiens BL, Linseman JV, Roden R, Gerber MJ. Efficacy and safety of darusentan in patients with resistant hypertension: results from a randomized, double-blind, placebo-controlled dose-ranging study. J Clin Hypertens (Greenwich) 2007;9:760-9.

8. Bátkai S, Pacher P, Osei-Hyiaman D, Radaeva S, Liu J, Harvey-White J, Offertáler L, Mackie K, Rudd MA, Bukoski RD, Kunos G. Endocannabinoids acting at cannabinoid-1 receptors regulate cardiovascular function in hypertension. Circulation 2004;110:1996-2002.

9. Bakris GL, Bank AJ, Kass DA, Neutel JM, Preston RA, Oparil S. Advanced glycation end-product crosslink breakers. A novel approach to cardiovascular pathologies related to the aging process. Am J Hypertens 2004;17:23S-30S.

10. Egan BM, Zhao Y, Axon RN. US Trends in prevalence, awareness, treatment, and control of hypertension, 1988-2008. JAMA 2010;303:2043-50.

11. Chobanian AV. The hypertension paradox - More uncontrolled disease despite improved therapy. New Eng J Med 2009;361:878-87.

12. Urquhart J. The electronic medication event monitor. Lessons for pharmacotherapy. Clin Pharmacokinet 1997;35:345-56.

13. Haynes RB, Taylor DW, Sackett DL. Compliance in health care. Baltimore:The John Hopkins University Press, 1979.

14. Horne R, Weinman J, Barber N, Elliott R, Morgan M. Concordane, adherence and compliance in medicine taking. London: National Co-ordinating Centre for NHS Service Delivery and Organisation NCCSDO, 2005.

15. McDonald HP, Garg AX, Haynes RB. Interventions to enhance patient adherence to medication prescriptions: scientific review. JAMA 2002;288:2868-79. 
16. Krousel-Wood M, Thomas S, Muntner P, Morisky D. Medication adherence: a key factor in achieving blood pressure control and good clinical outcomes in hypertensive patients. Curr Opin Cardiol 2004;19:357-62.

17. Vrijens B, Vincze G, Kristanto $P$, Urquhart J, Burnier M. Adherence to prescribed antihypertensive drug treatments: longitudinal study of electronically compiled dosing histories. BMJ 2008;336:1114-7.

18. Urquhart J. Pharmacodynamics of variable patient compliance: implications for pharmaceutical value. Adv Drug Deliv Rev 1998;33:207-19.

19. Osterberg LG, Urquhart J, Blaschke TF. Understanding forgiveness: minding and mining the gaps between pharmacokinetics and therapeutics. Clin Pharmacol Ther 2010;88:457-9.

20. CVZ Farmacotherapeutisch Kompas. http://www.fk.cvz.nl. Consulted on March 172011.

21. Lowy A, Munk VC, Ong SH, Burnier M, Vrijens B, Tousset EP, Urquhart J. Effects on blood pressure and cardiovascular risk of variations in patients' adherence to prescribed antihypertensive drugs: role of duration of drug action. Int J Clin Pract 2011;65:41-53.

22. Van Wijk BL, Shrank WH, Klungel OH, Schneeweiss S, Brookhart MA, Avorn J. A cross-national study of the persistence of antihypertensive medication use in the elderly. J Hypertens 2008;26:145-53.

23. Caro JJ, Salas M, Speekman JL, Raggio G, Jackson JD. Persistence with treatment for hypertension in actual practice. Can Med Assoc J 1999;160:31-7.

24. Bourgalt $C$, Sénécal M, Brisson M, Marentette MA, Grégoire JP. Persistence and discontinuation patterns of antihypertensive therapy among newly treated patients: a population-based study. J Hum Hypertens 2005;19:607-13.

25. Rudd P, Ahmed S, Zachary V, Barton C, Bonduelle D. Improved compliance measures: applications in an ambulatory hypertensive drug trial. Clin Pharmacol Ther 1990;48:676-85.

26. Cramer JA, Mattson RH, Prevey ML, Scheyer RD, Ouellette VL. How often is medication taken as prescribed? A novel assessment technique. JAMA 1989;261:3273-7.

27. Choo PW, Rand CS, Inui TS, Lee M-LT, Cain E, Cordeiro-Breault M, Canning C, Platt R. Validation of patient reports, automated pharmacy records, and pill count with electronic monitoring of adherence to antihypertensive therapy. Med Care 1999;37:846-57.

28. Burnier M, Schneider MP, Chioléro A, Fallab Stubi CL, Brunner HR. Electronic compliance monitoring in resistant hypertension: the basis for rational therapeutic decisions. J Hypertens 2001;19:335-41.

29. Schroeder K, Fahey T, Hay AD, Montgomery A, Peters TJ. Relationship between medication adherence and blood pressure in primary care: prospective study. J Hum Hypertens 2006;20:625-7.

30. Lee JY, Kusek JW, Greene PG, Bernhard S, Norris K, Smith D, Wilkening B, Wright, Jr JT. Assessing medication adherence by pill count and electronic monitoring in the African American study of kidney disease and hypertension (AASK) pilot study. Am J Hypertens 1996;9:719-25.

31. DiMatteo MR, Giordani P, Lepper HS, Croghan TW. Patient adherence and medical treatment outcomes: a meta-analysis. Med Care 2002;40:749-811.

32. Sabate E. Adherence to long term therapies: evidence for action. Geneva:World Health Organization, 2003.

33. Ockene IS, Hayman LL, Pasternak RC, Schron E, Dunbar-Jacob J. Task force \#4-adherence issues and behaviour changes: achieving a long-term solution. 33rd Bethesda Conference. J Am Coll Cardiol 2002;40:630-40.

34. Horne R, Weinman J, Hankins M. The beliefs about medicines questionnaire: the development and evaluation of a new method for assessing the cognitive representation of medication. Psychology and Health 1999;14:1-24.

35. Rudd P. In search of the gold standard for compliance measurement. Arch Intern Med 1979;139: 627-9.

36. Osterberg L, Blaschke T. Adherence to medication. New Eng J Med 2005;353:487-97. 
18 


\section{Chapter 2}

\section{Effectiveness of interventions to improve adherence to treatment in patients with hypertension}

A systematic review

Hein AW van Onzenoort, Paul-Hugo M van der Kuy, Willem J Verberk, Cees Neef, Peter $W$ de Leeuw

Submitted 


\section{Abstract}

\section{Background}

Knowledge of the effectiveness of the available methods to improve adherence in the treatment of hypertension is limited. In addition it is not well known which factors contribute to non-adherence.

\section{Methods}

We systematically reviewed the literature to evaluate the effectiveness of interventions which aimed to improve adherence to treatment in patients with hypertension and tried to apply these interventions to a conceptual framework of intentional and unintentional non-adherence. We searched Pubmed, the Cochrane Central Register of Controlled Trials, Embase and Cinahl from 1966 to November 2010 for all studies whether controlled or uncontrolled, prospective or retrospective, and randomised or non-randomised that included an intervention to improve adherence to antihypertensive treatment. Interventions were categorized into those employing determinants of intentional non-adherence and those focusing on external determinants of unintentional non-adherence.

\section{Results}

A total of 78 studies matched our inclusion criteria. In general, the methodological quality of the included studies was poor. Thirty-three (42\%) studies showed a significant improvement in adherence to treatment. Successful randomised controlled trials $(n=27)$ showed an increase in adherence level from 0.5 to $62 \%$ compared to 15 to $17.2 \%$ in non-randomised controlled trials $(n=6)$. Interventions targeting both intentional and unintentional non-adherence were not more successful than those which focused on one of these. Almost all interventions were complex, including combinations of education, self measurement of blood pressure, motivational interviewing, and establishing a health behaviour change.

\section{Conclusion}

Current methods of improving adherence are complex and not consistently effective. The conceptual framework of non-adherence may be unsuitable for the population at large. Future studies should focus on the individual patient's behavioural intentions, barriers and subjective norms. 


\section{Introduction}

Over the past decade, several systematic reviews and meta-analyses have addressed the issue of improving adherence in patients with hypertension ${ }^{1-6}$. Overall, the results of these analyses suggest that no single intervention is superiorly effective, and that a combination of different interventions may be more successful in improving adherence than a single intervention. To achieve fuller benefits of adherence improving strategies a better understanding of which factors are involved in (non-)adherence is needed ${ }^{1}$.

The complexity of non-adherence could be explained better by applying the conceptual distinction of 'unintentional' and 'intentional' non-adherence in patients who are non-adherent ${ }^{7}$. Unintentional non-adherence refers to barriers for patients to take their medicines as prescribed; intentional adherence refers to deliberate decisions patients may take to adjust their medication use. In the latter case, patients may modify the prescribed drug regimen by altering the dose or frequency of the medication or only take treatment when having symptoms of the disease, or discontinue treatment at all. These reasoned actions, or behavioural intentions, are influenced by attitudes and subjective norms ${ }^{8}$ and may, to some extent, be predictable. Barriers to patients taking medicines resulting in unintentional nonadherence arise from capacity and resource limitations of the patient, such as memory, knowledge or dexterity deficiencies ${ }^{7}$.

Interventions for improving adherence to treatment are most easily targeted on barriers resulting in unintentional non-adherence. It is however questionable whether these interventions are effective and last for a sufficient long period of time. Eventually, patients must have the intention to take medication as prescribed or as agreed, ideally life-long. Whether the effect of such interventions differs from those targeting intentional non-adherence is unknown. To investigate this, we systematically reviewed the literature to investigate the effectiveness of interventions aimed at improving adherence to treatment in patients with hypertension.

\section{Methods}

\section{Data sources and extraction}

We searched Pubmed, the Cochrane Central Register of Controlled Trials, Embase and Cinahl from 1966 to November 2010 for all studies whether controlled or uncontrolled, prospective or retrospective, and randomised or non-randomised that included an intervention to improve adherence to antihypertensive treatment. The key words used in the search strategy are displayed in Figure 2.1. Simplification of dosing regimens or regimens in which fixed-doses were investigated were out of scope of this review. The population of interest consisted of adults aged 18 years or 
older with newly diagnosed or established hypertension. Articles had to be published in the English language. Adherence could be measured through pharmacy refill data, pill count, self-report, medication diaries, electronic monitoring and serum and/or urine concentrations of antihypertensive drugs. At least one measurement of adherence was used in the included studies. The primary goal of the intervention was not restricted to improvement of adherence itself, but might also be improvement of clinical outcome.

\begin{tabular}{|ll|}
\hline Disease & Hypertension \\
Outcome measures & (Non-)Adherence \\
& (Non-)Compliance \\
& (Non-)Persistence \\
& Discontinuation \\
& Concordance \\
Interventions & Self-measurement of BP \\
& Packaging \\
& Telephone/Mail/Video/Aides \\
& Pharmaceutical care \\
& Social care \\
& MEMS \\
& Poster/Pamphlet/Brochure \\
& Reminders \\
& Education \\
& Motivation/Counselling/Feedback/Coach/Communication \\
\hline
\end{tabular}

Figure 2.1 Key words used in search strategy.

\section{Review of citations and included studies}

Two authors (HO, PHK) independently selected potentially relevant studies by screening retrieved citations and abstracts according to the inclusion criteria. Studies assessed as definite or uncertain for inclusion were retrieved as full papers. When disagreement between the two authors occurred, a third author (WV) assessed the specific articles. All authors were not blinded with regard to authors or journal. Data were extracted using a structured data collection form, consisting study design, patients' and study characteristics, type of intervention(s) subject to research, measurement of adherence and adherence results (Appendix 2.1). References of all included studies were screened for further potentially relevant citations, as were systematic reviews and meta-analyses that were included in the initial citation search.

\section{Conceptual framework of intentional and unintentional non-adherence}

This framework conceptualises non-adherence as intentional and unintentional behaviours with internal and external determinants'. Several 'internal' factors determine patients' motivation, which may be modified by environmental or 
'external' factors, such as social support, media, or social norms ${ }^{7}$. The interventions subject to this systematic review were independently categorized by two authors (HO, PHK) into interventions that targeted internal and external factors, or both. Single interventions were categorized as internal or external; combinations of interventions were categorized as internal, external or a combination of both. In the case of disagreement between the two authors, consensus with respect to those interventions was reached after discussion.

\section{Quality of included studies}

The methodological quality of included studies was assessed according to the Downs and Black checklist ${ }^{9}$. This checklist can be used to assess the methodological quality of randomised and non-randomised studies, and consists of 27 questions to evaluate the quality of reporting, external validity, internal validity with respect to bias and confounding, and power. The power of the included studies was evaluated by comparing the size of the smallest intervention group with the theoretical size of this group. The theoretical number of patients was calculated based on the following assumptions: power of $80 \%$, alpha of 0.05 , mean adherence level of $65 \%$ (standard deviation of $30 \%$ ) or a proportion of adherent patients of $50 \%$ with an estimated $10 \%$ increase of the intervention on adherence or in the number of adherent patients.

\section{Successfulness of interventions}

We considered interventions in randomised and non-randomised controlled trials as successful when patients in the intervention group showed a significant $(P<0.05)$ higher adherence rate than patients in the control group; in single-group trials a significant increase in adherence rate at the end of the follow-up period compared to baseline was considered successful. Studies in which differences between groups were statistically not powered were considered as unsuccessful.

\section{Results}

Searches identified 2997 potential citations. After initial screening of the abstracts 180 full studies were retrieved for possible inclusion in the review of which 61 met the inclusion criteria. Reference tracking of the included studies as well as reviews and meta-analyses revealed an additional 17 studies. Consequently, 78 studies were included in the review (Figure 2.2).

Table 2.1 summarizes the characteristics of the included studies. Sixty-one were randomised controlled studies (RCTs) ${ }^{10-70}$ and 9 were non-randomised controlled studies $^{71-79}$. Six studies were non-crossover single-group trials ${ }^{80-85}$, and 2 were retrospective, observational studies ${ }^{86,87}$. The majority of the included studies had been 
performed in the United States $(n=41)$ and European countries $(n=12)$. Forty-five studies had been published in the past 10 years. The number of patients ranged from 10 to 10,577 , with a mean follow-up period of 8.8 months (standard deviation (SD) 5.7 months). In 36 studies, adherence to treatment was the primary outcome ${ }^{11,12,14-16,19-21 \text {, }}$ $23,26,33-35,37,38,40,46,48,49,52-54,56,57,60,62,63,65-67,69,70,72,75,83,86$. Interventions were categorized as nurse support ${ }^{13,19,22,23,25,26,36,39,43,44,53,55,59,64,66,70,81}$, pharmacist support so, $12,16,24,27,28,31^{-}$ $33,37,45,46,50-52,54,61,63,68,69,73,77,78,80,84$, physician support ${ }^{15,49,56,74,76,79,85}$, or support from a combination of several health care practitioners $3,38,47,57,62$, whereas in the remaining studies interventions were done by computers, trained research assistants or aides. In most studies adherence was measured by self-report ( $n=32$; Table 2.2 and 2.3$)^{13,17,18,}$ $22,26-30,33,35,38,39,41,43,44,47,48,50,52,53,59,61,64,71,75,76,78,80,82,83,87$, pill count $(n=25)^{10,16,19,24,32-34,36,37}$ $40,41,46,52,54-56,61,62,65,68-70,72,79,83,84$, or electronic monitoring $(n=12)^{11,14,15,20,21,23,25,42,48,49,66,67}$. Thirteen studies used two or more methods for adherence measurement $^{28,33,37,39,41,48,52-54,56,61,78,83}$. Because of heterogeneity between studies in terms of interventions and the methods used to measure adherence, we did not pool the results.

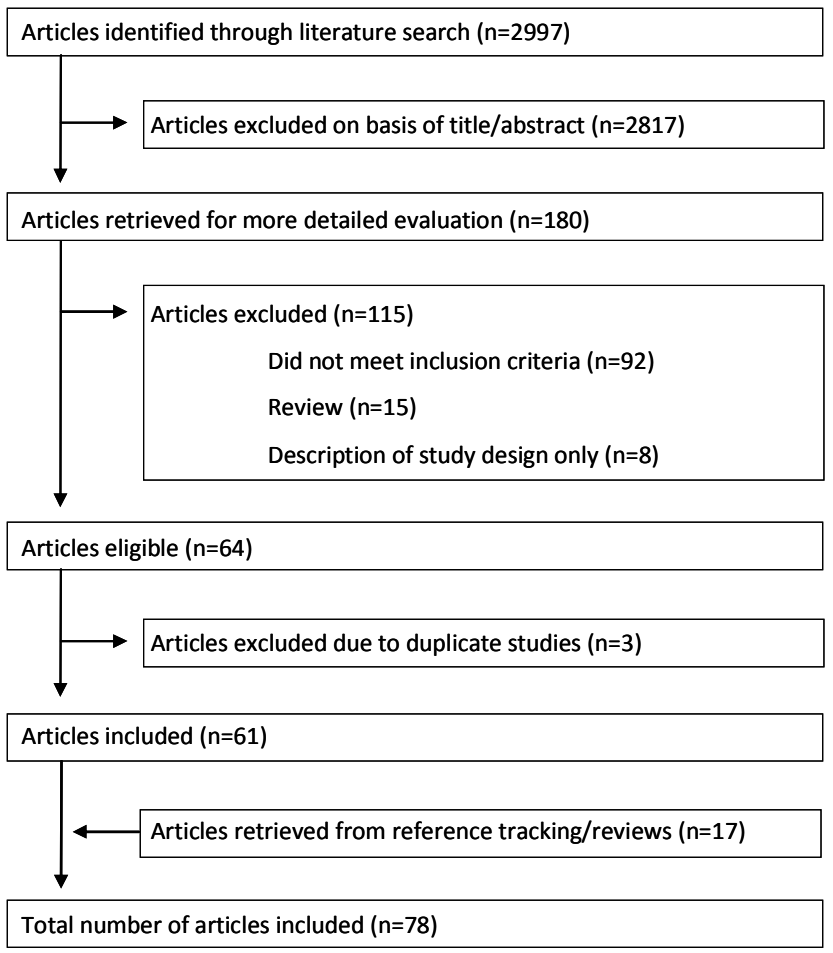

Figure 2.2 Flow of papers through study. 


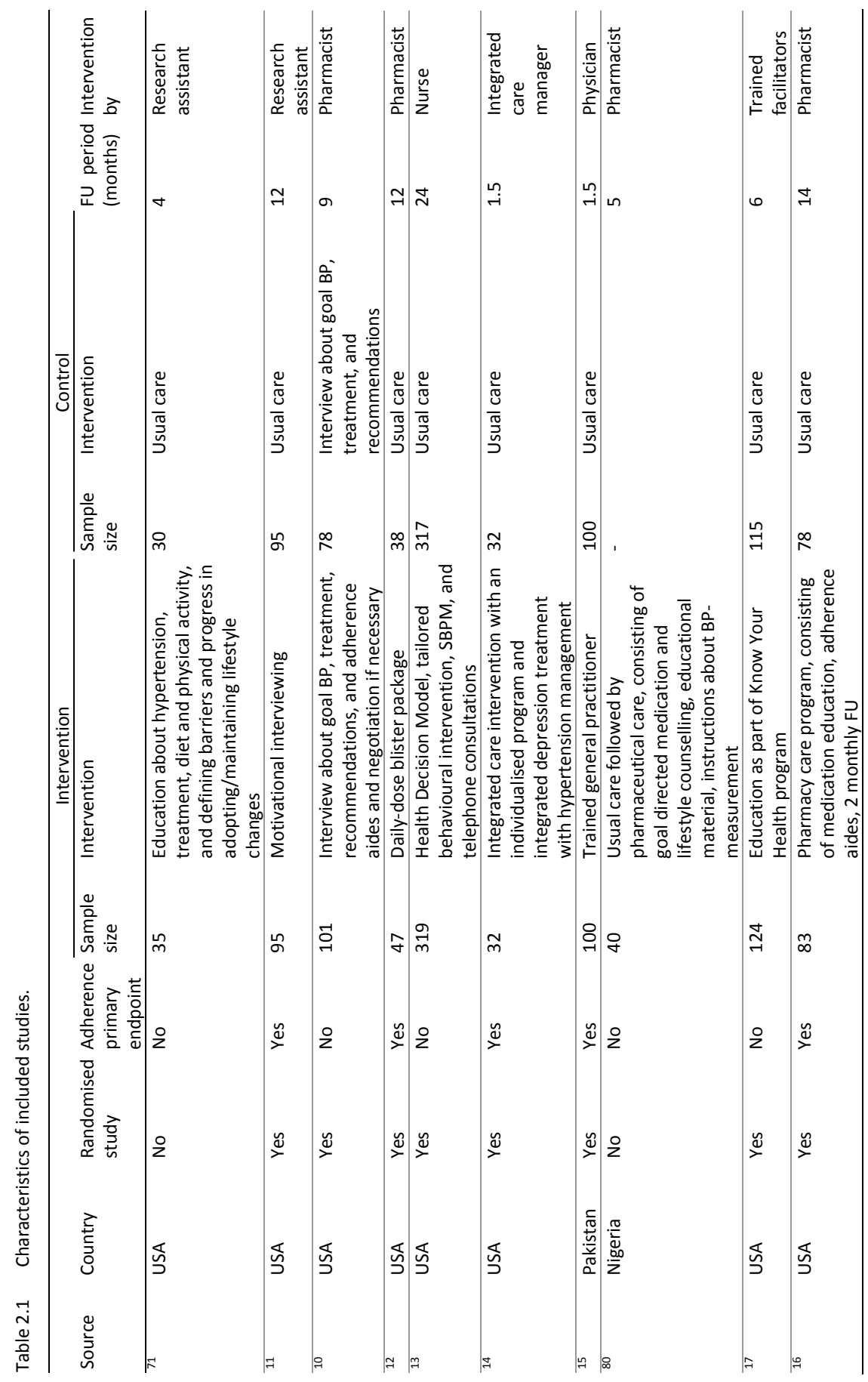




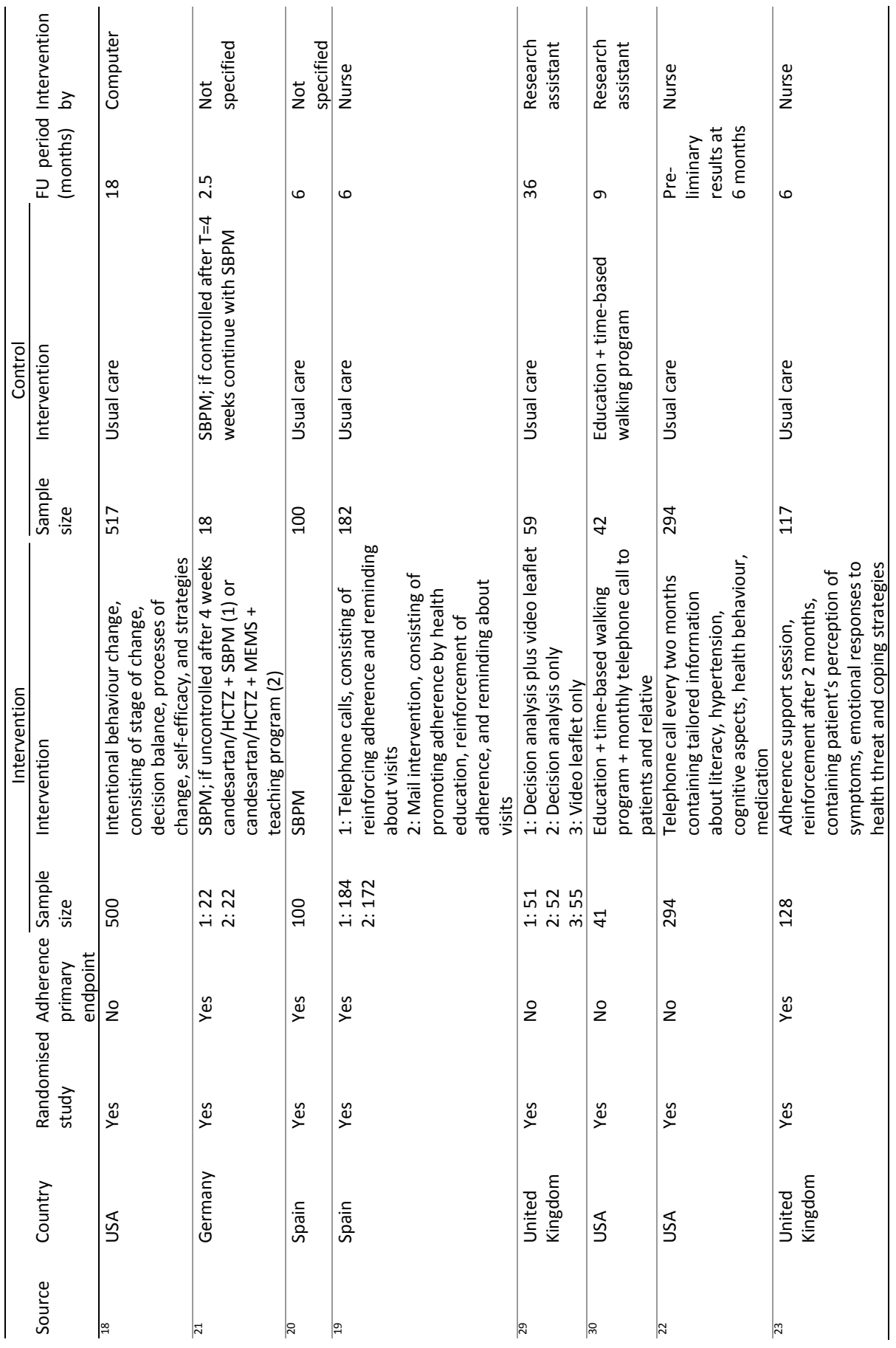




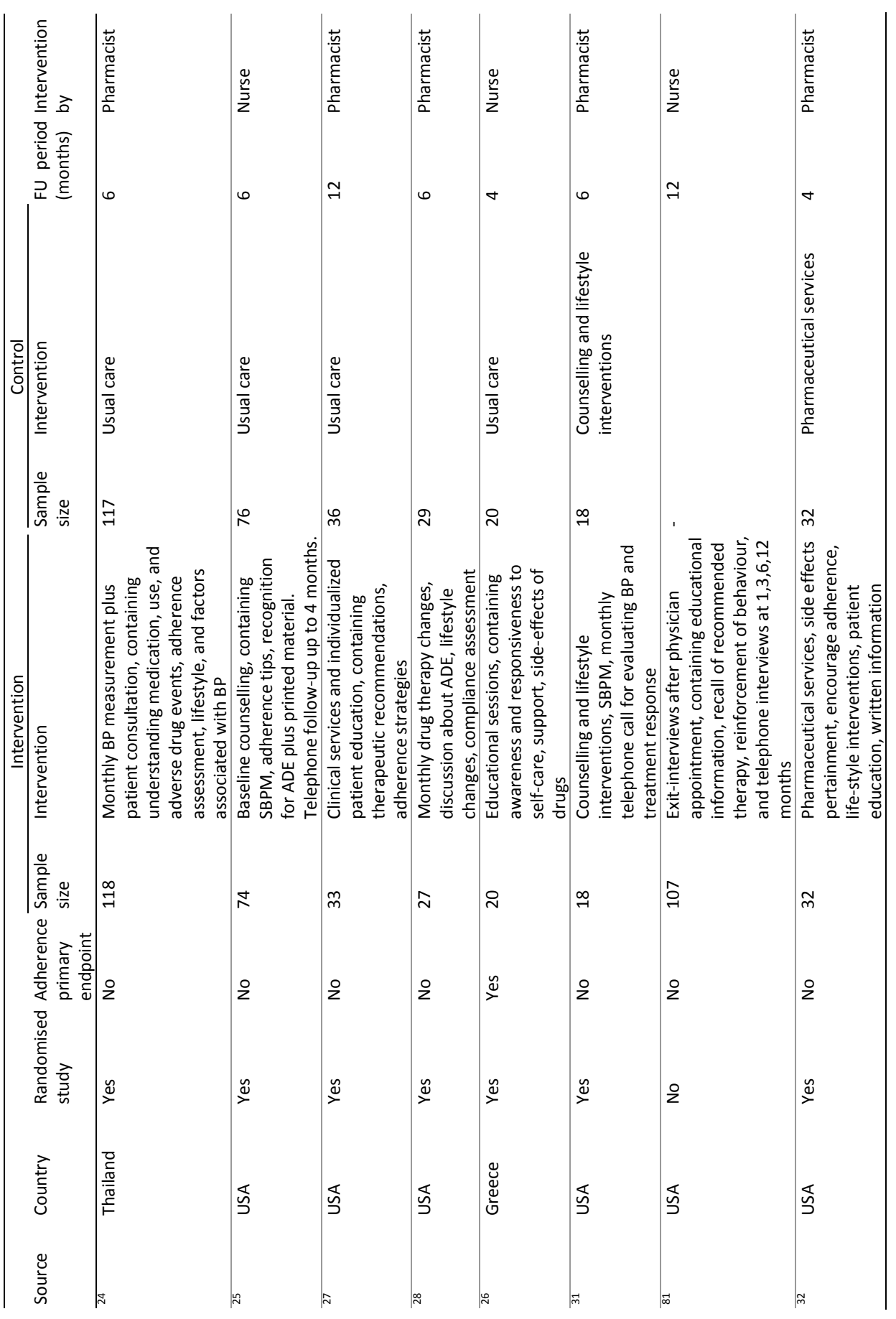




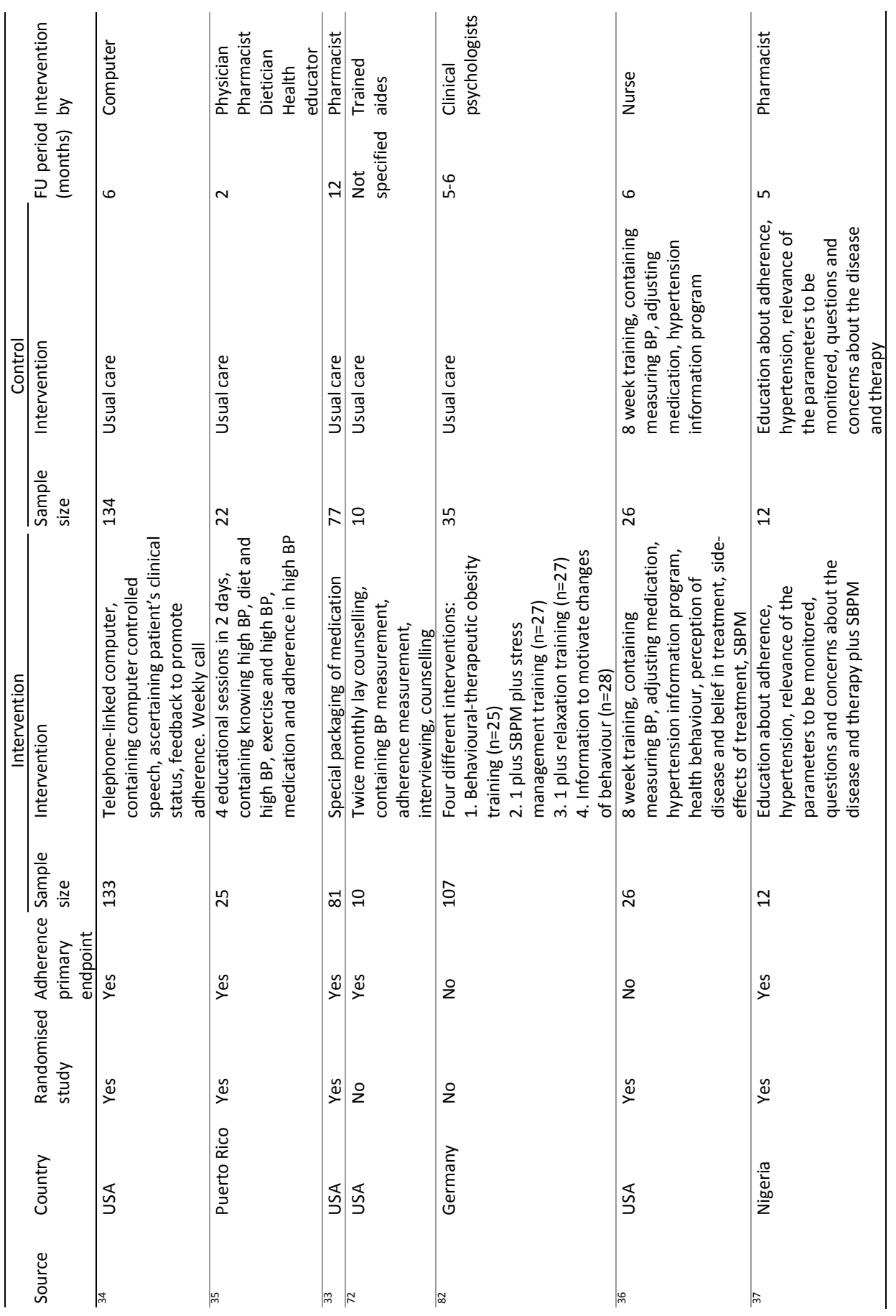




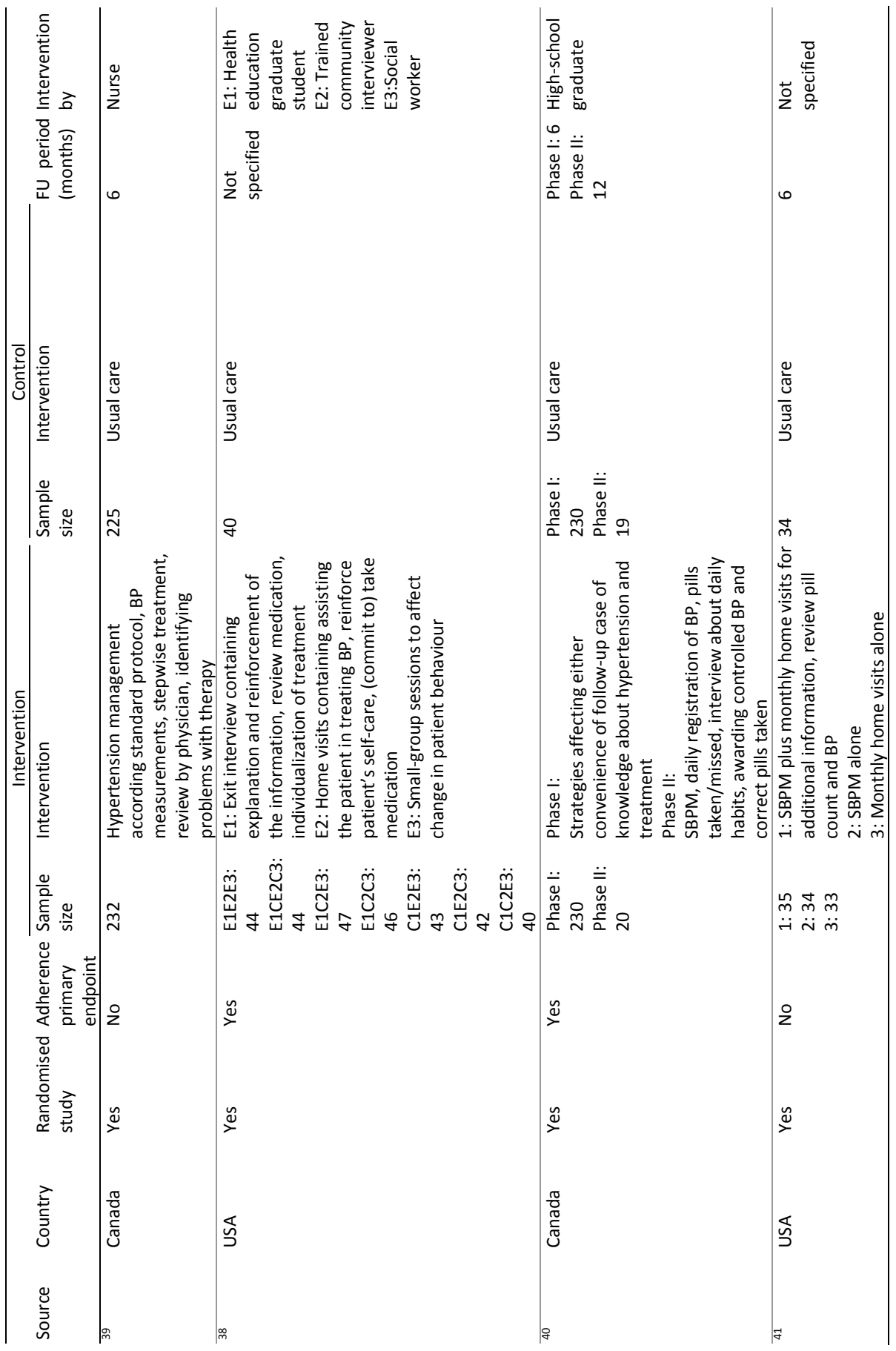




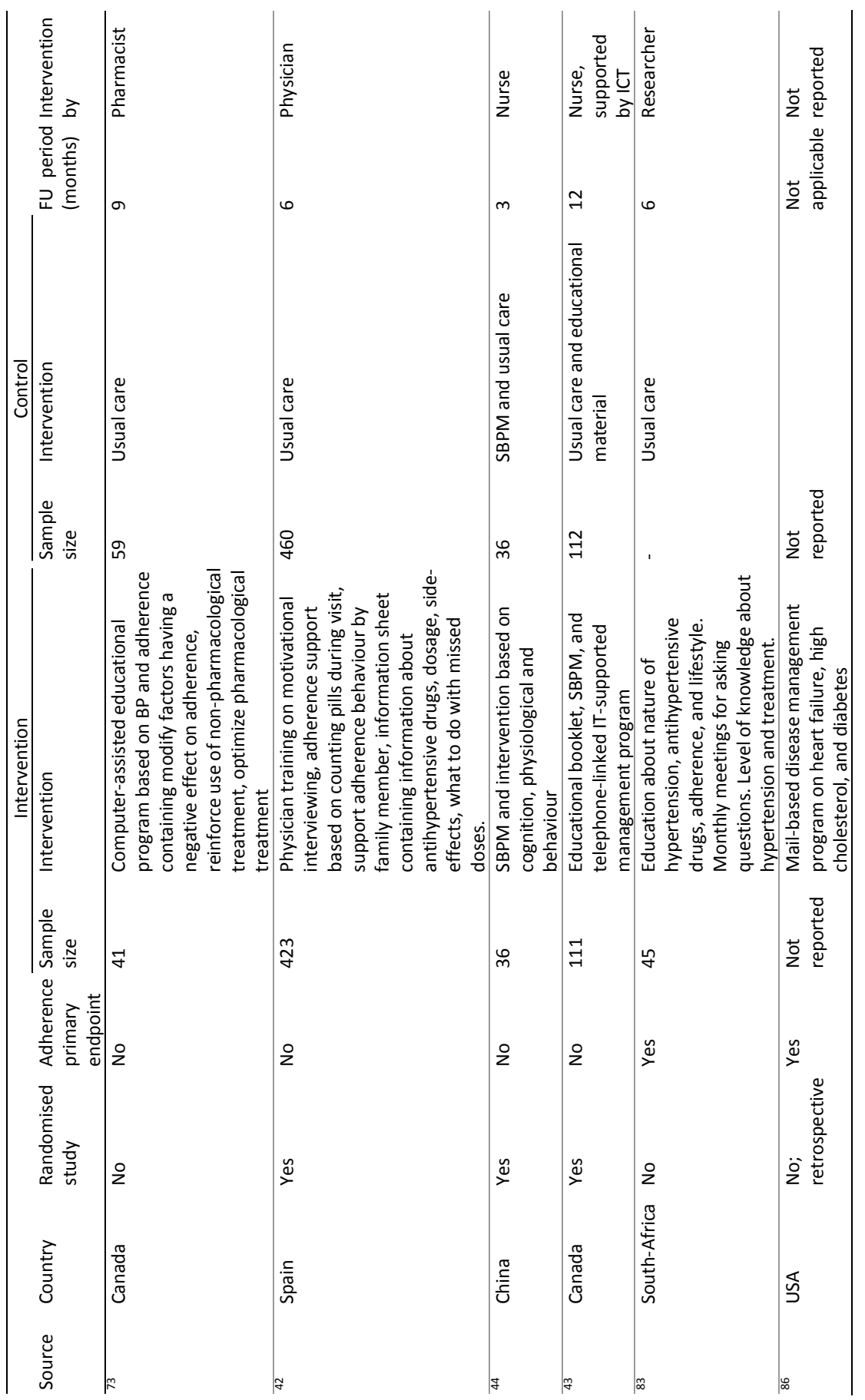




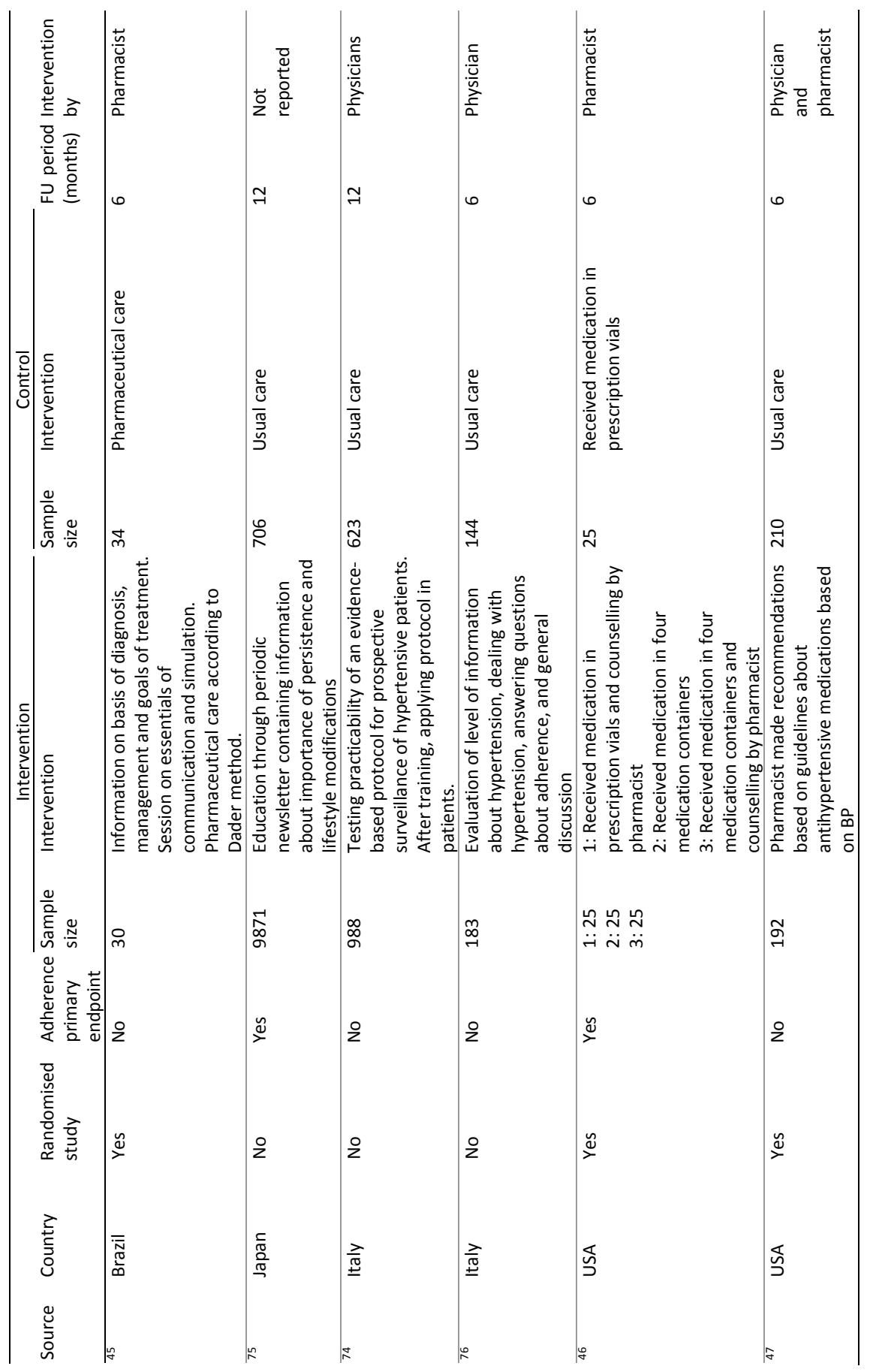


32 Chapter 2

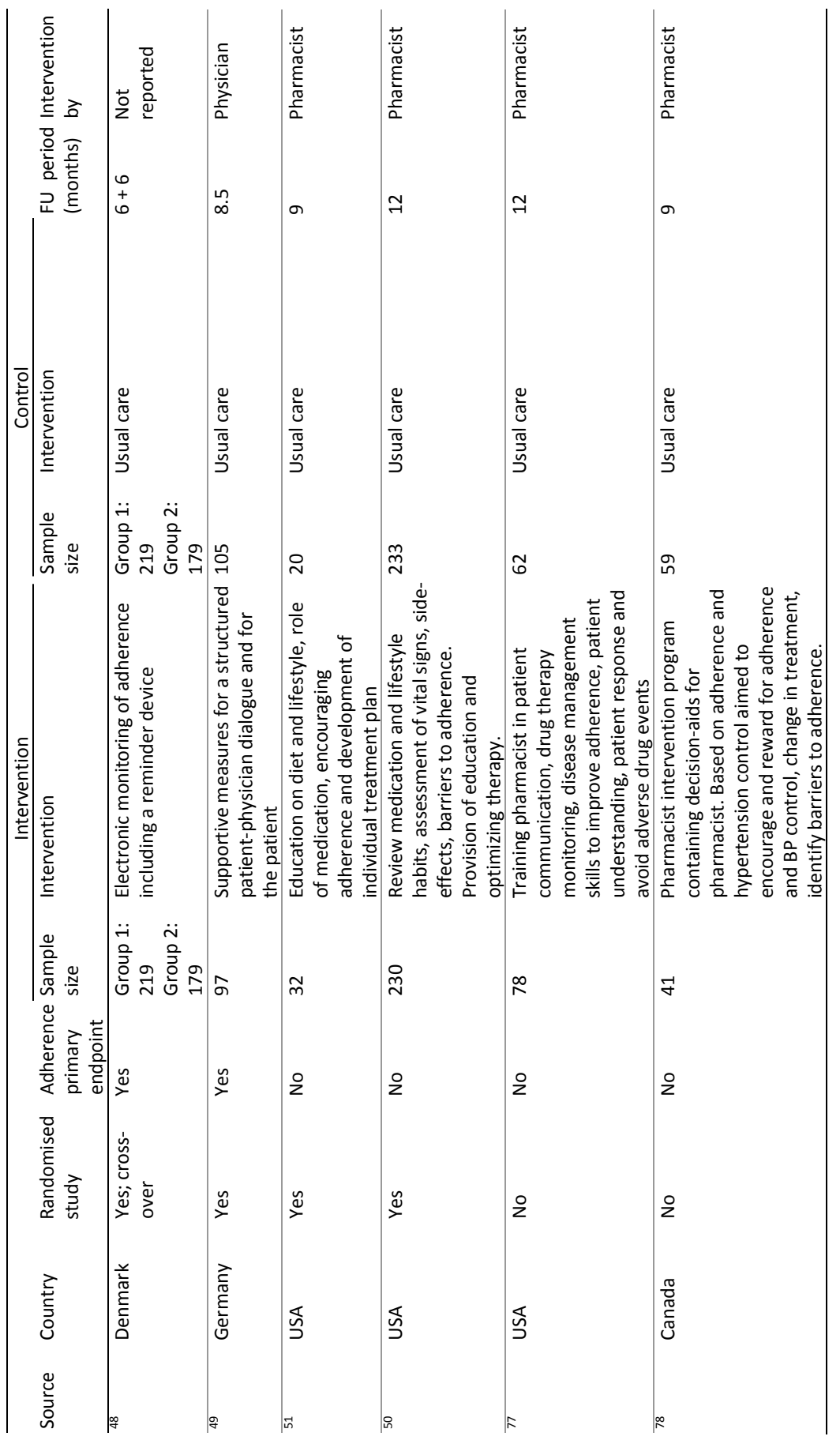




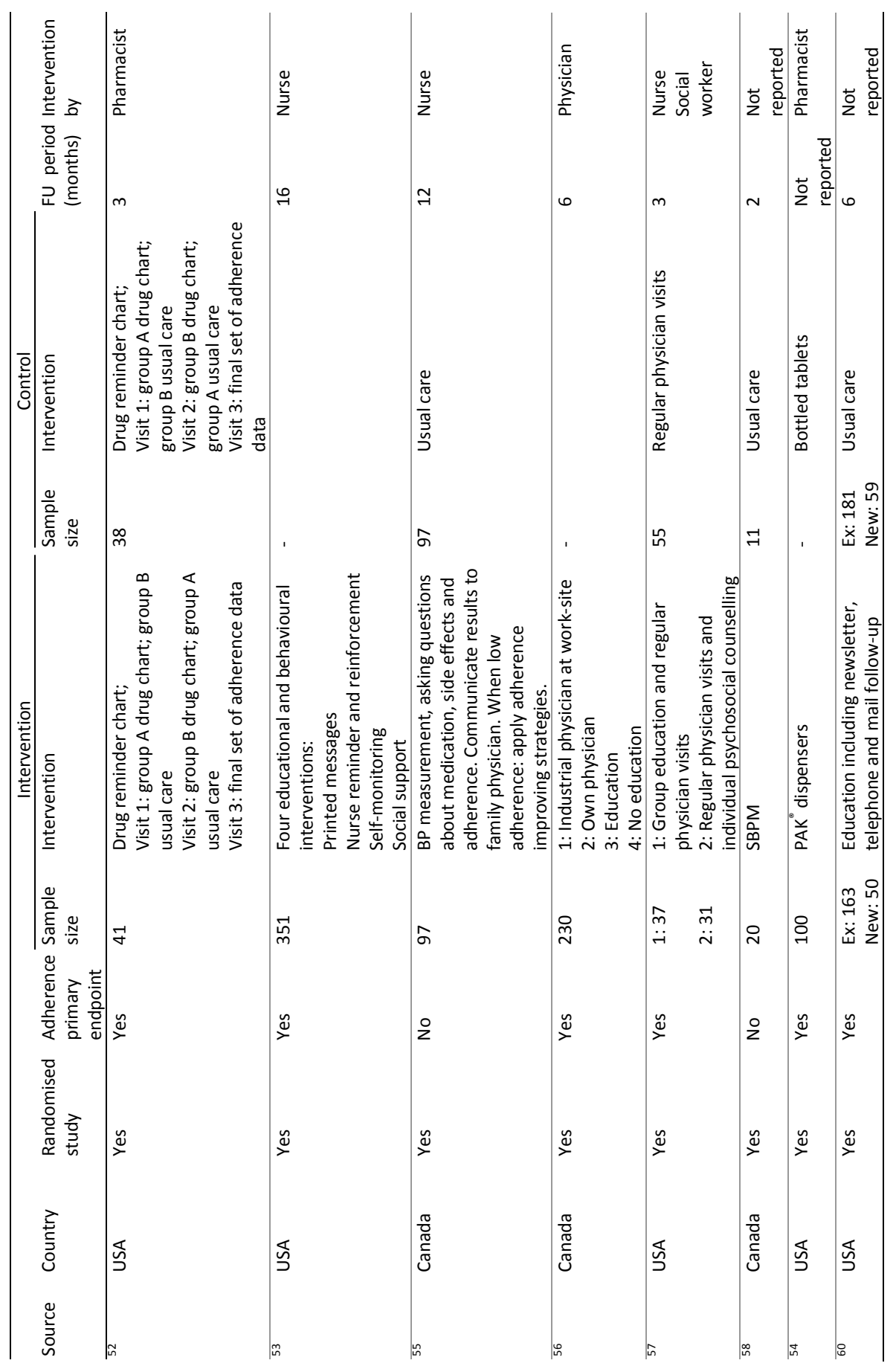




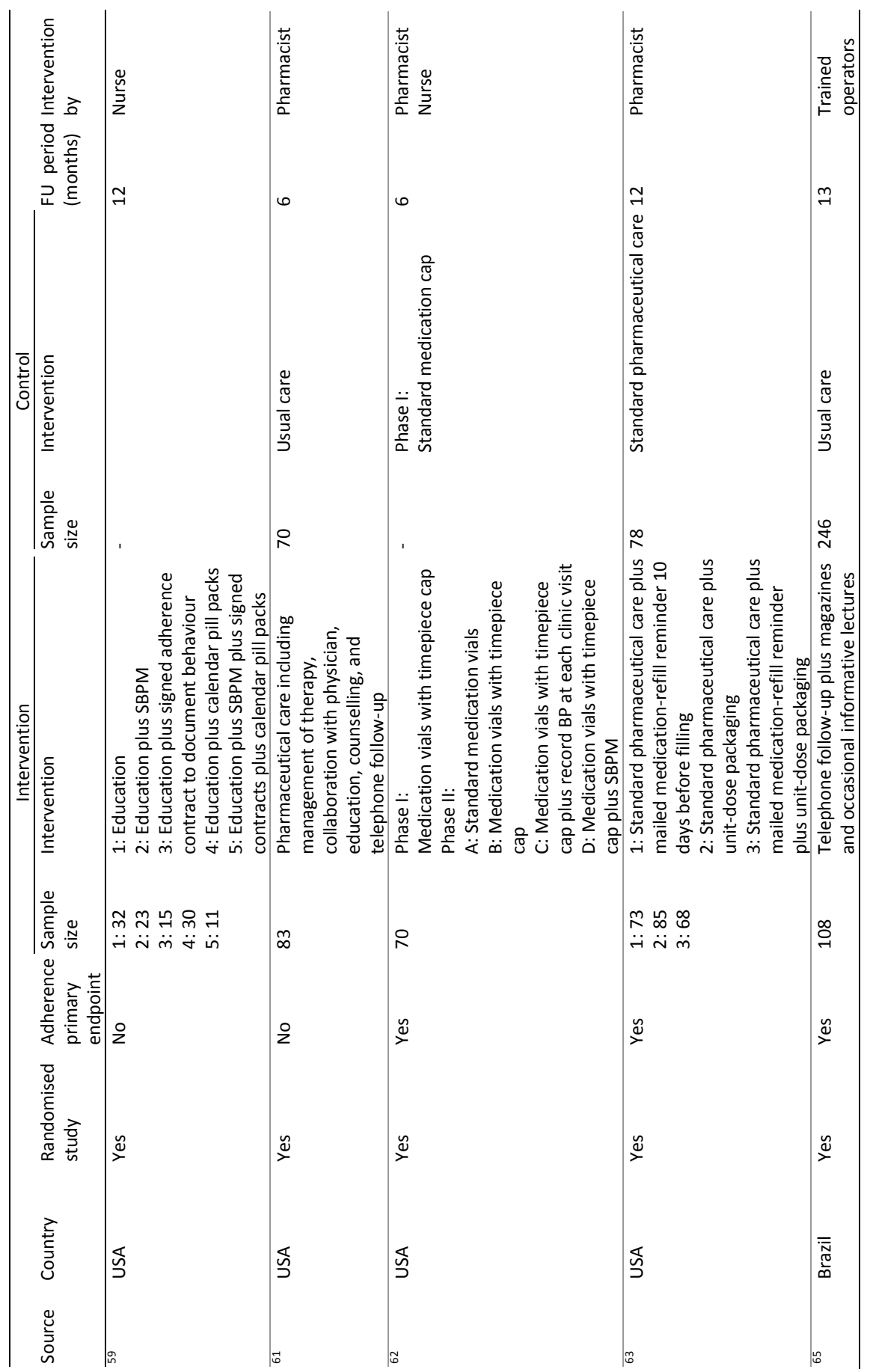




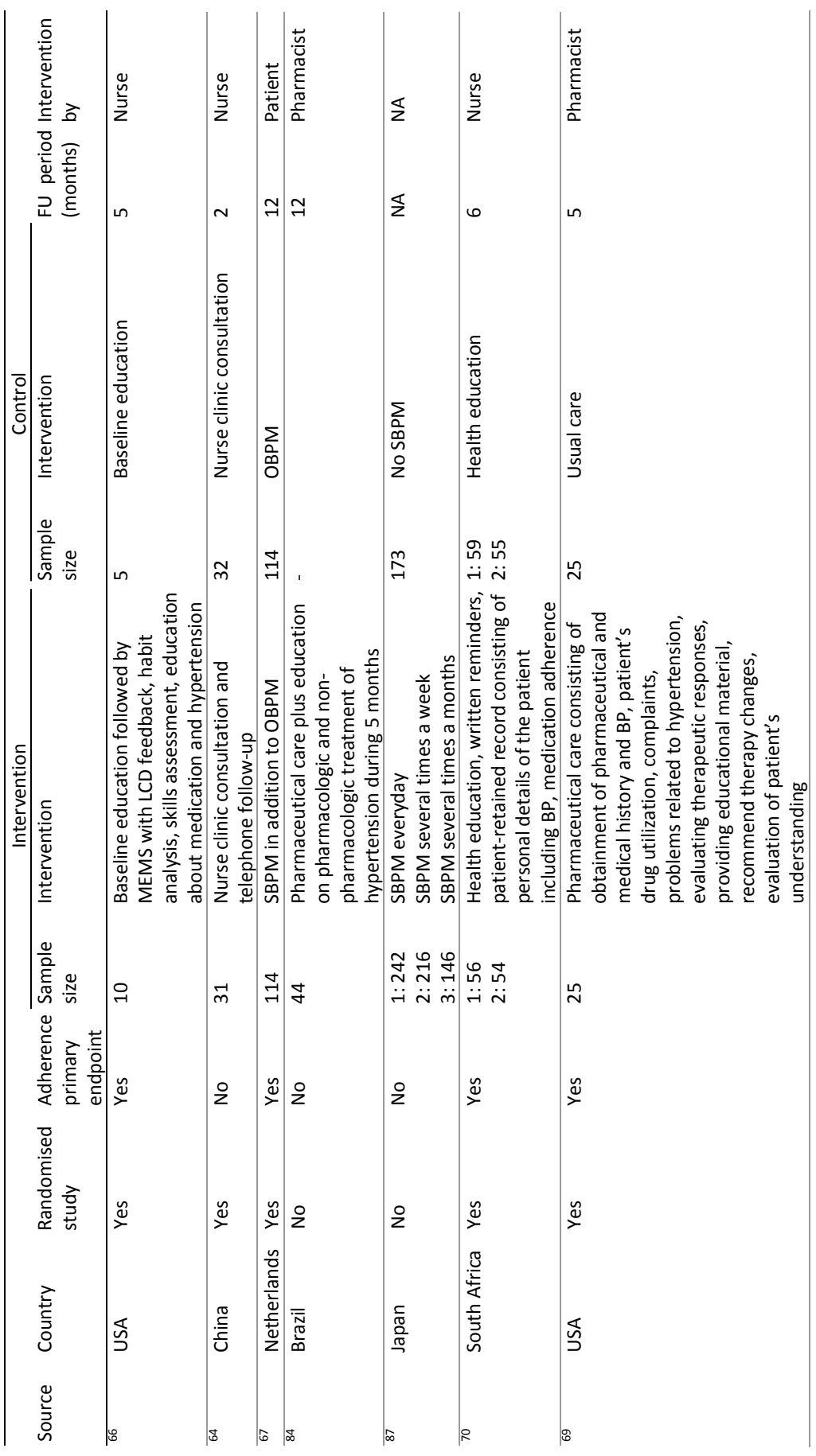


Table 2.2 Effectiveness of interventions on adherence to treatment.

\begin{tabular}{|c|c|c|c|c|c|c|c|}
\hline \multirow[b]{2}{*}{ Source } & \multirow[b]{2}{*}{ Adherence outcome } & \multicolumn{2}{|c|}{$\begin{array}{l}\text { Adherence results at } \\
\text { baseline }\end{array}$} & \multirow[b]{2}{*}{$P$-value } & \multicolumn{2}{|c|}{$\begin{array}{l}\text { Adherence results at end } \\
\text { follow-up period }\end{array}$} & \multirow[b]{2}{*}{$P$-value } \\
\hline & & Intervention & Control & & Intervention & Control & \\
\hline & Electronic monitoring & $55.4 \%$ & $55.2 \%$ & $\begin{array}{l}\text { Not } \\
\text { specified }\end{array}$ & $56.9 \%$ & $42.9 \%$ & 0.027 \\
\hline 10 & Pill count & $71 \%$ & $89 \%$ & $<0.01$ & $94 \%$ & $92 \%$ & 0.369 \\
\hline 12 & Pharmacy records & & & & $80.4 \%$ & $66.1 \%$ & 0.012 \\
\hline 13 & Self-report & $63 \%$ & $67 \%$ & $\begin{array}{l}\text { Not } \\
\text { specified }\end{array}$ & $72 \%$ & $68 \%$ & $\begin{array}{l}\text { Not } \\
\text { specified }\end{array}$ \\
\hline 15 & Electronic monitoring & & & & $48.1 \%$ & $32.4 \%$ & 0.048 \\
\hline 80 & Self-report & $66.3 \%$ & & & $83.5 \%$ & & 0.001 \\
\hline 17 & Self-report & $\begin{array}{l}3.4 \text { ( } \mathrm{t}=3 \\
\text { months) }\end{array}$ & $\begin{array}{l}3.3 \text { ( } \mathrm{t}=3 \\
\text { months) }\end{array}$ & $>0.05$ & 3.2 & 3.2 & $>0.05$ \\
\hline 18 & Self-report & & & & Not specified & & $<0.05$ \\
\hline 21 & Electronic monitoring & $\begin{array}{l}1: 77.7 \% \\
2: 77.7 \%\end{array}$ & $86.3 \%$ & $>0.05$ & $\begin{array}{l}1: 92.8 \% \\
2: 97.1 \%\end{array}$ & $91.3 \%$ & $>0.05$ \\
\hline 20 & Electronic monitoring & & & & $89.4 \%$ & $83.7 \%$ & $<0.001$ \\
\hline 19 & Pill count & & & & $\begin{array}{l}1: 99.1 \% \\
2: 96.6 \%\end{array}$ & $89.6 \%$ & 0.0001 \\
\hline 29 & $\begin{array}{l}\text { Self-report (proportion } \\
\text { taking all medication) }\end{array}$ & & & & $\begin{array}{l}1 \text { vs. } 2: O R=1 \\
3 \text { vs. } 4: O R=0\end{array}$ & $\begin{array}{l}1.56 \\
0.53\end{array}$ & $\begin{array}{l}0.45 \\
0.32\end{array}$ \\
\hline 23 & Electronic monitoring & & & & $87.2 \%$ & $90.2 \%$ & 0.63 \\
\hline 25 & Electronic monitoring & & & & $80.5 \%$ & $69.2 \%$ & 0.03 \\
\hline 28 & Self-report (survey) & & & & $\begin{array}{l}\text { Self-report: } \\
\text { Not } \\
\text { specified }\end{array}$ & $\begin{array}{l}\text { Self-report: } \\
\text { Not } \\
\text { specified }\end{array}$ & \\
\hline & Pharmacy records & & & & $\begin{array}{l}\text { Pharmacy } \\
\text { records: } \\
85 \%\end{array}$ & $\begin{array}{l}\text { Pharmacy } \\
\text { records: } \\
93 \%\end{array}$ & $>0.42$ \\
\hline 26 & $\begin{array}{l}\text { Self-report; 5-points } \\
\text { scale }\end{array}$ & & & & 4.85 & 4.25 & $<0.05$ \\
\hline 31 & Pharmacy records & & & & $82 \%$ & $89 \%$ & 0.29 \\
\hline 32 & Pill count & & & & $86.8 \%$ & $89.1 \%$ & $>0.05$ \\
\hline 72 & Pill count & & & & $84 \%$ & $69 \%$ & $<0.01$ \\
\hline 36 & Pill count & & & & $88 \%$ & $61 \%$ & $<0.001$ \\
\hline 37 & Pharmacy records & $38 \%$ & $32 \%$ & $\begin{array}{l}\text { Not } \\
\text { specified }\end{array}$ & $73 \%$ & $59 \%$ & $\begin{array}{l}\text { Not } \\
\text { specified }\end{array}$ \\
\hline & Pill count & & & & $\begin{array}{l}\text { Not } \\
\text { specified }\end{array}$ & $\begin{array}{l}\text { Not } \\
\text { specified }\end{array}$ & \\
\hline 40 & Pill count & $44.5 \%$ & $44.7 \%$ & $\begin{array}{l}\text { Not } \\
\text { specified }\end{array}$ & $65.8 \%$ & $43.2 \%$ & 0.025 \\
\hline 41 & $\begin{array}{l}\text { Self-report } \\
\text { Pill count }\end{array}$ & $\begin{array}{l}1: 65.5 \% \\
2: 65.8 \% \\
3: 65.0 \%\end{array}$ & $70.1 \%$ & $>0.05$ & $\begin{array}{l}\text { 1: } 76.3 \% \\
2: 78.0 \% \\
3: 68.3 \%\end{array}$ & $68.5 \%$ & $>0.05$ \\
\hline 73 & $\begin{array}{l}\text { Pharmacy records } \\
\text { (non-adherence if refill } \\
\geq 8 \text { days late) }\end{array}$ & & & & $\begin{array}{l}\text { Number of } \\
\text { refills: } 13.6\end{array}$ & $\begin{array}{l}\text { Number of } \\
\text { refills: } 11.8\end{array}$ & 0.04 \\
\hline 42 & Electronic monitoring & & & & $92.2 \%$ & $89.0 \%$ & 0.002 \\
\hline 43 & Self-report & & & & $\begin{array}{l}0.95 \\
(0.76-1.00)\end{array}$ & $\begin{array}{l}0.91 \\
(0.54-1.00)\end{array}$ & 0.07 \\
\hline
\end{tabular}




\begin{tabular}{|c|c|c|c|c|c|c|c|}
\hline \multirow{3}{*}{ Source } & \multirow[b]{2}{*}{ Adherence outcome } & \multicolumn{2}{|c|}{$\begin{array}{l}\text { Adherence results at } \\
\text { baseline }\end{array}$} & \multirow[b]{2}{*}{$P$-value } & \multicolumn{2}{|c|}{$\begin{array}{l}\text { Adherence results at end } \\
\text { follow-up period }\end{array}$} & \multirow[b]{2}{*}{$P$-value } \\
\hline & & Intervention & Control & & Intervention & Control & \\
\hline & Self-report & & & & $81.8 \%$ & $83.6 \%$ & $>0.05$ \\
\hline & Pill count & & & & $15.27 \%$ & $12.28 \%$ & $<0.05$ \\
\hline & Refill data & & & & $63.4 \%$ & $74.6 \%$ & $>0.05$ \\
\hline 75 & Self-report & & & & $91.7 \%$ & $90.7 \%$ & $>0.05$ \\
\hline 49 & Electronic monitoring & & & & $\begin{array}{l}\text { Difference be } \\
\text { intervention } \\
9.6 \% \text { in favo } \\
\text { intervention }\end{array}$ & $\begin{array}{l}\text { etween } \\
\text { and control: } \\
\text { ar of }\end{array}$ & 0.012 \\
\hline 77 & Pharmacy records & & & & $\begin{array}{l}\text { Month 1-6: } \\
0.91\end{array}$ & $\begin{array}{l}\text { Month 1-6: } \\
0.78\end{array}$ & 0.02 \\
\hline & & & & & $\begin{array}{l}\text { Month 6- } \\
12: 0.91\end{array}$ & $\begin{array}{l}\text { Month 6-12: } \\
0.83\end{array}$ & 0.09 \\
\hline 52 & $\begin{array}{l}\text { Pill count } \\
\text { Self-report }\end{array}$ & & & & $\begin{array}{l}\text { Visit } 1 \\
\text { group A: } \\
65.8\end{array}$ & $\begin{array}{l}\text { Visit } 1 \\
\text { group } B \text { : } \\
66.4\end{array}$ & $>0.05$ \\
\hline & & & & & $\begin{array}{l}\text { Visit } 2 \\
\text { group B: } \\
70.4\end{array}$ & $\begin{array}{l}\text { Visit } 2 \text { group } \\
\text { A: } 82.4\end{array}$ & \\
\hline & & & & & $\begin{array}{l}\text { Visit 3: } \\
\text { A: } 88.9 \\
\text { B: } 91.8\end{array}$ & & \\
\hline 78 & Pharmacy records & $\begin{array}{l}\text { Not } \\
\text { specified }\end{array}$ & $\begin{array}{l}\text { Not } \\
\text { specified }\end{array}$ & $\begin{array}{l}\text { Not } \\
\text { specified }\end{array}$ & $\begin{array}{l}\text { Not } \\
\text { specified }\end{array}$ & $\begin{array}{l}\text { Not } \\
\text { specified }\end{array}$ & $\begin{array}{l}\text { Not } \\
\text { specified }\end{array}$ \\
\hline 51 & Pharmacy records & $80.5 \%$ & $79.5 \%$ & $\begin{array}{l}\text { Not } \\
\text { specified }\end{array}$ & $87.5 \%$ & $78.8 \%$ & 0.0712 \\
\hline 48 & Self-report & $\begin{array}{l}\text { Group 1: } \\
90.6 \%\end{array}$ & $\begin{array}{l}\text { Group 2: } \\
85.1 \%\end{array}$ & 0.072 & $\begin{array}{l}\text { Group 1: } \\
88.4 \%\end{array}$ & $\begin{array}{l}\text { Group 2: } \\
86.3 \%\end{array}$ & 0.612 \\
\hline & Electronic monitoring & & & & $\begin{array}{l}\text { Group 1: } \\
46.7 \%\end{array}$ & $\begin{array}{l}\text { Group 2: } \\
35.3 \%\end{array}$ & 0.037 \\
\hline 62 & Pill count & & & & $\begin{array}{l}\text { Phase I: } \\
95.1 \%\end{array}$ & $\begin{array}{l}\text { Phase I: } \\
78 \%\end{array}$ & 0.0002 \\
\hline & & & & & $\begin{array}{l}\text { Phase II: } \\
\text { A: } 79 \% \\
\text { B: } 93.6 \% \\
\text { C: } 98.7 \% \\
\text { D: } 100.2 \%\end{array}$ & Phase II: - & $\begin{array}{l}- \\
0.03 \\
<0.0001 \\
<0.0001\end{array}$ \\
\hline 63 & Pharmacy records & & & & $\begin{array}{l}1: 0.64 \\
2: 0.67 \\
3: 0.79\end{array}$ & 0.56 & $\begin{array}{l}<0.05 \\
<0.05 \\
<0.005\end{array}$ \\
\hline
\end{tabular}




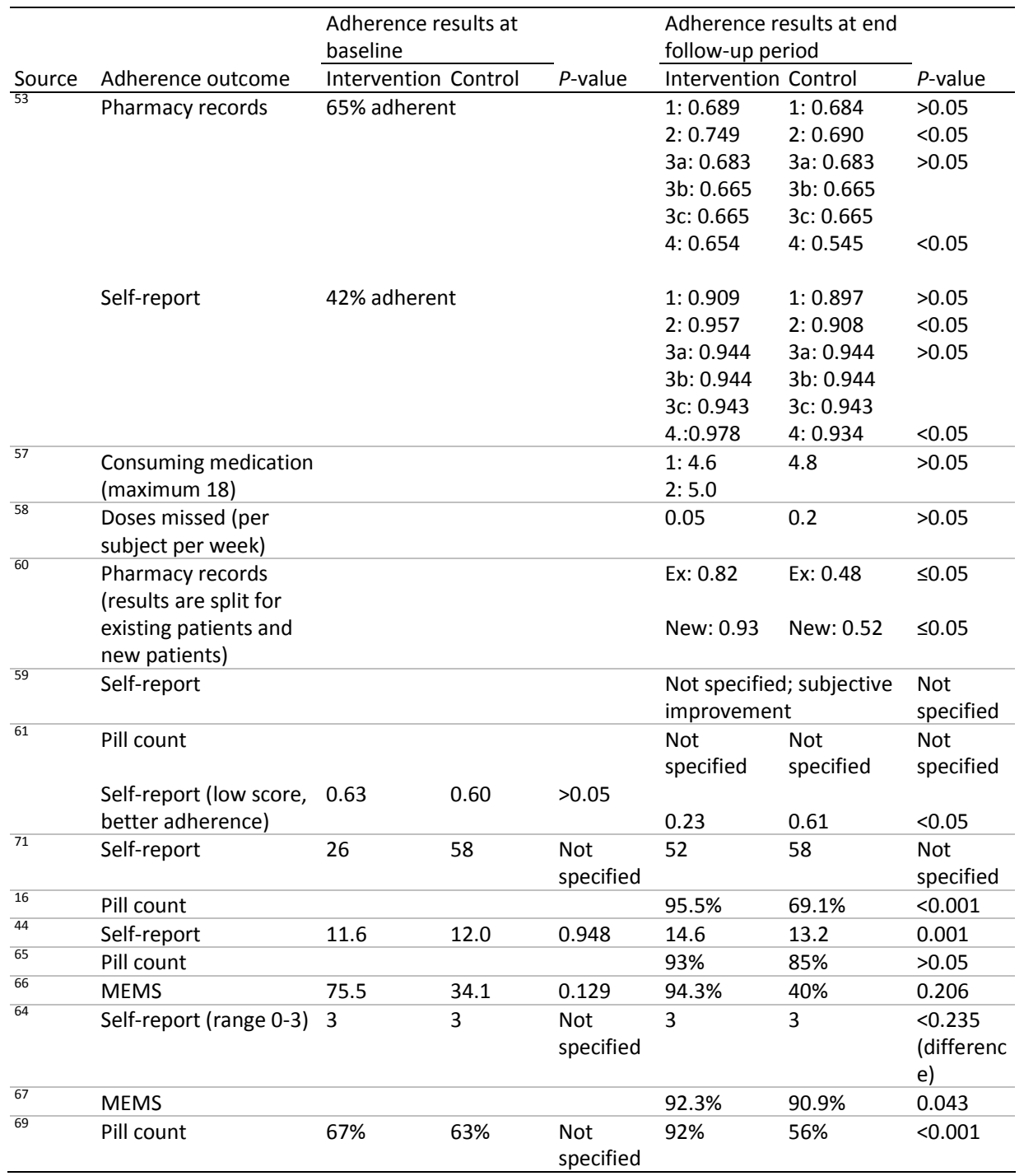

\section{Quality of the included studies}

Table 2.4 shows the quality of the included studies categorized by quality of reporting, external validity, bias, confounding, and the power of the study. In general, the methodological quality of the included studies was poor. The quality of reporting of the studies ranged from $30 \%$ (low quality) to $100 \%$ (good quality). External validity was assessed as poor in 6 studies $^{10,35,37,73,80,82}$ and as maximal in only 2 studies $^{12,78}$. The number of patients in 39 of the 78 (50\%) studies was judged as insufficient for showing a statistically significant effect of the studied intervention on adherence to 
treatment $^{12,14,21,26-32,35-38,40,41,44-46,51,52,57-60,64,66,69-73,78-80,83-86}$. Twenty-nine of these 39 studies were RCTs $s^{12,14,21,26-32,35-38,40,41,44-46,51,52,57-60,64,66,69,70}$

\section{Effects of interventions}

Of the 78 intervention studies, 33 (42\%) were classified as successful ${ }^{11,12,14-16,19,20,24-26 \text {, }}$ $34-36,39,40,42,44,46,49,53,60-63,67,69,70,72-74,80,82,87 ; 27$ of these were RCTs ${ }^{11,12,14-16,19,20,24-26,34-36,39}$, $40,42,44,46,49,53,60-63,67,69,70$. Interventions that were classified as successful showed an increase in adherence from 0.5 to $62 \%$ (Table 2.2) and a relative increase from 3.5 to $75.7 \%$ in the number of adherent patients (Table 2.3). Unsuccessful interventions resulted in a difference in adherence level of -12 to $75 \%$ or a relative difference of -20 to $71.4 \%$ in the number of adherent patients. Successful RCTs showed an increase in adherence level of 0.5 to $62 \%$ compared to 15 to $17.2 \%$ in non-randomised controlled trials. The same was observed in the number of patients becoming adherent: 3.5 to $75.7 \%$ for RCTs compared to 6 to $18 \%$ for non-randomised controlled trials.

Table 2.3 Effectiveness of interventions on the number of adherent patients.

\begin{tabular}{|c|c|c|c|c|c|c|c|}
\hline \multirow[b]{2}{*}{ Source } & \multirow[b]{2}{*}{$\begin{array}{l}\text { Adherence measure } \\
\text { (cut-off) }\end{array}$} & \multicolumn{2}{|c|}{$\begin{array}{l}\text { Number of adherent } \\
\text { patients at baseline } \\
\end{array}$} & \multirow{2}{*}{$P$-value } & \multicolumn{2}{|c|}{$\begin{array}{c}\text { Number of adherent patients } \\
\text { at end follow-up period }\end{array}$} & \multirow{2}{*}{$P$-value } \\
\hline & & $\begin{array}{l}\text { Intervention } \\
{[\mathrm{n}(\%)]}\end{array}$ & $\begin{array}{l}\text { Control } \\
{[\mathrm{n}(\%)]}\end{array}$ & & $\begin{array}{l}\text { Intervention } \\
\text { [n (\%)] }\end{array}$ & $\begin{array}{l}\text { Control } \\
{[\mathrm{n}(\%)]}\end{array}$ & \\
\hline$\overline{14}$ & $\begin{array}{l}\text { Electronic monitoring } \\
(\geq 80 \%)\end{array}$ & $16(50)$ & $11(34)$ & 0.31 & $25(78)$ & $10(31)$ & $<0.001$ \\
\hline 16 & Pill count $(>80 \%)$ & & & & $81(97.4)$ & $16(21.7)$ & $<0.001$ \\
\hline 20 & $\begin{array}{l}\text { Electronic monitoring } \\
(\geq 80 \%)\end{array}$ & & & & $92(92)$ & $74(74)$ & $<0.001$ \\
\hline \multirow[t]{2}{*}{30} & Self-report (yes/no) & $17(41)$ & $16(38)$ & 0.46 & \multicolumn{3}{|c|}{$\begin{array}{l}t=6 \text { months: } 26 \mathrm{t}=6 \text { months: } 170.05 \\
(65)\end{array}$} \\
\hline & & & & & \multicolumn{3}{|c|}{$\begin{array}{l}t=9 \text { months: } 18 \mathrm{t}=9 \text { months: } 130.56 \\
(86)\end{array}$} \\
\hline \multirow[t]{2}{*}{22} & Self-report (yes/no) & \multicolumn{3}{|c|}{ Adherent: 387 (66) } & $\begin{array}{l}\text { Remained } \\
\text { adherent: } 83 \%\end{array}$ & $\begin{array}{l}\text { Remained } \\
\text { adherent: } 85 \%\end{array}$ & 0.68 \\
\hline & & \multicolumn{3}{|c|}{$\begin{array}{l}\text { Non-adherent: } 200 \\
\text { (34) }\end{array}$} & \multicolumn{3}{|c|}{ adherent: $46 \%$ adherent: $34 \% 0.08$} \\
\hline 24 & Pill count $(\geq 80 \%)$ & $58(51 \%)$ & $61(56 \%)$ & 0.534 & $70(64)$ & $60(56)$ & 0.014 \\
\hline 27 & Self-report $(\geq 80 \%)$ & $28(84.9)$ & $32(88.9)$ & 0.728 & $33(100)$ & $32(88.9)$ & 0.115 \\
\hline 81 & $\begin{array}{l}\text { Pharmacy records } \\
(\geq 90 \%)\end{array}$ & \multicolumn{3}{|c|}{$<90 \%$ adherence } & \multicolumn{2}{|c|}{$\begin{array}{l}\text { Turned adherent: } 7 \\
\text { Remained non-adherent: } 19\end{array}$} & $\begin{array}{l}\text { Not } \\
\text { specified }\end{array}$ \\
\hline 34 & Pill count $(\geq 80 \%)$ & & & & $\begin{array}{l}+24(+17.7) \\
\text { adherent }\end{array}$ & $\begin{array}{l}+16(+11.7) \\
\text { adherent }\end{array}$ & 0.03 \\
\hline 35 & Self-report (yes/no) & $8(30)$ & $4(20)$ & $>0.05$ & $24(96)$ & $8(36)$ & 0.04 \\
\hline \multirow[t]{2}{*}{33} & Self-report (yes/no) & $45(53.6)$ & $43(50.6)$ & $\begin{array}{l}\text { Not } \\
\text { specified }\end{array}$ & $47(56.0)$ & $46(54.1)$ & $\begin{array}{l}\text { Not } \\
\text { specified }\end{array}$ \\
\hline & Pill count $(\geq 80 \%)$ & & & & $68(84.0)$ & $58(75.3)$ & $\begin{array}{l}\text { Not } \\
\text { specified }\end{array}$ \\
\hline 82 & Self-report (yes/no) & & & & $65(61)$ & $15(43)$ & $<0.05$ \\
\hline
\end{tabular}




\begin{tabular}{|c|c|c|c|c|c|c|c|}
\hline \multirow[b]{2}{*}{ Source } & \multirow[b]{2}{*}{$\begin{array}{l}\text { Adherence measure } \\
\text { (cut-off) }\end{array}$} & \multicolumn{2}{|c|}{$\begin{array}{l}\text { Number of adherent } \\
\text { patients at baseline }\end{array}$} & \multirow{2}{*}{$P$-value } & \multicolumn{2}{|c|}{$\begin{array}{l}\text { Number of adherent patients } \\
\text { at end follow-up period }\end{array}$} & \multirow{2}{*}{ P-value } \\
\hline & & $\begin{array}{l}\text { Intervention } \\
{[\mathrm{n}(\%)]}\end{array}$ & $\begin{array}{l}\text { Control } \\
{[\mathrm{n}(\%)]}\end{array}$ & & $\begin{array}{l}\text { Intervention } \\
{[\mathrm{n}(\%)]}\end{array}$ & $\begin{array}{l}\text { Control } \\
{[\mathrm{n}(\%)]}\end{array}$ & \\
\hline$\overline{39}$ & $\begin{array}{l}\text { Self-report (yes/no) } \\
\text { combined with pill count } \\
(\geq 80 \%)\end{array}$ & & & & $115(67.6)$ & $53(49.1)$ & $<0.005$ \\
\hline 38 & $\begin{array}{l}\text { Self-report (low- } \\
\text { medium-high) }\end{array}$ & & & & $\begin{array}{l}\text { E1E2C3: } 23 \\
\text { (53) high }\end{array}$ & $\begin{array}{l}\text { C1C2C3: } 16 \\
\text { (40) high }\end{array}$ & $\begin{array}{l}\text { Not } \\
\text { specified }\end{array}$ \\
\hline 42 & OR $\geq 80 \%$ adherent & & & & $\mathrm{OR}=1.91$ & $-3.05)$ & \\
\hline 86 & Refill data & & & & $\begin{array}{l}\text { OR for being a } \\
=1.52\end{array}$ & dherent & $\begin{array}{l}\text { Not } \\
\text { specified }\end{array}$ \\
\hline 45 & $\begin{array}{l}\text { Blood level of } \\
\text { hydrochlorothiazide } \\
\text { (yes/no) }\end{array}$ & & & & $\begin{array}{l}21 \text { out of } 27 \\
(78)\end{array}$ & $\begin{array}{l}2 \text { out of } 30 \\
(6.7)\end{array}$ & 0.904 \\
\hline 74 & $\begin{array}{l}\text { Not reported; poor } \\
\text { adherence }\end{array}$ & $51(5.2)$ & 49 (7.9) & $\begin{array}{l}\text { Not } \\
\text { specified }\end{array}$ & $38(3.8)$ & $61(9.8)$ & 0.004 \\
\hline 76 & $\begin{array}{l}\text { Self-report ('Ever forget } \\
\text { to take medication?') }\end{array}$ & & & & $\begin{array}{l}\text { Yes: } 0(0) \\
\text { Never: } 130 \\
(71.0) \\
\text { Sometimes: } 53 \\
(29.0)\end{array}$ & $\begin{array}{l}\text { Yes: } 23 \text { (16.1) } \\
\text { Never: } 87 \\
(60.2) \\
\text { Sometimes: } 34 \\
(23.7)\end{array}$ & $\begin{array}{l}\text { Not } \\
\text { specified }\end{array}$ \\
\hline 46 & Pill count ( $\geq 95 \%)$ & & & & Results not to & be interpreted & $\begin{array}{l}<0.01 \text { for } \\
2 \text { and } 3 \\
\text { compared } \\
\text { to } 1 \text { or } \\
\text { control }\end{array}$ \\
\hline 47 & $\begin{array}{l}\text { Self-report (low } \\
\text { adherence) }\end{array}$ & $33(17.3)$ & $39(18.7)$ & 0.98 & $28(14.6)$ & $31(14.7)$ & 0.80 \\
\hline 50 & $\begin{array}{l}\text { Self-report (high } \\
\text { adherence) }\end{array}$ & & & & $67 \%$ & $69 \%$ & 0.77 \\
\hline 78 & Self-report (yes/no) & & & & $\begin{array}{l}\text { Low income: } \\
15(68 \%) \\
\text { adherent }\end{array}$ & $\begin{array}{l}\text { Low income: } \\
22(88 \%) \\
\text { adherent }\end{array}$ & 0.095 \\
\hline & & & & & $\begin{array}{l}\text { High income: } \\
11(85 \%) \\
\text { adherent }\end{array}$ & $\begin{array}{l}\text { High income: } \\
23(74 \%) \\
\text { adherent }\end{array}$ & 0.067 \\
\hline 55 & Pill count ( $\geq 80 \%)$ & & & & $43(55.4)$ & $38(55.7)$ & $>0.05$ \\
\hline 56 & $\begin{array}{l}\text { Pill count }(\geq 80 \%) \\
\text { Urine sample }\end{array}$ & & & & $\begin{array}{l}1: 47(54) \\
2: 29(51) \\
3: 40(50) \\
4: 36(56)\end{array}$ & - & $\begin{array}{l}\text { Not } \\
\text { specified }\end{array}$ \\
\hline 54 & $\begin{array}{l}\text { Pill count (adherent yes) } \\
\text { Urine sample for } \\
\text { chlorthalidone (adherent } \\
\text { yes) }\end{array}$ & & & & $17(63)$ & $30(61)$ & $>0.05$ \\
\hline 67 & MEMS ( $\geq 85 \%)$ & & & & $92(81)$ & $84(74)$ & $>0.05$ \\
\hline 84 & Pill count $(\geq 80 \%)$ & & & & $\begin{array}{l}\text { Visit 1: } 28(64) \\
\text { Visit 2: } 35(80) \\
\text { Visit 3: } 40(91) \\
\text { Visit 4: } 42(96)\end{array}$ & & 0.96 \\
\hline 87 & $\begin{array}{l}\text { Self-report (occasionally } \\
\text { missed a dose [once or } \\
\text { more/week]) }\end{array}$ & & & & $\begin{array}{l}\text { 1: } 16(6.5) \\
2: 22(10.1) \\
3: 16(11.0)\end{array}$ & $25(14.5)$ & $<0.01$ \\
\hline
\end{tabular}




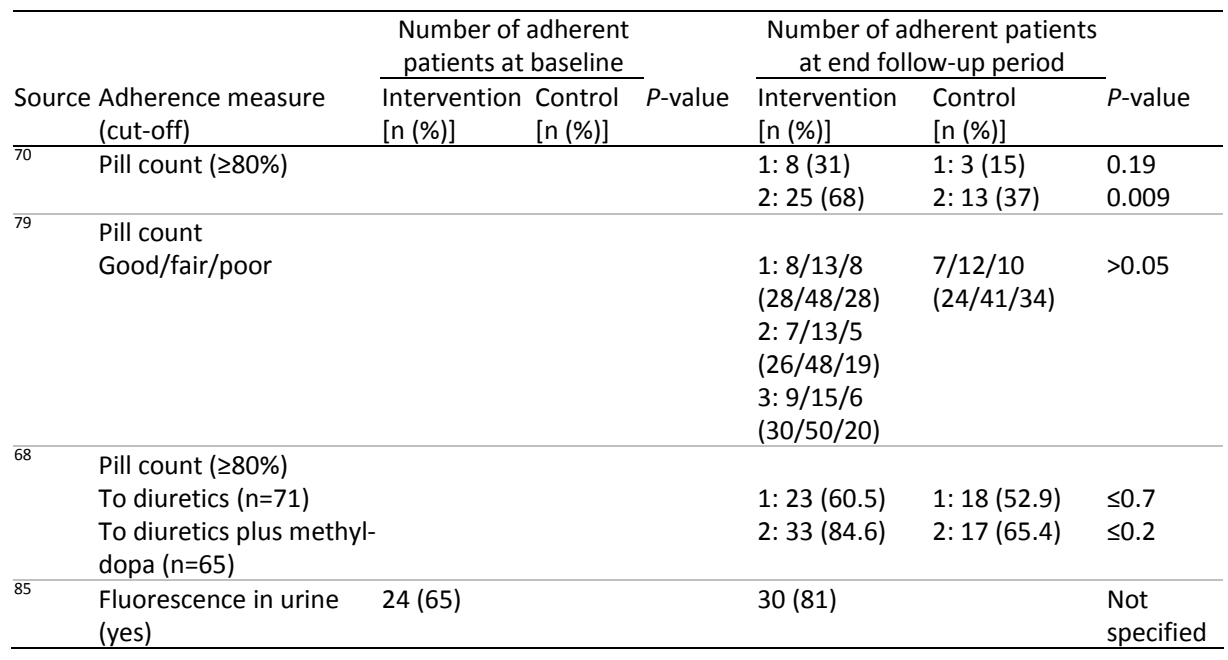

Twenty-six studies targeted external factors ${ }^{12,15,16,30,33-35,45-48,52,54-56,60,61,63-65,68,70,72,74,84,86}$ of which 12 (46\%) interventions were successful ${ }^{12,15,16,34,35,46,60,61,63,70,72,74}$ (Figure 2.3). The increase in adherence rate ranged between 1.4 and 62\%; the increase in number of adherent patients ranged between 6 and 75.7\%. Twenty-three studies targeted internal factors ${ }^{11,14,17,18,20,21,23,24,26,28,38,40,41,44,58,67,73,75,78,82,83,85,87}$ of which 11 (48\%) interventions were successful ${ }^{11,14,20,24,26,40,44,67,73,82,87}$. In this category, the increase in adherence rate ranged between 0.5 and $36 \%$; the increase in number of adherent patients was $18.5 \%$. Of the remaining 29 studies that targeted internal as well as external factors ${ }^{10,13,19,22,25,27,29,31,32,36,37,39,42,43,49-51,53,57,59,62,66,69,71,76,77,79-81}, \quad 10$ (34\%) showed a significant increase in adherence to treatment ${ }^{19,25}, 36,39,42,49,53,62,69,80$. Differences in adherence rates ranged between 5.7 and 22.6\%; the increase in number of adherent patients ranged between 3.5 and 57\%. Most interventions that targeted at internal factors only were, irrespective of their success able to induce a health behaviour change and introduction of self-measurement of blood pressure (BP). Providing patients with information and/or educate patients, special packaging of antihypertensive drugs, and mail and/or telephone follow-up were the most investigated interventions targeting external factors only. Unsuccessful studies that investigated interventions targeting both internal and external factors showed that telephone and/or video follow-up and providing patients with information or educate patients were more frequently investigated than in successful studies. The same could be applied to the internal factors intended to achieve a health behaviour change and educate patients in behaviour and perception. 
Table 2.4 Quality of included studies according to Downs and Black ${ }^{9}$.

\begin{tabular}{|c|c|c|c|c|c|}
\hline Source & $\begin{array}{l}\text { Reporting of the } \\
\text { study (\%) }\end{array}$ & $\begin{array}{l}\text { External validity } \\
(\%)\end{array}$ & $\begin{array}{c}\text { Internal validity - } \\
\text { bias (\%) }\end{array}$ & $\begin{array}{l}\text { Internal validity - } \\
\text { confounding (\%) }\end{array}$ & $\begin{array}{c}\text { Power } \\
\text { (range } 0-5)^{*}\end{array}$ \\
\hline 71 & 100 & 67 & 57 & 33 & 0 \\
\hline 11 & 100 & 67 & 71 & 67 & 3 \\
\hline 10 & 90 & 0 & 86 & 83 & 1 \\
\hline 12 & 90 & 100 & 71 & 83 & 0 \\
\hline 13 & 60 & 67 & 29 & 50 & 5 \\
\hline 14 & 100 & 33 & 71 & 50 & 0 \\
\hline 15 & 90 & 67 & 71 & 83 & 3 \\
\hline 80 & 80 & 0 & 57 & 17 & 0 \\
\hline 17 & 60 & 33 & 43 & 33 & 3 \\
\hline 16 & 100 & 67 & 86 & 100 & 1 \\
\hline 18 & 70 & 33 & 71 & 50 & 5 \\
\hline 21 & 70 & 33 & 71 & 50 & 0 \\
\hline 20 & 100 & 67 & 71 & 83 & 3 \\
\hline 19 & 100 & 33 & 57 & 83 & 5 \\
\hline 29 & 100 & 67 & 71 & 83 & 0 \\
\hline 30 & 70 & 33 & 71 & 67 & 0 \\
\hline 22 & 70 & 67 & 43 & 50 & 5 \\
\hline 23 & 90 & 67 & 71 & 100 & 4 \\
\hline 24 & 80 & 33 & 71 & 67 & 4 \\
\hline 25 & 60 & 33 & 57 & 67 & 1 \\
\hline 27 & 90 & 33 & 43 & 50 & 0 \\
\hline 28 & 90 & 67 & 71 & 67 & 0 \\
\hline 26 & 80 & 33 & 71 & 67 & 0 \\
\hline 31 & 90 & 67 & 43 & 67 & 0 \\
\hline 81 & 50 & 67 & 71 & 50 & 3 \\
\hline 32 & 60 & 33 & 57 & 17 & 0 \\
\hline 34 & 100 & 67 & 57 & 50 & 4 \\
\hline 35 & 80 & 0 & 57 & 50 & 0 \\
\hline 33 & 70 & 67 & 57 & 50 & 1 \\
\hline 72 & 60 & 33 & 29 & 0 & 0 \\
\hline 82 & 60 & 0 & 43 & 33 & 3 \\
\hline 36 & 70 & 67 & 57 & 50 & 0 \\
\hline 37 & 60 & 0 & 43 & 33 & 0 \\
\hline 39 & 80 & 67 & 71 & 50 & 5 \\
\hline 38 & 70 & 67 & 57 & 50 & 0 \\
\hline 40 & 80 & 67 & 71 & 50 & 0 \\
\hline 41 & 60 & 33 & 57 & 33 & 0 \\
\hline 73 & 90 & 0 & 57 & 0 & 0 \\
\hline 42 & 100 & 67 & 71 & 83 & 5 \\
\hline 44 & 100 & 33 & 71 & 83 & 0 \\
\hline 43 & 80 & 67 & 71 & 67 & 3 \\
\hline 83 & 50 & 33 & 57 & 17 & 0 \\
\hline 86 & 50 & 67 & 57 & 33 & 0 \\
\hline 45 & 90 & 67 & 57 & 50 & 0 \\
\hline 75 & 50 & 67 & 29 & 33 & 5 \\
\hline 74 & 100 & 33 & 71 & 50 & 5 \\
\hline 76 & 50 & 33 & 43 & 33 & 5 \\
\hline 46 & 60 & 67 & 43 & 50 & 0 \\
\hline 47 & 100 & 67 & 86 & 83 & 5 \\
\hline 48 & 70 & 67 & 71 & 33 & 5 \\
\hline 49 & 70 & 67 & 57 & 50 & 3 \\
\hline 51 & 70 & 67 & 57 & 50 & 0 \\
\hline 50 & 100 & 67 & 71 & 67 & 5 \\
\hline 77 & 70 & 67 & 43 & 33 & 1 \\
\hline
\end{tabular}




\begin{tabular}{lccccc}
\hline Source & $\begin{array}{c}\text { Reporting of the } \\
\text { study (\%) }\end{array}$ & $\begin{array}{c}\text { External validity } \\
(\%)\end{array}$ & $\begin{array}{c}\text { Internal validity - } \\
\text { bias (\%) }\end{array}$ & $\begin{array}{c}\text { Internal validity - } \\
\text { confounding (\%) }\end{array}$ & $\begin{array}{c}\text { Power } \\
\text { (range 0-5) }\end{array}$ \\
\hline 78 & 100 & 100 & 86 & 67 & 0 \\
52 & 70 & 67 & 57 & 50 & 0 \\
53 & 60 & 67 & 71 & 50 & 5 \\
55 & 80 & 67 & 71 & 67 & 4 \\
56 & 70 & 67 & 86 & 50 & 5 \\
57 & 70 & 67 & 71 & 50 & 0 \\
58 & 90 & 67 & 71 & 50 & 0 \\
54 & 40 & 67 & 43 & 33 & 4 \\
60 & 80 & 67 & 57 & 50 & 0 \\
59 & 30 & 67 & 57 & 33 & 0 \\
61 & 80 & 67 & 71 & 50 & 1 \\
62 & 70 & 67 & 71 & 17 & 1 \\
63 & 80 & 67 & 43 & 33 & 2 \\
65 & 90 & 67 & 71 & 67 & 3 \\
66 & 90 & 67 & 71 & 67 & 0 \\
64 & 90 & 67 & 57 & 50 & 0 \\
67 & 90 & 67 & 86 & 67 & 3 \\
84 & 70 & 67 & 57 & 50 & 0 \\
87 & 60 & 67 & 43 & 33 & 5 \\
70 & 80 & 67 & 71 & 50 & 0 \\
69 & 60 & 67 & 71 & 33 & 0 \\
79 & 50 & 67 & 86 & 17 & 0 \\
68 & 70 & 67 & 43 & 50 & 5 \\
85 & 50 & 33 & 43 & 0 & 0 \\
\hline
\end{tabular}

* $0,1,2,3,4,5$ corresponds to a power of $70,80,85,90,95$, and $99 \%$, respectively 
44 Chapter 2

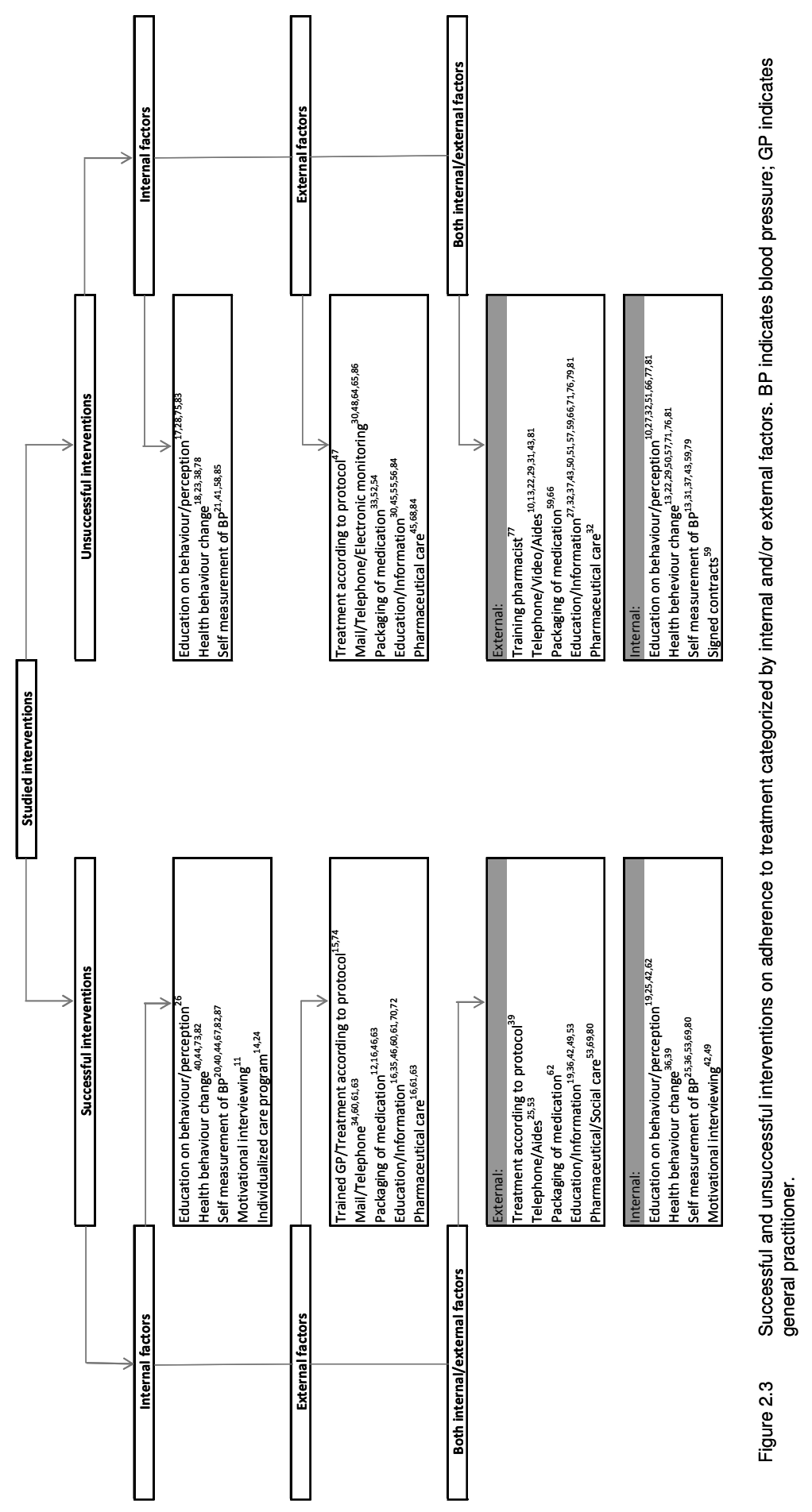




\section{Discussion}

We reviewed studies that assessed interventions designed to improve adherence to antihypertensive medication. Thirty-three of the 78 studies which were available for analysis showed a significant increase in adherence to medication. Interventions targeting both internal and external factors were not more successful than interventions targeting internal or external factors only. Almost all interventions were complex, including combinations of education, self measurement of $\mathrm{BP}$, motivational interviewing, and establishing a health behaviour change.

Poor adherence to treatment is considered one of the biggest problems in overall healthcare. For hypertension, a prevalent and largely asymptomatic disease, this problem even is bigger as optimal outcomes in the treatment of hypertension necessitates that patients take their medication not only properly (medication adherence) but also continue to do so for a long period of time (persistence). Indeed, the World Health Organization stated that poor adherence severely compromises the effectiveness of treatment ${ }^{88}$. Improving medication-taking behaviour therefore represents an important potential source of health and economic improvement. Moreover, from all factors influencing hypertensive treatment, improvement of treatment adherence yields the greatest gain both in terms of cost effectiveness and of efficiency ${ }^{89}$. It is therefore not surprising that in the last 10 years many studies addressed this topic and tried to apply the most effective intervention(s). In general, it appears that current methods of improving adherence are complex and not consistently effective. However, heterogeneity between the studies makes it difficult to draw conclusions with regard to effective interventions. More specifically, interpretation of the results has been limited to different methods of adherence measurement used and to differences between, as it may appear at first sight, comparable interventions that were subject to research.

We tried to minimize the differences between interventions by applying the conceptual framework of intentional and unintentional adherence and, consequently, by dividing interventions into strategies targeting internal and/or external factors. We hypothesized that interventions targeting internal and external factors would yield more successful studies than interventions targeting either internal or external factors only. Ideally, changing patients' health behaviour make them more inclined to adhere and persist to prescribed medication when there is an external incentive that moderates patients' perception of the disease and its treatment than when this external incentive is wanting. Unfortunately, we were unable to identify successful interventions targeting internal and external factors. Moreover, the number of interventions considered successful was comparable in all three categories. This suggests that the effect of an intervention is independent of which factors are targeted in the intervention. Furthermore, any additional effect of strategies targeting external factors on the effect of strategies targeting internal factors seems to be limited. There are several explanations for these observations. First of all, differences 
between internal and external factors may be difficult to distinguish. For example, we classified mail and telephone contact with patients as an external factor. However, these external factors may moderate patients' perception, and hence, intake behaviour. This may limit an adequate categorization of the interventions. Secondly, since external factors may modify patients' perception about their disease and treatment, the effect of interventions targeting external factors on adherence to treatment may be more important for influencing adherence behaviour than interventions targeting internal factors or a combination of internal and external factors. Nevertheless, a comparable number of studies targeting external factors were unsuccessful in increasing adherence to treatment.

Of all included RCTs, only 27 presented interventions that were considered successful. It is possible that RCTs are less suitable for evaluating adherence improving strategies than observational studies. A major disadvantage of RCTs is the lower external validity compared to observational studies. Participants may be more inclined to adhere to the prescribed treatment regimen because of the specific design of the study in which participants usually have to attend the clinic more often than usual. In addition, participants may be more willing to participate in a trial in which adherence is monitored, and may, therefore, be more adherent upfront as compared to what is observed in a general population. All these considerations may compromise the generalizibility of trial-derived adherence results.

The majority of the included studies in this review used self-report as method for adherence measurement. It is generally acknowledged that self-report overestimates actual adherence ${ }^{90,91}$ and should preferably not be incorporated into studies for adherence measurement. Despite the availability of objective measures of adherence such as the Medication Event Monitoring System (MEMS), presently considered to be the gold standard and available since 1989, our observations show that only $20 \%$ of the included studies performed after 1989 used electronic monitoring for adherence measurement. Although electronic monitoring is considered to be expensive, it provides a more accurate measure of actual adherence, and should be incorporated into studies whenever possible.

\section{Future perspectives}

The results of this review highlight a number of problems encountered in adherence research. First of all, the majority of the studies used methods for adherence measurement that may not be suitable for the aims of the studied topic. Secondly, the methodological quality of the included studies usually is poor. Larger trials of higher quality using suitable methods for adherence measurement are needed. Thirdly, it appears to be difficult to unravel the complexity of non-adherence by applying the conceptual framework of intentional and unintentional non-adherence and translate that into successful strategies for adherence improvement. Determinants of nonadherence such as long duration of therapy, symptomless nature of the disease, and 
medication related issues may predict non-adherence insufficiently. Patient's perception about the disease and its treatment and patient's motivation may predict non-adherence better. Consequently, as this framework seems to be less suitable for the population at large, it may be applied to patients individually. Future studies should focus on the individual patient's behavioural intentions, barriers and subjective norms. 


\section{References}

1. Haynes RB, Ackloo E, Sahota N, McDonald HP, Yao X. Interventions for enhancing medication adherence. Cochrane Database Syst Rev 2008(2):CD000011.

2. Chapman RH, Ferrufino CP, Kowal SL, Classi P, Roberts CS. The cost and effectiveness of adherenceimproving interventions for antihypertensive and lipid-lowering drugs*. Int J Clin Pract 2010;64: 169-81.

3. Morgado MP, Morgado SR, Mendes LC, Pereira LJ, Castelo-Branco M. Pharmacist interventions to enhance blood pressure control and adherence to antihypertensive therapy: Review and metaanalysis. Am J Health Syst Pharm 2011;68:241-53.

4. Schroeder K, Fahey T, Ebrahim S. Interventions for improving adherence to treatment in patients with high blood pressure in ambulatory settings. Cochrane Database Syst Rev 2004(3):CD004804.

5. van Dulmen S, Sluijs E, van Dijk L, de Ridder D, Heerdink R, Bensing J. Patient adherence to medical treatment: a review of reviews. BMC Health Serv Res 2007;7:55.

6. Van Wijk BL, Klungel $\mathrm{OH}$, Heerdink ER, de Boer A. Effectiveness of interventions by community pharmacists to improve patient adherence to chronic medication: a systematic review. Ann Pharmacother 2005;39:319-28.

7. Horne R, Weinman J, Barber N, Elliott R, Morgan M. Concordane, adherence and compliance in medicine taking. London: National Co-ordinating Centre for NHS Service Delivery and Organisation NCCSDO, 2005.

8. Horne R, Weinman J, Hankins M. The beliefs about medicines questionnaire: the development and evaluation of a new method for assessing the cognitive representation of medication. Psychology and Health 1999;14:1-24.

9. Downs SH, Black N. The feasibility of creating a checklist for the assessment of the methodological quality both of randomised and non-randomised studies of health care interventions. J Epidemiol Community Health 1998;52:377-84.

10. Carter BL, Bergus GR, Dawson JD, Farris KB, Doucette WR, Chrischilles EA, Hartz AJ. A cluster randomized trial to evaluate physician/pharmacist collaboration to improve blood pressure control. J Clin Hypertens (Greenwich) 2008;10:260-71.

11. Ogedegbe G, Chaplin W, Schoenthaler A, Statman D, Berger D, Richardson T, Phillips E, Spencer J, Allegrante JP. A practice-based trial of motivational interviewing and adherence in hypertensive African Americans. Am J Hypertens 2008;21:1137-43.

12. Schneider PJ, Murphy JE, Pedersen CA. Impact of medication packaging on adherence and treatment outcomes in older ambulatory patients. J Am Pharm Assoc (2003) 2008;48:58-63.

13. Bosworth HB, Olsen MK, Neary A, Orr M, Grubber J, Svetkey L, Adams M, Oddone EZ. Take Control of Your Blood Pressure (TCYB) study: a multifactorial tailored behavioural and educational intervention for achieving blood pressure control. Patient Educ Couns 2008;70:338-47.

14. Bogner HR, de Vries HF. Integration of depression and hypertension treatment: a pilot, randomized controlled trial. Ann Fam Med 2008;6:295-301.

15. Qureshi NN, Hatcher J, Chaturvedi N, Jafar TH. Effect of general practitioner education on adherence to antihypertensive drugs: cluster randomised controlled trial. BMJ 2007;335:1030.

16. Lee JK, Grace KA, Taylor AJ. Effect of a pharmacy care program on medication adherence and persistence, blood pressure, and low-density lipoprotein cholesterol: a randomized controlled trial. JAMA 2006;296:2563-71.

17. Thomas PD, Miceli R. Evaluation of the 'Know Your Health' program for type 2 diabetes mellitus and hypertension in a large employer group. Am J Manag Care 2006;12 Spec no.:SP33-9.

18. Johnson SS, Driskell MM, Johnson JL, Prochaska JM, Zwick W, Prochaska JO. Efficacy of a transtheoretical model-based expert system for antihypertensive adherence. Dis Manag 2006;9: 291-301.

19. Marquez Contreras E, Vegazo Garcia O, Claros NM, Gil Guillen V, de la Figuera von Wichmann M, Casado Martinez JJ, Fernandez R. Efficacy of telephone and mail intervention in patient compliance with antihypertensive drugs in hypertension. ETECUM-HTA study. Blood Press 2005;14:151-8. 
20. Marquez-Contreras E, Martell-Claros N, Gil-Guillen V, de la Figuera-Von Wichmann M, CasadoMartinez JJ, Martin-de Pablos JL, Figueras M, Galera J, Serra A. Efficacy of a home blood pressure monitoring programme on therapeutic compliance in hypertension: the EAPACUM-HTA study. J Hypertens 2006;24:169-75.

21. Mengden $T$, Vetter H, Tousset E, Uen S. Management of patients with uncontrolled arterial hypertension--the role of electronic compliance monitoring, 24-h ambulatory blood pressure monitoring and Candesartan/HCTZ. BMC Cardiovasc Disord 2006;6:36.

22. Bosworth HB, Olsen MK, Gentry P, Orr M, Dudley T, McCant F, Oddone EZ. Nurse administered telephone intervention for blood pressure control: a patient-tailored multifactorial intervention. Patient Educ Couns 2005;57:5-14.

23. Schroeder K, Fahey T, Hollinghurst S, Peters TJ. Nurse-led adherence support in hypertension: a randomized controlled trial. Fam Pract 2005;22:144-51.

24. Sookaneknun P, Richards RM, Sanguansermsri J, Teerasut C. Pharmacist involvement in primary care improves hypertensive patient clinical outcomes. Ann Pharmacother 2004;38:2023-8.

25. Rudd P, Miller NH, Kaufman J, Kraemer HC, Bandura A, Greenwald G, Debusk RF. Nurse management for hypertension. A systems approach. Am J Hypertens 2004;17:921-7.

26. Saounatsou M, Patsi O, Fasoi G, Stylianou M, Kavga A, Economou O, Mandi P, Nicolaou M. The influence of the hypertensive patient's education in compliance with their medication. Public Health Nurs 2001;18:436-42.

27. Taylor CT, Byrd DC, Krueger K. Improving primary care in rural Alabama with a pharmacy initiative. Am J Health Syst Pharm 2003;60:1123-9.

28. Vivian EM. Improving blood pressure control in a pharmacist-managed hypertension clinic. Pharmacotherapy 2002;22:1533-40.

29. Emmett CL, Montgomery AA, Peters TJ, Fahey T. Three-year follow-up of a factorial randomised controlled trial of two decision aids for newly diagnosed hypertensive patients. $\mathrm{Br} J$ Gen Pract 2005;55:551-3.

30. Stewart A, Noakes T, Eales C, Shepard K, Becker P, Veriawa Y. Adherence to cardiovascular risk factor modification in patients with hypertension. Cardiovasc J S Afr 2005;16:102-7.

31. Mehos BM, Saseen JJ, MacLaughlin EJ. Effect of pharmacist intervention and initiation of home blood pressure monitoring in patients with uncontrolled hypertension. Pharmacotherapy 2000;20:1384-9.

32. Park JJ, Kelly P, Carter BL, Burgess PP. Comprehensive pharmaceutical care in the chain setting. J Am Pharm Assoc (Wash) 1996;NS36:443-51.

33. Becker LA, Glanz K, Sobel E, Mossey J, Zinn SL, Knott KA. A randomized trial of special packaging of antihypertensive medications. J Fam Pract 1986;22:357-61.

34. Friedman RH, Kazis LE, Jette A, Smith MB, Stollerman J, Torgerson J, Carey K. A telecommunications system for monitoring and counselling patients with hypertension. Impact on medication adherence and blood pressure control. Am J Hypertens 1996;9:285-92.

35. Gonzalez-Fernandez RA, Rivera M, Torres D, Quiles J, Jackson A. Usefulness of a systemic hypertension in-hospital educational program. Am J Cardiol 1990;65:1384-6.

36. Nessman DG, Carnahan JE, Nugent CA. Increasing compliance. Patient-operated hypertension groups. Arch Intern Med 1980;140:1427-30.

37. Ogbuokiri JE. Self-monitoring of blood pressures in hypertensive subjects and its effects on patient compliance. Drug Intell Clin Pharm 1980;14:424-7.

38. Levine DM, Green LW, Deeds SG, Chwalow J, Russell RP, Finlay J. Health education for hypertensive patients. JAMA 1979;241:1700-3.

39. Logan AG, Milne BJ, Achber C, Campbell WP, Haynes RB. Work-site treatment of hypertension by specially trained nurses. A controlled trial. Lancet 1979;2:1175-8.

40. Haynes RB, Sackett DL, Gibson ES, Taylor DW, Hackett BC, Roberts RS, Johnson AL. Improvement of medication compliance in uncontrolled hypertension. Lancet 1976;1:1265-8.

41. Johnson AL, Taylor DW, Sackett DL, Dunnett CW, Shimizu AG. Self-recording of blood pressure in the management of hypertension. Can Med Assoc J 1978;119:1034-9.

42. Pladevall M, Brotons C, Gabriel R, Arnau A, Suarez C, de la Figuera M, Marquez E, Coca A, Sobrino J, Divine G, Heisler M, Williams LK. Multicenter cluster-randomized trial of a multifactorial intervention to improve antihypertensive medication adherence and blood pressure control among patients at high cardiovascular risk (the COM99 study). Circulation 2010;122:1183-91. 
43. Rinfret S, Lussier MT, Peirce A, Duhamel F, Cossette S, Lalonde L, Tremblay C, Guertin MC, LeLorier J, Turgeon J, Hamet $P$. The impact of a multidisciplinary information technology-supported program on blood pressure control in primary care. Circ Cardiovasc Qual Outcomes 2009;2:170-7.

44. Zang XY, Liu JF, Chai YF, Wong FK, Zhao Y. Effect on blood pressure of a continued nursing intervention using chronotherapeutics for adult Chinese hypertensive patients. J Clin Nurs 2010;19: 1149-56.

45. de Castro MS, Fuchs FD, Santos MC, Maximiliano P, Gus M, Moreira LB, Ferreira MB. Pharmaceutical care program for patients with uncontrolled hypertension. Report of a double-blind clinical trial with ambulatory blood pressure monitoring. Am J Hypertens 2006;19:528-33.

46. Rehder TL, McCoy LK, Blackwell B, Whitehead W, Robinson A. Improving medication compliance by counselling and special prescription container. Am J Hosp Pharm 1980;37:379-85.

47. Carter BL, Ardery G, Dawson JD, James PA, Bergus GR, Doucette WR, Chrischilles EA, Franciscus CL, Xu Y. Physician and pharmacist collaboration to improve blood pressure control. Arch Intern Med 2009;169:1996-2002.

48. Christensen A, Christrup LL, Fabricius PE, Chrostowska M, Wronka M, Narkiewicz K, Hansen EH. The impact of an electronic monitoring and reminder device on patient compliance with antihypertensive therapy: a randomized controlled trial. J Hypertens 2010;28:194-200.

49. Dusing R, Handrock R, Klebs S, Tousset E, Vrijens B. Impact of supportive measures on drug adherence in patients with essential hypertension treated with valsartan: the randomized, open-label, parallel group study VALIDATE. J Hypertens 2009;27:894-901.

50. Hunt JS, Siemienczuk J, Pape G, Rozenfeld Y, MacKay J, LeBlanc BH, Touchette D. A randomized controlled trial of team-based care: impact of physician-pharmacist collaboration on uncontrolled hypertension. J Gen Intern Med 2008;23:1966-72.

51. Planas LG, Crosby KM, Mitchell KD, Farmer KC. Evaluation of a hypertension medication therapy management program in patients with diabetes. J Am Pharm Assoc (2003) 2009;49:164-70.

52. Gabriel M, Gagnon JP, Bryan CK. Improved patients compliance through use of a daily drug reminder chart. Am J Public Health 1977;67:968-9.

53. Kirscht JP, Kirscht JL, Rosenstock IM. A test of interventions to increase adherence to hypertensive medical regimens. Health Educ Q 1981;8:261-72.

54. Eshelman FN, Fitzloff J. Effect of packaging on patient compliance with an antihypertensive medication. Curr Ther Res Clin Exp 1976;20:215-9.

55. Logan AG, Milne BJ, Flanagan PT, Haynes RB. Clinical effectiveness and cost-effectiveness of monitoring blood pressure of hypertensive employees at work. Hypertension 1983;5:828-36.

56. Sackett DL, Haynes RB, Gibson ES, Hackett BC, Taylor DW, Roberts RS, Johnson AL. Randomised clinical trial of strategies for improving medication compliance in primary hypertension. Lancet 1975;1:1205-7.

57. Webb PA. Effectiveness of patient education and psychosocial counselling in promoting compliance and control among hypertensive patients. J Fam Pract 1980;10:1047-55.

58. Zarnke KB, Feagan BG, Mahon JL, Feldman RD. A randomized study comparing a patient-directed hypertension management strategy with usual office-based care. Am J Hypertens 1997;10:58-67.

59. Binstock ML, Franklin KL. A comparison of compliance techniques on the control of high blood pressure. Am J Hypertens 1988;1:192S-4S.

60. Sclar DA, Chin A, Skaer TL, Okamoto MP, Nakahiro RK, Gill MA. Effect of health education in promoting prescription refill compliance among patients with hypertension. Clin Ther 1991;13: 489-95.

61. Solomon DK, Portner TS, Bass GE, Gourley DR, Gourley GA, Holt JM, Wicke WR, Braden RL, Eberle TN, Self TH, Lawrence BL. Clinical and economic outcomes in the hypertension and COPD arms of a multicenter outcomes study. J Am Pharm Assoc (Wash) 1998;38:574-85.

62. McKenney JM, Munroe WP, Wright JT, Jr. Impact of an electronic medication compliance aid on longterm blood pressure control. J Clin Pharmacol 1992;32:277-83.

63. Skaer TL, Sclar DA, Markowski DJ, Won JK. Effect of value-added utilities on prescription refill compliance and health care expenditures for hypertension. J Hum Hypertens 1993;7:515-8.

64. Chui CW, Wong FKY. Effects of 8 weeks sustained follow-up after a nurse consultation on hypertension: a randomised trial. International Journal of Nursing Studies 2010;47:1374-82. 
65. Ortega KC, Gusmao JL, Pierin AM, Nishiura JL, Ignez EC, Segre CA, Ventura CG, Mano GP, Fontes V, Cunha FM, Mion D, Jr. How to avoid discontinuation of antihypertensive treatment: The experience in Sao Paulo, Brazil. Clinics (Sao Paulo) 2010;65:857-63.

66. Ruppar TM. Randomized pilot study of a behavioural feedback intervention to improve medication adherence in older adults with hypertension. J Cardiovasc Nurs 2010;25:470-9.

67. Van Onzenoort HAW, Verberk WJ, Kroon AA, Kessels AG, Nelemans PJ, van der Kuy PH, Neef C, de Leeuw PW. Effect of self-measurement of blood pressure on adherence to treatment in patients with mild-to-moderate hypertension. J Hypertens 2010;28:622-7.

68. Hawkins DW, Fiedler FP, Douglas HL, Eschbach RC. Evaluation of a clinical pharmacist in caring for hypertensive and diabetic patients. Am J Hosp Pharm 1979;36:1321-5.

69. McKenney JM, Slining JM, Henderson HR, Devins D, Barr M. The effect of clinical pharmacy services on patients with essential hypertension. Circulation 1973;48:1104-11.

70. Saunders LD, Irwig LM, Gear JS, Ramushu DL. A randomized controlled trial of compliance improving strategies in Soweto hypertensives. Med Care 1991;29:669-78.

71. Fernandez S, Scales KL, Pineiro JM, Schoenthaler AM, Ogedegbe G. A senior center-based pilot trial of the effect of lifestyle intervention on blood pressure in minority elderly people with hypertension. J Am Geriatr Soc 2008;56:1860-6.

72. Hovell MF, Geary DC, Black DR, Kamachi K, Kirk R. The effects of lay counselling on medication adherence and blood pressure: adjunctive treatment for hypertension. Patient Educ Couns 1984;6: 91-4.

73. Cote I, Gregoire JP, Moisan J, Chabot I, Lacroix G. A pharmacy-based health promotion programme in hypertension: cost-benefit analysis. Pharmacoeconomics 2003;21:415-28.

74. Avanzini F, Corsetti A, Maglione T, Alli C, Colombo F, Torri V, Floriani I, Tognoni G. Simple, shared guidelines raise the quality of antihypertensive treatment in routine care. Am Heart J 2002;144: 726-32.

75. Saito I, Saruta T. Effect of education through a periodic newsletter on persistence with antihypertensive therapy. Hypertens Res 2003;26:159-62.

76. Cuspidi C, Lonati L, Sampieri L, Michev I, Macca G, Fusi V, Salerno M, Zanchetti A. 'To better know hypertension': educational meetings for hypertensive patients. Blood Press 2000;9:255-9.

77. Robinson JD, Segal R, Lopez LM, Doty RE. Impact of a pharmaceutical care intervention on blood pressure control in a chain pharmacy practice. Ann Pharmacother 2010;44:88-96.

78. Chabot I, Moisan J, Gregoire JP, Milot A. Pharmacist intervention program for control of hypertension. Ann Pharmacother 2003;37:1186-93.

79. Pierce JP, Watson DS, Knights S, Gliddon T, Williams S, Watson R. A controlled trial of health education in the physician's office. Prev Med 1984;13:185-94.

80. Aguwa CN, Ukwe CV, Ekwunife Ol. Effect of pharmaceutical care programme on blood pressure and quality of life in a Nigerian pharmacy. Pharm World Sci 2008;30:107-10.

81. Patton K, Meyers J, Lewis BE. Enhancement of compliance among patients with hypertension. Am J Manag Care 1997;3:1693-8.

82. Basler HD, Brinkmeier U, Buser K, Haehn KD, Molders-Kober R. Psychological group treatment of essential hypertension in general practice. Br J Clin Psychol 1982;21:295-302.

83. Magadza C, Radloff SE, Srinivas SC. The effect of an educational intervention on patients' knowledge about hypertension, beliefs about medicines, and adherence. Res Social Adm Pharm 2009;5:363-75.

84. de Souza WA, Yugar-Toledo JC, Bergsten-Mendes G, Sabha M, Moreno H, Jr. Effect of pharmaceutical care on blood pressure control and health-related quality of life in patients with resistant hypertension. Am J Health Syst Pharm 2007;64:1955-61.

85. Edmonds D, Foerster E, Groth H, Greminger P, Siegenthaler W, Vetter W. Does self-measurement of blood pressure improve patient compliance in hypertension? J Hypertens Suppl 1985;3:S31-4.

86. Kuo S, Burrill J. Differences in antihypertensive compliance by BCBSRI disease and case management intervention group. Med Health R I 2007;90:381-4.

87. Ashida T, Sugiyama T, Okuno S, Ebihara A, Fujii J. Relationship between home blood pressure measurement and medication compliance and name recognition of antihypertensive drugs. Hypertens Res 2000;23:21-4.

88. Sabaté E. Adherence to long term therapies: evidence for action. Geneva:World Health Organization, 2003. 
89. Mar J, Rodriguez-Artalejo F. Which is more important for the efficiency of hypertension treatment: hypertension stage, type of drug or therapeutic compliance? J Hypertens 2001;19:149-55.

90. Farmer KC. Methods for measuring and monitoring medication regimen adherence in clinical trials and clinical practice. Clin Ther 1999;21:1074-90.

91. Urquhart J. The electronic medication event monitor. Lessons for pharmacotherapy. Clin Pharmacokinet 1997;32:345-56. 


\section{Appendix 2.1 Data collection form}

\section{Coding sheet 'Effect of intervention on adherence to treatment'}

- Coder: $\square$ PHK

$\square \mathrm{HO}$

WV

- Title article:

- Author(s):

- Year of publication:

- Article satisfies all of the following inclusion criteria

1. Consist population of patients with hypertension? $\square$ Yes $\square$ No

2. Is the population of interest older than 19 years? $\square$ Yes $\square$ No

3. Has an intervention been described? $\square$ Yes $\square$ No

4. Is adherence to treatment an endpoint of the study? $\square$ Yes $\square$ No

$\square$ Primary?

$\square$ Secondary?

- Methodology?

$\square$ Comparative, non-randomised

Comparative, randomised

$\square$ Other:

- Characteristics

1. Number of patients:

If applicable

a. In intervention group:

b. In control group:

2. Age patients:

If applicable

a. In intervention group:

b. In control group:

3. Country in which study has been performed:

4. Follow-up period: 
- Describe intervention:

- How has adherence been measured?

$\square$ Pharmacy records

$\square$ Pill count

$\square$ Self-report

$\square$ Electronic monitoring

$\square$ Blood concentration of drug

$\square$ Not specified

$\square$ Other:

- On which moments has adherence been measured?

$\square$ Baseline/end follow-up

$\square$ End follow-up

$\square$ Pre-defined period

Other:

- How has adherence been expressed?

$\square$ Percentage

What was the level of adherence at each moment?

- In the intervention group:

- In the control group:

Adherent yes/no

- What was the cut-off value?

- Percentage of patients being adherent

- In the intervention group:

- In the control group:

- Was the effect of the intervention significant $(P<0.05)$ ?

Yes

$\square$ No

$\square$ Not specified 


\section{Chapter 3}

\section{Electronic monitoring of adherence, treatment of hypertension and blood pressure control}

Hein AW van Onzenoort, Willem J Verberk, Abraham A Kroon, Alfons G Kessels, Cees Neef, Paul-Hugo M van der Kuy, Peter W de Leeuw

American Journal of Hypertension 2012;25;54-59 


\section{Abstract}

\section{Background}

Although it is generally acknowledged that electronic monitoring of adherence to treatment improves blood pressure (BP) control by increasing patients' awareness to their treatment, little information is available on the long-term effect of this intervention.

\section{Methods}

In this observational study among a total of 470 patients with mild-to-moderate hypertension, adherence was measured in 228 patients by means of both the Medication Event Monitoring System (MEMS) and pill count (intervention group), and in 242 patients by means of pill count alone (control group). During a follow-up period of 1 year consisting of seven visits to the physician's office, BP measurements were performed and medication adjusted based on the achieved BP. In addition, at each visit adherence to treatment was assessed.

\section{Results}

On the basis of pill count, median adherence to treatment did not differ between the intervention group and the control group (96.1 vs. $94.2 \% ; P=0.97$ ). In both groups, systolic and diastolic BP decreased similarly: $23 / 13$ vs. $22 / 12 \mathrm{mmHg}$ in the intervention and control group respectively. Drug changes and the number of drugs used were associated with BP at the start of study, but not with electronic monitoring.

\section{Conclusion}

In this study, electronic monitoring of adherence to treatment by means of MEMS did not lead to better long-term BP control nor did it result in less drug changes and drug use. 


\section{Introduction}

Poor adherence to treatment remains one of the major limitations in the management of hypertension and may contribute to increased morbidity, mortality and $\operatorname{costs}^{1-5}$. It is estimated that at least $50 \%$ of the patients with hypertension do not take antihypertensive medication as prescribed ${ }^{6}$. Several large studies have shown that persistence with antihypertensive treatment decreases with time: discontinuation rates vary from 22 to almost $50 \%$ during the first year after initiation of therapy ${ }^{7-10}$. Therefore, improving adherence to treatment remains a major challenge to the treating physician.

Electronic monitoring devices, such as the Medication Event Monitoring System (MEMS, AARDEX Ltd., Zug, Switzerland), have been used extensively in assessing adherence to antihypertensive drugs. The advantage of electronic monitoring is that a more detailed and accurate information is obtained than can be achieved with other methods $^{11-14}$. In addition, electronic monitoring may improve adherence to treatment, as patients are aware of adherence monitoring. Hence, it may improve blood pressure (BP) control. Indeed, several studies have demonstrated a positive effect of electronic monitoring of adherence on BP control ${ }^{15-19}$. However, most of these studies have followed patients for only a short period of time ${ }^{15-18}$, making it difficult to predict how long the effect of electronic monitoring is sustained. Today, only one randomised study investigated the effect of electronic monitoring on long-term BP control ${ }^{19}$. Patients whose drug intake was monitored had a greater decrease in BP than patients who received usual care. However, as adherence results were discussed with the patient it is not clear whether the greater reduction in BP is attributable to the electronic monitoring, the discussion with patients, or a combination of both.

Therefore, we investigated the effect of electronic monitoring of adherence to treatment, without discussing the results with the patients, on long-term BP control in patients with mild to moderate hypertension.

\section{Methods}

We performed an observational study in which all participating patients from the HOMERUS trial were included ${ }^{20-21}$. In brief, HOMERUS is a multi-centre, prospective, randomised, double blind trial with a parallel-group design. Patients, aged 18 years and older whose office BP was above $139 \mathrm{mmHg}$ systolic and/or $89 \mathrm{mmHg}$ diastolic were recruited from the outpatient departments of four participating university hospitals and affiliated general practices. If the BP remained above $139 / 89 \mathrm{mmHg}$ at the second visit, patients were randomly allocated (minimization procedure) to either the self pressure (SP) group or the office pressure (OP) group. If randomised to the SP group antihypertensive treatment was guided by the results of self BP measurement (SBPM). In the OP group, treatment was titrated on the basis of the office BP 
measurement (OBPM). Both previously treated and untreated patients qualified for inclusion. In all of them, secondary hypertension had been ruled out by laboratory investigation. At entry into the study, any existing antihypertensive therapy was discontinued whenever possible and participants entered a placebo run-in period of four weeks duration before study treatment was initiated. Patients were followed-up for seven visits for a period of 1 year. After the third visit, patients were followed monthly; after the fifth visit patients were followed at a 2-months interval. The primary objective of the HOMERUS-study was to examine whether decisions concerning antihypertensive therapy based on SBPM could lead to less antihypertensive drugs used and associated costs, when compared to decisions based on OBPM. As a secondary objective, the effect of SBPM on adherence to medication within random subgroups of the SP and OP groups was investigated. For this secondary objective, adherence to treatment was electronically measured in all patients recruited by the coordinating centre (Maastricht University Hospital) and surrounding general practitioners' practices. All patients gave their informed consent and the study was approved by the ethical committees of all participating centres before inclusion of patients into the study.

\section{Blood pressure measurements}

At every visit, three consecutive OBPMs were performed in the hospital or at the general practitioners clinic. SBPM was performed six times a day (three in the morning and three in the evening) for a 7-day period, prior to every visit. Patients were requested to register their self-measurements on a form and to print out all measurements. Both OBPM and SBPM were always performed at the non-dominant arm in sitting position after at least 5 min of rest, using the same fully automated device (Omron HEM-705 CP) ${ }^{22}$.

\section{Study treatment protocol}

Treatment was instituted stepwise according to the following schedule:

Step 1: Lisinopril $10 \mathrm{mg}$ once daily plus one tablet of placebo once daily;

Step 2: Lisinopril $20 \mathrm{mg}$ once daily plus one tablet of placebo once daily;

Step 3: Lisinopril $20 \mathrm{mg}$ once daily plus hydrochlorothiazide $12.5 \mathrm{mg}$;

Step 4: Lisinopril $20 \mathrm{mg}$ once daily plus hydrochlorothiazide $12.5 \mathrm{mg}$ plus amlodipine $5 \mathrm{mg}$.

In both the OP and SP group, the goal BP ranged between 120 and $139 \mathrm{mmHg}$ systolic and between 80 and $89 \mathrm{mmHg}$ diastolic. In patients who were above the target BP (systolic $>139 \mathrm{mmHg}$ and/or diastolic $>89 \mathrm{mmHg}$ ), antihypertensive treatment was intensified by one step. If BP was lower than the target (systolic $<120 \mathrm{mmHg}$ and diastolic $<80 \mathrm{mmHg}$ ), treatment was reduced by one step, eventually until termination of treatment. If patients were on their target, treatment remained unchanged. In case 
of refractory hypertension, defined as a sitting BP systolic $>160 \mathrm{mmHg}$ or diastolic $>100 \mathrm{mmHg}$ while the patient was already on the maximum combination therapy (i.e. step 4), additional strategies from other drug classes were instituted in order to further decrease BP level. Treatment decisions were taken at each visit and at the coordinating centre so that both the doctor and the patient were blinded for all study medication drugs. All drugs were prescribed to be taken in the morning and were supplied by the patient's own pharmacist.

\section{Adherence measurements}

In all patients pill count were performed in order to calculate adherence rates. To minimize changes in patient's behaviour, pill count were done out of sight of the patient. In a sub-population of 228 patients, recruited by the coordinating centre (Maastricht University Hospital) and surrounding general practitioners' practices, drug intake was, in addition to pill count, monitored electronically. Their adherence to antihypertensive medication was measured with Medication Event Monitoring System (MEMS) V TrackCaps (Aardex Corp., Zug, Switzerland), but without giving them feedback about their adherence behaviour. The MEMS-TrackCap is an electronic monitoring system designed to compile the dosing histories of ambulatory patients who are prescribed oral medications ${ }^{11}$. Microelectronics integrated into the cap of pill containers record the time and date that the container is opened or closed.

\section{Statistical analysis}

Baseline characteristics were defined at enrolment of patients (visit 1), except for baseline blood pressure which was determined at visit 3 after the placebo run-in period and before initiation of study treatment. The 228 patients from the centre in which drug intake was monitored both electronically and by pill count comprised the intervention group. The remaining patients originating from the other three centres at which only pill count was performed acted as controls. Although this study was an observational study nested in a randomised controlled trial, sample size calculations showed that at least 64 patients had to be included in both groups to detect a significant difference in change in BP between both groups. This calculation was based on a power of $80 \%$, a significance level of $<0.05$, a minimal relevant difference in change in BP of $10 \mathrm{mmHg}$, with a standard deviation of $20 \mathrm{mmHg}^{15-19}$.

Adherence measured by MEMS was expressed as 'percentage of days with correct dosing'; a drug was considered to have been taken correctly when the MEMS bottles were opened once every 24 hours. Adherence measured by pill count was calculated as the percentage of the number of prescribed pills corrected for the number of returned pills divided by the period (in days) multiplied by $100 \%$. Defined Daily Doses (DDDs) of antihypertensive drugs were calculated according to data of the WHO Collaborating Centre for Drug Statistics Methodology ${ }^{23}$. DDDs are defined as the assumed average maintenance dose per day for a drug used for its main indication in 
adults $^{\prime 23}$. Antihypertensive drug modification was defined as an increase in drug dosage or adding in a new drug, or as a decrease in drug dosage or stopping a drug, or as a switch from one drug to another drug. Differences in adherence were analyzed as a continuous variable with the Mann-Whitney $U$ test for non-normally distributed data. Differences in normally distributed continuous variables were analyzed with the Student's T-test. Chi-square tests were used to compare differences in categorical variables. Logistic regression models were fitted to assess the association of reaching target BP ( $<140 / 90 \mathrm{mmHg})$ and allocated group adjusted for the following potential confounders: study centre, baseline BP, patient's age and sex, SP group, and DDDs. A $P$-value smaller than 0.05 was considered to be statistically significant. Analyses were done on an intention-to-treat basis using SPSS version 15.0 (SPSS, Inc. Chicago, Illinois). The last observation carried forward method was applied for missing values when data of $\geq 2$ consecutive visits were available.

\section{Results}

In total, 510 patients met the inclusion criteria and were considered eligible for the study. Of these patients 40 withdrew or refused consent for various reasons. Consequently, 470 patients entered the study after a 4 week run-in period and started trial medication. Of these, 228 and 242 patients were categorised into the intervention and control group, respectively. Patients' baseline characteristics are presented in Table 3.1. Differences in baseline characteristics between the participating centres were significant for age, sex and baseline office BP (both systolic and diastolic BP).

In the intervention group median adherence, expressed as days of correct dosing, was 91.6\% (Inter Quartile Range (IQR) 85.7 - 94.0\%), whereas adherence according to pill count was $96.1 \%$ (IQR 88.8 - 98.4\%) in this group. Patients in the intervention group showed an adherence determined by pill count which did not differ from controls (96.1 vs. 94.2\%; $P=0.97$ ). Based on pill count, median adherence in the total population to the antihypertensive drugs lisinopril, hydrochlorothiazide, amlodipine, and atenolol (i.e. the drugs that were prescribed according to the study protocol) was 93.1, 95.3, 94.9, and 92.9\%, respectively ( $P=0.001)$.

Mean number of DDDs prescribed was higher in the intervention group than in the control group (2.3 vs. 1.9; $P=0.001$ ). The number of DDDs prescribed for both groups increased throughout the study. For the periods between visit 7 to 8 ( $P=0.025), 8$ to 9 $(P=0.009)$, and 9 to $10(P=0.002)$ more DDDs were prescribed for patients in the intervention than in the control group. The number of DDDs was positively associated with adherence to treatment determined by pill count $(P=0.008)$, regardless of MEMS monitoring $(P=0.79)$. Table 3.2 presents the number of drug additions or dose adjustments in both groups. Of the patients in the intervention group, 203 (89\%) patients experienced one or more dose adjustments or drug additions compared to 
196 (81\%) patients in the control group $\left(\mathrm{OR}_{\text {adjusted }}=1.54 ; 95 \%\right.$ confidence interval $(\mathrm{Cl})=0.87-2.71)$. Patients who had a higher mean BP at baseline used more DDDs than patients who had a lower mean BP at baseline. This was observed in the intervention as well in the control group. Differences between groups were statistically not significant (Figure 3.1).

Table 3.1 Baseline characteristics of the patients

\begin{tabular}{|c|c|c|c|}
\hline Characteristic & $\begin{array}{l}\text { Intervention } \\
\quad(n=228)\end{array}$ & $\begin{array}{l}\text { Control } \\
(n=242)\end{array}$ & $P$-value \\
\hline Age [years (SD)] & $57(10)$ & $54(11)$ & $<0.001$ \\
\hline Male $[\mathrm{n}(\%)]$ & $112(49)$ & $143(59)$ & 0.030 \\
\hline Smoking [n (\%)] & $41(18)^{\ddagger}$ & $41(17)$ & 0.43 \\
\hline Alcohol $[\mathrm{n}(\%)]$ & $174(76)^{\dagger}$ & $190(79)^{*}$ & 0.67 \\
\hline Body Mass Index $\left[\mathrm{kg} / \mathrm{m}^{2}(\mathrm{SD})\right]$ & $27(4)$ & $28(4)$ & 0.64 \\
\hline Diabetes Mellitus [n (\%)] & $14(6)^{\ddagger}$ & $10(4)$ & 0.43 \\
\hline SP group $[\mathrm{n}(\%)]$ & $114(50)$ & $125(52)$ & 0.72 \\
\hline \multicolumn{4}{|c|}{ Baseline office blood pressure [mm Hg (SD)] } \\
\hline Systolic & $169(21)$ & $160(17)$ & $<0.001$ \\
\hline Diastolic & $99(11)$ & $96(10)$ & 0.001 \\
\hline \multicolumn{4}{|c|}{$\begin{array}{l}\text { Number of patients on previous antihypertensive } \\
\text { drugs [n (\%)] }\end{array}$} \\
\hline 0 & $40(18)$ & $85(35)$ & $<0.001$ \\
\hline 1 & $86(38)$ & $91(38)$ & 0.98 \\
\hline 2 & $74(32)$ & $46(20)$ & $<0.001$ \\
\hline 3 or more & $28(12)$ & $19(8)$ & 0.11 \\
\hline \multicolumn{4}{|l|}{ Previous antihypertensive drugs [n (\%)] } \\
\hline Diuretics & $74(32)$ & $77(32)$ & 0.88 \\
\hline RAS-inhibitors & $118(52)$ & $81(33)$ & $<0.001$ \\
\hline Beta-blockers & $83(36)$ & $61(25)$ & 0.0084 \\
\hline Calcium channel blockers & $38(17)$ & $24(10)$ & 0.03 \\
\hline Alpha-blockers & $4(2)$ & $5(2)$ & 0.81 \\
\hline
\end{tabular}

Data are mean (standard deviation (SD)) for continuous variables and number (\%) for categorical variables; SP indicates self-pressure; Data are missing for *=one, $\dagger=$ two and $\ddagger=$ three patients

Table 3.2 Number of drug additions or dose adjustments at the end of the follow-up period in the intervention and control group.

\begin{tabular}{lccc}
\hline \multicolumn{4}{c}{$\begin{array}{c}\text { Number of patients with drug additions } \\
\text { and/or dose increases [n (\%)] }\end{array}$} \\
\hline $\begin{array}{l}\text { Number of drug additions and/or dose } \\
\text { increases }\end{array}$ & $\begin{array}{c}\text { Intervention } \\
(\mathrm{n}=228)\end{array}$ & $\begin{array}{c}\text { Controls } \\
(\mathrm{n}=242)\end{array}$ & $\mathrm{RR}(95 \% \mathrm{Cl})$ \\
\hline-2 & $0(0)$ & $2(0.8)$ & - \\
-1 & $12(5)$ & $14(6)$ & $0.91(0.42-1.97)$ \\
0 & $25(11)$ & $46(19)$ & $0.58(0.36-0.94)$ \\
1 & $30(13)$ & $47(19)$ & $0.68(0.43-1.08)$ \\
2 & $50(22)$ & $34(14)$ & $1.56(1.01-2.41)$ \\
$\geq 3$ & $111(49)$ & $95(39)$ & $1.24(0.94-1.63)$ \\
\hline
\end{tabular}




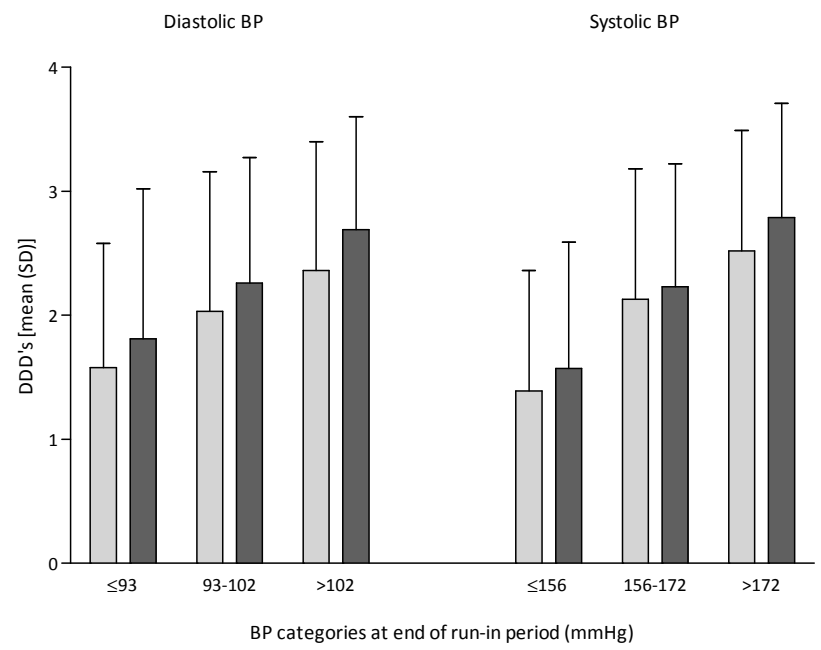

Figure 3.1 Number of DDDs prescribed during the study based on categories of BP (systolic/diastolic) at baseline in the intervention ( $\square$ ) and control ( $\square$ ) group.

BP indicates blood pressure; DDD indicates defined daily dose. $P$-value for differences between intervention and control group $>0.05$; $P$-value for DDDs at different BP-values within intervention or control group $<0.05$.

At the end of the study, patients in the intervention group reached a significant higher systolic and diastolic BP than patients in the control group (146/86 vs. $141 / 85 \mathrm{mmHg}$, $p_{\text {adjusted }}=0.001$ and $p_{\text {adjusted }}=0.002$ for systolic and diastolic BP, respectively; Table 3.3 ). Figure 3.2 illustrates the time course of the office BP during the study. Systolic and diastolic BP increased after visit 1 when the run-in period started and the previous antihypertensive medications were discontinued. After visit 3, systolic and diastolic BP decreased in both groups. During that follow-up period, systolic and diastolic BP in the intervention group remained significantly higher than in the control group with the exception of visit 6 and 8 for diastolic BP. When we subtracted the achieved BP from the baseline BP, the net decrease in systolic and diastolic BP was comparable in both groups (Table 3.3).

Table 3.3 Blood pressure results after 12 months follow-up in intervention and control group.

\begin{tabular}{|c|c|c|c|}
\hline & Intervention ( $n=228)$ & Controls ( $n=242)$ & $P$-value \\
\hline \multicolumn{4}{|c|}{ Achieved BP [mm Hg (SD)] } \\
\hline Systolic & $146(19)$ & $141(18)$ & 0.001 \\
\hline Diastolic & $86(10)$ & $85(11)$ & 0.002 \\
\hline \multicolumn{4}{|c|}{ Differences between initial and achieved } \\
\hline \multicolumn{4}{|c|}{$\mathrm{BP}[\mathrm{mm} \mathrm{Hg}(\mathrm{SD})]$} \\
\hline Systolic & $23(23)$ & $22(19)$ & 0.42 \\
\hline Diastolic & $13(13)$ & $12(11)$ & 0.62 \\
\hline
\end{tabular}

BP indicates blood pressure; *Adjusted for systolic and diastolic BP at baseline, age, and DDDs 

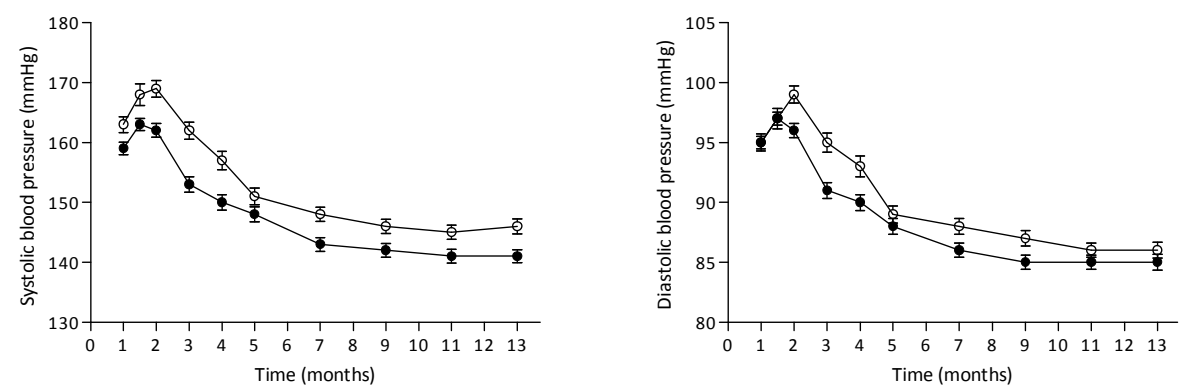

Figure 3.2 Time course of systolic and diastolic BP in the intervention (o) and control $(\bullet)$ group. Differences in systolic BP between the intervention and control group are significant at all visits; differences in diastolic BP between the intervention and control group are significant at all visits, except at visit $1,2,6$, and 8 .

Over the 12-month period, less patients in the intervention group reached target BP $(<140 / 90 \mathrm{mmHg}$ ) when compared to patients in the control group: 90 (40\%) vs. 131 (54\%), $P=0.001$. Monitoring was associated with an $\mathrm{OR}=0.55$ (95\% $\mathrm{Cl}=0.38-0.80)$ for reaching blood pressure control before adjustment, and an $\mathrm{OR}=0.44(95 \% \mathrm{Cl}=0.28$ $0.69)$ after adjustment for study centre $(P=0.012)$, age $(P=0.43)$, female sex $(P=0.002)$, systolic $(P<0.001)$ and diastolic $(P=0.004)$ blood pressure at baseline, and DDDs prescribed $(P=0.98)$.

\section{Discussion}

The results from the present study suggest that BP is not better controlled in patients whose drug adherence is monitored electronically in addition to pill count compared to those whose adherence is monitored by pill count only. Therefore, these data do not support electronic monitoring of drug adherence as a useful tool to improve the management of hypertensive patients over a long period of time.

An effect of electronic monitoring on BP control may be a result of an increase in adherence to treatment in the intervention group. Although, we did not measure adherence electronically in the control group, we performed pill count in both groups. Adherence according to pill count was comparable in both groups. However, this result could be confounded by a difference in the number of DDDs prescribed between the intervention and control group. At the start of the HOMERUS trial, BP rates among patients in the intervention group were higher than in the control group. Consequently, the former used more DDDs for BP reduction. Although the number of DDDs was positively associated with adherence to treatment determined by pill count, MEMS monitoring did not influence this association. These results may suggest that 
electronic monitoring by means of MEMS has no effect on adherence, resulting in comparable BP reduction rates in both groups.

In both the intervention and the control group we found a high median adherence according to pill count of more than $94 \%$. Moreover, our results showed that an increase in DDDs resulted in an increase in adherence. These observations could be a result of our study design in which patients had to attend many appointments with the physician in one year of follow-up. Recently, we have found that patients are more inclined to take their drugs as prescribed when they are faced with an upcoming consultation $^{24}$. This phenomenon, also called white-coat adherence, underscores the importance of clinical visits for patients with hypertension. As a result, the absence of an effect of MEMS as an intervention on BP control and the high observed adherence may be explained by the frequent visits patients had to attend.

At this time, only two studies have investigated the effect of electronic monitoring of adherence to treatment on BP control in a randomised controlled setting ${ }^{18,19}$. Wetzels and colleagues demonstrated that electronic monitoring reduces drug changes and drug use with BP control comparable to usual care ${ }^{18}$. In contrast, we did not find an indication that electronic monitoring was associated with less drug changes and drug use. In our study, the number of DDDs used was based on the initial BP at baseline. Recently, Santschi and colleagues demonstrated that electronic monitoring led to better BP control, however the effect decreased over time ${ }^{19}$. In that 12 months follow-up study, adherence rates were discussed with the patients, thereby possibly influencing the true effect of electronic monitoring on BP control. Given our results, the effect observed in Santschi's study may be attributable solely to the feedback provided by physicians to patients.

The results of our study must be interpreted within the context of its limitations. First of all, this study was not designed as a randomised controlled trial. In addition, the analysis was not powered to investigate differences between the intervention and control group. Adherence to treatment was measured electronically in a group of patients from the HOMERUS trial. The remaining population officiated as controls. Although, imbalances were observed in baseline characteristics between the intervention and control group, adjusting for these differences in a multivariate model had no effect on the association between electronic monitoring and BP control. It is therefore less likely that the study design influenced our results. Secondly, all patients in this study were aware that their adherence was being monitored, either by MEMS or by pill count. In addition, patients had many appointments to attend with the physician within one year of follow-up. This may have resulted in a greater adherence than what is usually seen in the general population and, hence, overestimation of the habitual adherence of these subjects. Although, ideally, one would prefer not to inform patients that their adherence is being measured, ethical considerations preclude such an approach.

The extraordinary high adherence rate in the present study may complicate extrapolation of these results to the population at large. However, this high 
adherence rate does not necessarily imply that the study participants and/or their adherence behaviour deviate from those in other studies. The two randomised studies performed by Wetzels and Santschi also showed adherence levels of more than $90 \%{ }^{18,19}$. In these studies the effect of electronic monitoring on BP reduction was only noticeable in the first months of the study. Several observational studies showed that electronic monitoring significantly decreases BP. Despite comparable adherence levels between those studies and our study, the follow-up period was shorter when compared to our study (3-6 months versus 12 months $)^{15-17}$. Given our results and the long term results observed by Santschi and colleagues ${ }^{19}$, it is likely that an effect of electronic monitoring on BP diminishes when patients are followed for a longer period. It is however not known whether this effect is different in patients who are less adherent than patients in the described studies. Future studies should elucidate this.

Recently, we investigated whether deviant drug intake behaviour occurred by comparing MEMS data and pill count data ${ }^{25}$. In that report we showed that deviant intake behaviour occurred frequently but that this did not necessarily led to differences in BP control between groups. Consequently, we concluded that pill count could be a useful adjunct to MEMS caps for exploring deviant intake behaviour. Furthermore, we stated that counting pills in adjunct to MEMS registration should be performed to identify true non-adherers. In the present study, we compared the 228 patients that were also included in the previous article with a population that did not participate in the previous study. The results of our previous paper and the present one can best be summarized as follows: today, none of the methods that are applied to monitor adherence to treatment is ideal and each has its specific shortcomings. Of the available methods MEMS seems to be the best, primarily because it provides hard data. Those hard data, however, refer only to the monitoring of the exact dates and times the patient is concerned with his or her medication. It does not give insight into the actual taking of the medication. Consequently, we previously recommended to combine MEMS with pill count. Nevertheless, whatever method one applies, it does not correlate very well with achieved blood pressures. This means that either all our methods, including MEMS, are fraught with error or there is more to reaching an acceptable blood pressure level than adherence alone.

Taking our data together, our findings do not support the hypotheses that electronic monitoring by means of MEMS leads to better BP control or that it results in less drug changes and drug use. This may be due to the high overall adherence we have observed in our study as a consequence of the specific study design. 


\section{References}

1. Mar J, Rodriguez-Artalejo F. Which is more important for the efficiency of hypertension treatment: hypertension stage, type of drug or therapeutic compliance? J Hypertens 2001;19:149-55.

2. Hughes DA, Bagust A, Haycox A, Walley T. The impact of non-compliance on cost-effectiveness of pharmaceuticals: a review of the literature. Health Economics 2001;10:601-15.

3. Urquhart J. Partial compliance in cardiovascular disease: risk implications. $\mathrm{Br} \mathrm{J}$ Clin Pract Suppl 1994;73:2-12.

4. Urquhart J. Patient non-compliance with drug regimens: measurement, clinical correlates, economic impact. Eur Heart J 1996;17 Suppl A:8-15.

5. The sixth report of the joint national committee on prevention, detection, evaluation, and treatment of high blood pressure. Arch Int Med 1997;157:2413-56.

6. Sabate E. Adherence to long term therapies: evidence for action. Geneva:World Health Organization, 2003.

7. Vrijens B, Vincze G, Kristanto P, Urquhart J, Burnier M. Adherence to prescribed antihypertensive drug treatments: longitudinal study of electronically compiled dosing histories. BMJ 2008;336:1114-7.

8. Van Wijk BL, Shrank WH, Klungel OH, Schneeweiss S, Brookhart MA, Avorn J. A cross-national study of the persistence of antihypertensive medication use in the elderly. J Hypertens 2008;26:145-53.

9. Caro JJ, Salas M, Speekman JL, Raggio G, Jackson JD. Persistence with treatment for hypertension in actual practice. Can Med Assoc J 1999;160:31-7.

10. Bourgalt $C$, Sénécal $M$, Brisson M, Marentette MA, Grégoire JP. Persistence and discontinuation patterns of antihypertensive therapy among newly treated patients: a population-based study. J Hum Hypertens 2005;19:607-13.

11. Cramer JA, Mattson RH, Prevey ML, Scheyer RD, Ouellette VL. How often is medication taken as prescribed? A novel assessment technique. JAMA 1989;261:3272-7.

12. Urquhart J, De Klerk E. Contending paradigms for the interpretation of data on patient compliance with therapeutic drug regimens. Stat Med 1998;17:251-67.

13. Pullar T, Kumar S, Tindall H, Feely M. Time to stop counting the tablets? Clin Pharmacol Ther 1989;47:547.

14. Matsui D, Hermann C, Klein JJ, Berkovitch M, Olivieri M, Koren G. Critical comparison of novel and existing methods of compliance assessment during a clinical trial of an oral iron chelator. J Clin Pharmacol 1994;34:944-9.

15. Burnier M, Schneider MP, Chiolero A, Stubi CL, Brunner HR. Electronic compliance monitoring in resistant hypertension: the basis for rational therapeutic decisions. J Hypertens 2001;19:335-41.

16. Bertholet N, Favrat B, Fallab-Stubi CL, Brunner HR, Burnier M. Why objective monitoring of compliance is important in the management of hypertension. J Clin Hypertens (Greenwich) 2000;2:258-62.

17. Waeber B, Vetter W, Darioli R, Keller U, Brunner HR. Improved blood pressure control by monitoring compliance with antihypertensive therapy. Int J Clin Pract 1999;53:37-8.

18. Wetzels GE, Nelemans PJ, Schouten JS, Dirksen CD, van der Weijden T, Stoffers HE, Janknegt R, de Leeuw PW, Prins $\mathrm{MH}$. Electronic monitoring of adherence as a tool to improve blood pressure control. A randomized controlled trial. Am J Hypertens 2007;20:119-25.

19. Santschi V, Rodondi N, Bugnon O, Burnier M. Impact of electronic monitoring of drug adherence on blood pressure control in primary care: A cluster 12-month randomized controlled study. Eur J Int Med 2008;19:427-34.

20. Verberk WJ, Kroon AA, Kessels AG, Dirksen C, Nelemans PJ, Lenders JWM, Thien TA, van Montfrans GA, Smit AJ, de Leeuw PW. Home versus Office blood pressure MEasurements: Reduction of Unnecessary treatment Study: rationale and study design of the HOMERUS trial. Blood Press 2003;12: 326-33.

21. Verberk WJ, Thien T, Kroon AA, Lenders JW, van Montfrans GA, Smit AJ, de Leeuw PW. Selfmeasurement of blood pressure at home reduces the need for antihypertensive drugs: a randomized, controlled trial. Hypertension 2007;50:1019-25. 
22. O'Brien E, Mee F, Atkins N, Thomas M. Evaluation of three devices for self-measurement of blood pressure according to the revised British Hypertension Society Protocol: the Omron HEM-705CP, Philips HP5332, and Nissei DS-175. Blood Press Monit 1996;1:55-61.

23. WHO Collaborating Centre for Drug Statistics Methodology. http://www.whocc.no/atcddd/. Consulted on June 22010.

24. Van Onzenoort HAW, Verberk WJ, Kroon AA, Kessels AGH, Nelemans PJ, van der Kuy P-HM, Neef C, de Leeuw PW. Effect of self-measurement of blood pressure on adherence to treatment in patients with mild to moderate hypertension. J Hypertens 2010;28:622-7.

25. Van Onzenoort HAW, Verberk WJ, Kessels AGH, Kroon AA, Neef C, van der Kuy PHM, de Leeuw PW. Assessing medication adherence simultaneously by electronic monitoring and pill count in patients with mild-to-moderate hypertension. Am J Hypertens 2010;32:149-54. 


\section{Chapter 4}

\section{Effect of self-measurement of blood pressure on adherence to treatment in patients with mild to moderate hypertension}

Hein AW van Onzenoort, Willem J Verberk, Abraham A Kroon, Alfons G Kessels, Patty J Nelemans, Paul-Hugo M van der Kuy, Cees Neef, Peter W de Leeuw Journal of Hypertension 2010;28:622-627 


\section{Abstract}

\section{Background}

Poor adherence to treatment is one of the major problems in the treatment of hypertension. Self blood pressure measurement (SBPM) may help patients to improve their adherence to treatment.

\section{Methods}

In this prospective, randomised controlled study coordinated by a university hospital a total of 228 mild-to-moderate hypertensive patients were randomised to either a group that performed self-measurements at home in addition to office blood pressure measurements (OPBM): the self pressure group (SP; $n=114)$ or a group that only underwent OBPM: the office pressure group (OP; $n=114$ ). Patients were followed for one year in which treatment was adjusted, if necessary, at each visit to the physician's office according to the achieved blood pressure. Adherence to treatment was assessed by means of medication event monitoring system (MEMS) TrackCaps.

\section{Results}

Median adherence was slightly greater in patients from the SP group than in those from the OP group (92.3 vs. $90.9 \% ; P=0.043$ ). Although identical among both groups, in the week directly after each visit to the physician's office adherence (71.4\% [IQR 71$79 \%])$ was significantly lower $(P<0.001)$ than at the last seven days prior to each visit (100\% [IQR 90-100\%]). On the remaining days between the visits patients from the SP group displayed a modestly better adherence than patients from the OP group (97.6 vs. $97.0 \% ; P=0.024)$.

\section{Conclusion}

Although SBPM as an adjunct to OBPM led to somewhat better adherence to treatment in this study, the difference was only small and not clinically significant. The time relative to a visit to the doctor seems to be a more important predictor of adherence. 


\section{Introduction}

Adherence to treatment is disappointingly low among patients with chronic conditions, dropping most dramatically after the first six months of therapy ${ }^{1}$. In this respect, hypertension forms no exception as according to the World Health Organization half of the hypertensive patients does not take treatment as prescribed ${ }^{2}$. Poor adherence to treatment remains one of the major limitations in the management of hypertension and may contribute to increased morbidity, mortality and $\operatorname{costs}^{3-6}$. Amongst other factors, low adherence to antihypertensive treatment may be related to the fact that such therapy often has untoward side effects with little or no relief of symptoms that are attributed by the patient to high blood pressure (BP). In addition, patients may simply forget to take their medication since there are no physical signs that stimulate adherence.

Several reports suggest that self blood pressure measurement (SBPM) may increase adherence to prescribed drugs ${ }^{7-11}$. Indeed, patients are more aware of their elevated BP as they will notice a rise in pressure when they fail to take their medication. Implementation of self-measurements in the routine diagnostic and therapeutic follow-up could, therefore, be of great value in the management of hypertension. This prompted us to examine the influence of SBPM on adherence to antihypertensive treatment in more detail by comparing two groups of randomised patients. In one group only office blood pressure measurement (OBPM) was performed, while the other group had SBPM as well. We hypothesized that adherence to treatment would be better in those who would perform self-measurements.

\section{Methods}

All patients in this study participated in the HOMERUS trial, the design and results of which have been described in detail elsewhere ${ }^{12,13}$. In brief, HOMERUS is a multicentre, prospective, randomised, double blind trial with a parallel-group design. Patients, aged 18 years and older whose office BP was above $139 \mathrm{mmHg}$ systolic and/or $89 \mathrm{mmHg}$ diastolic were recruited from the outpatient departments of four participating university hospitals and affiliated general practices. After stratification for several variables, including centre, they were randomly allocated (minimization procedure) to either the self pressure (SP) group or the office pressure (OP) group. If randomised to the SP group antihypertensive treatment was guided by the results of SBPM. In the OP group, treatment was titrated on the basis of the OBPM. Both previously treated and untreated patients qualified for inclusion. In all of them, secondary hypertension had been ruled out by laboratory investigation. At entry into the study, any existing antihypertensive therapy was discontinued whenever possible and patients entered a placebo run-in period of four weeks duration before study treatment was initiated. Treatment decisions were taken at the coordinating centre so 
that both the doctor and the patient were blinded for all study medication drugs. Patients were followed-up for seven visits for a period of 1 year. The primary objective of the HOMERUS-study was to examine whether decisions concerning antihypertensive therapy based on SBPM could lead to less antihypertensive drugs used and associated costs, when compared to decisions based on OBPM. As a secondary objective, the effect of SBPM on adherence to medication within random subgroups of the SP and OP groups was investigated. All patients gave their informed consent and the study was approved by the ethical committees of all participating centres before inclusion of patients into the study.

\section{BP measurements}

At every visit, three consecutive OBPMs were performed in the hospital or at the general practitioners clinic. SBPM was performed six times a day (three in the morning and three in the evening) for a 7-day period, prior to every visit. Patients were requested to register their self-measurements on a form and to print out all measurements. Both OBPM and SBPM were always performed at the non-dominant arm in sitting position after at least 5 min of rest, using the same fully automated device (Omron HEM-705 CP) $)^{14}$.

\section{Study treatment}

Treatment was instituted stepwise according to the following schedule:

Step 1: Lisinopril $10 \mathrm{mg}$ once daily plus one tablet of placebo once daily; Step 2: Lisinopril $20 \mathrm{mg}$ once daily plus one tablet of placebo once daily; Step 3: Lisinopril $20 \mathrm{mg}$ once daily plus hydrochlorothiazide $12.5 \mathrm{mg}$; Step 4: Lisinopril $20 \mathrm{mg}$ once daily plus hydrochlorothiazide $12.5 \mathrm{mg}$ plus amlodipine $5 \mathrm{mg}$.

In both the OP and SP group, the goal BP ranged between 120 and $139 \mathrm{mmHg}$ systolic and between 80 and $89 \mathrm{mmHg}$ diastolic. In patients who were above the target BP (systolic $>139 \mathrm{mmHg}$ and/or diastolic $>89 \mathrm{mmHg}$ ), antihypertensive treatment was intensified by one step. If BP was lower than the target (systolic $<120 \mathrm{mmHg}$ and diastolic $<80 \mathrm{mmHg}$ ), treatment was reduced by one step. All drugs were prescribed to be taken in the morning.

\section{Adherence}

From the patients of the HOMERUS-trial, a population of 228 patients, recruited by the coordinating centre (Maastricht University Hospital) and surrounding general practitioners' practices were included from October 2001 until January 2005. Their adherence to antihypertensive medication was measured with Medication Event Monitoring System (MEMS) V TrackCaps (Aardex Corp., Zug, Switzerland), but without 
giving them feedback about their adherence behaviour. The MEMS-TrackCap is an electronic monitoring system designed to compile the dosing histories of ambulatory patients who are prescribed oral medications ${ }^{15}$. Microelectronics integrated into the cap of pill containers record the time and date that the container is opened or closed. Under the assumption that the patients indeed take their medication when they open their pillboxes, MEMS-TrackCaps offer the opportunity to determine how often and at which time interval the MEMS-TrackCap is opened.

\section{Statistical analysis}

Adherence was expressed as 'percentage of days with correct dosing'; a drug was considered as correctly taken when the pill boxes were opened once every 24 hours (between 03.00 and $03.00 \mathrm{hr}$ at the next day). An adherence level of at least $85 \%$ was defined as acceptable. Patients with an adherence of $85 \%$ or more were then classified as adequate adherers, whereas patients with an adherence of less than $85 \%$ were classified as poor adherers. Defined Daily Doses (DDDs) of antihypertensive drugs were calculated according to data of the WHO Collaborating Centre for Drug Statistics Methodology ${ }^{16}$. DDDs are defined as the assumed average maintenance dose per day for a drug used for its main indication in adults ${ }^{\prime 16}$. Differences in adherence as a continuous variable were analyzed with the Mann-Whitney $U$ test for non-normally distributed data and relative risks (RR) with $95 \%$ confidence intervals (CI) for SP versus OP group were calculated for categorical variables. The impact of potential confounders, i.e. age, newly diagnosed hypertension, baseline BP and the number of DDDs, was analyzed by logistic regression analysis. The chance of finding an adequate adherence level $(\geq 85 \%)$ in patients from the SP group is presented by crude and adjusted Odds Ratios (ORs). A P-value smaller than 0.05 was considered to be statistically significant. Analyses were done on an intention-to-treat basis using SPSS version 15.0 (SPSS, Inc. Chicago, Illinois).

For this adherence study, we calculated that the minimum required number of patients per group would be 60 , based on the following assumptions: a power of $80 \%$, a one-sided significance level of 0.05 , a mean adherence rate in the OP-group of $70 \%$ and a minimal relevant difference between the SP and OP groups of $10 \%$. The standard deviation (8\%) was estimated from a log transformed distribution of adherence. A blinded interim calculation of overall adherence (i.e. without knowing to which group patients were randomised) showed a higher adherence than expected. Therefore, we re-calculated the number of patients required based on a mean adherence rate in the OP-group of $75 \%$ and a difference between the SP and OP groups of $5 \%$. This increased the number of patients required to 114 per group. 


\section{Results}

A total of 228 patients met the inclusion criteria and underwent randomization into the SP $(n=114)$ or OP $(n=114)$ group. Table 4.1 lists the baseline characteristics of the two groups at the time of inclusion. There were no differences between both groups.

Table 4.1 Clinical characteristics at baseline.

\begin{tabular}{lccc}
\hline Characteristic & $\begin{array}{c}\text { SP } \\
(n=114)\end{array}$ & $\begin{array}{c}\text { OP } \\
(\mathrm{n}=114)\end{array}$ & $\begin{array}{c}\text { All patients } \\
(\mathrm{n}=228)\end{array}$ \\
\hline Age [years (SD)] & $57(9)$ & $57(11)$ & $57(10)$ \\
Sex [n (\%)] $\quad$ & & \\
$\quad$ Female & $58(51)$ & $58(51)$ & $116(51)$ \\
Smoking [n (\%)] & $\ddagger 24(21)$ & $17(15)$ & $41(18)$ \\
Alcohol [n (\%)] & $+88(77)$ & $86(75)$ & $174(76)$ \\
Body Mass Index [kg/m² (SD)] & $27(4.1)$ & $27(4.1)$ & $27(4.1)$ \\
Diabetes Mellitus [n (\%)] & $+6(5)$ & $* 8(7)$ & $14(6)$ \\
Baseline fasting glucose level [mmol/I (SD)] & $5.6(0.8)$ & $5.8(1.5)$ & $5.7(1.2)$ \\
Baseline total cholesterol level [mmol/I (SD)] & $5.7(1.2)$ & $5.8(1.0)$ & $5.7(1.1)$ \\
Baseline office BP [mmHg (SD)] & & & $169(21)$ \\
$\quad$ Systolic & $169(21)$ & $169(21)$ & $99(11)$ \\
$\quad$ Diastolic & $98(11)$ & $99(11)$ & $55(24)$ \\
Newly diagnosed hypertension [n (\%)] & $26(23)$ & $29(25)$ & $9.6(8.1)$ \\
Time past since diagnosis of hypertension [years (SD)] & $10.5(8.8)$ & $8.7(7.2)$ & \\
\hline
\end{tabular}

BP indicates blood pressure; Data are mean (standard deviation (SD)) for continuous variables and number (\%) for categorical variables; Data missing for * one, + two, and $\ddagger$ three patients

On average, patients used the MEMS-TrackCaps for $311 \pm 81$ days with a median adherence expressed as days of correct dosing of 91.6\% (Inter Quartile Range [IQR] 85.7-94.0\%). At the end of the study a slight yet statistically significant difference in adherence was observed between patients from the SP group (median adherence 92.3\% [IQR 86.9-94.4\%]) and patients from the OP group (median adherence $90.9 \%$ [IQR 82.9-93.7\%]; $P=0.043$ ). At the other visits during the study (visit 3-9), adherence also tended to be better in patients from the SP group, but none of the comparisons reached statistical significance (Figure 4.1). Adequate adherence, defined as an adherence of $85 \%$ or more, occurred more frequently in the SP group than in the OP group, but again the difference was not statistically significant ( 81 vs. $74 \%$; $R R=1.10$; $95 \% \mathrm{Cl}=0.95-1.26)$. Table 4.2 shows the numbers and proportions of patients in the SP and the OP group in four different categories of adherence: $<70 \%, 70-80 \%, 80-90 \%$, and $\geq 90 \%$. Poor adherence ( $<70 \%)$ occurred less frequently in the SP group than in the OP group, whereas good adherence ( $\geq 90 \%)$ was more frequently observed in the SP group. 


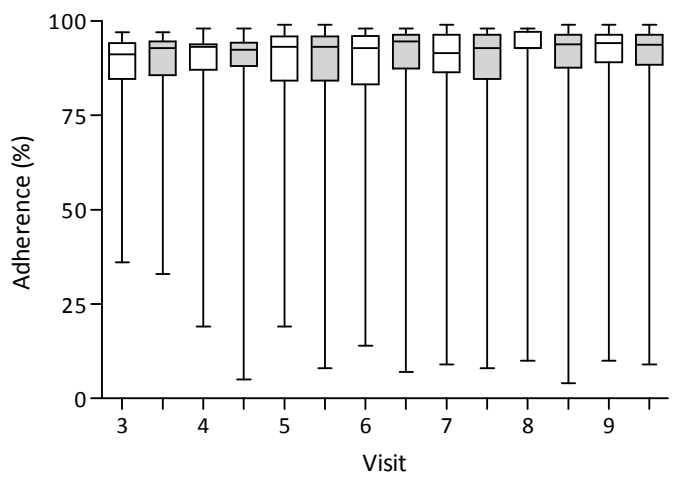

Figure 4.1 Median adherence at the separate visits in the SP and the OP group; $\square$ represents OP group, represents SP group.

Table 4.2 Distribution of patients according to percentage adherence.

\begin{tabular}{cccc}
\hline & SP-group & OP-group & RR (95\% CI) \\
\hline $\begin{array}{c}\text { Percentage adherence [n (\%)] } \\
<70 \%\end{array}$ & $4(4)$ & $7(6)$ & $0.57(0.17-1.89)$ \\
$70-80 \%$ & $10(9)$ & $14(12)$ & $0.71(0.33-1.53)$ \\
$80-90 \%$ & $28(25)$ & $27(24)$ & $1.04(0.66-1.65)$ \\
$\geq 90 \%$ & $72(63)$ & $66(58)$ & $1.09(0.88-1.34)$ \\
\hline
\end{tabular}

* $\mathrm{RR}$ indicates relative risk; $\mathrm{Cl}$ indicates confidence interval

We also analyzed whether adherence to treatment varied over time between two subsequent visits to the hospital or general practitioners' (GP) office. We found that in the week prior to each visit, median adherence was significantly higher than on the remaining days between the visits (100\% [IQR 90-100\%] vs. $85.7 \%$ [IQR 71-98\%]; $P<0.001)$. This greater adherence during the seven days prior to the next visit was comparable in both groups. Median adherence was lowest (71.4\% [IQR 71-79\%]) during the first seven days after the patient's visit to the hospital or GP, again without differences between the SP and the OP group (Figure 4.2). On the remaining days (i.e. without the seven days prior to and after each visit) patients from the SP group displayed a modestly higher median adherence than patients from the OP group (97.6 vs. 97.0\%; $P=0.024)$. For separate visits, the same results were observed, except for the first two visits in which median adherence was in both groups $100 \%$ (Figure 4.3). Patients who missed one or more clinical visits $(n=16)$ were slightly less adherent than patients who attended all visits, but this difference was not significant (90.9 vs. $91.8 \%$; $P=0.29)$. 


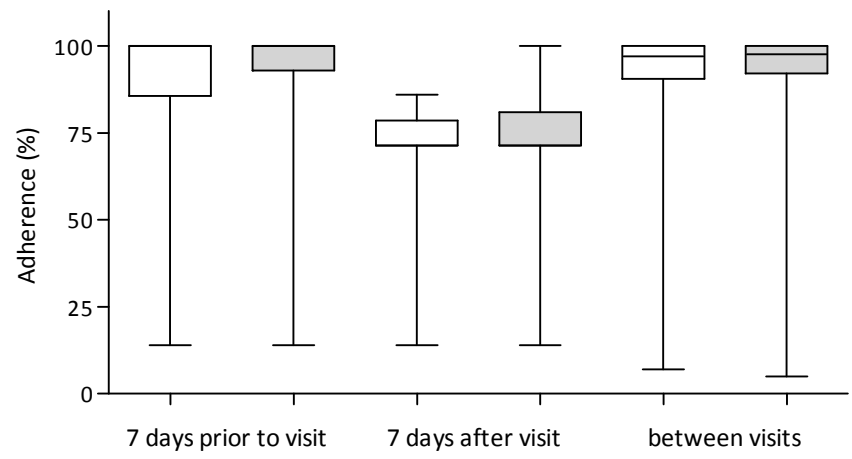

Figure 4.2 Median adherence by SP and OP group for three periods: 7 days prior to each visit, between two visits, and 7 days after visit; $\square$ represents OP group, $₫$ represents SP group.

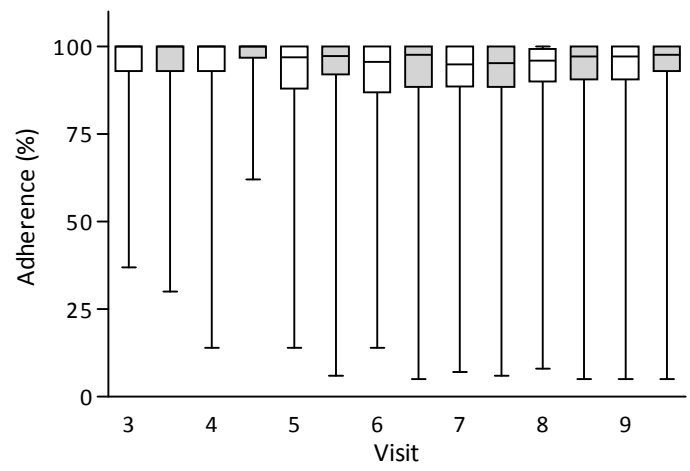

Figure 4.3 Median adherence by SP and OP group for days between visit; $\square$ represents OP group, represents SP group.

Patients in the SP group had to measure their blood pressure six times a day during seven days prior to the next visit (in total 42 measurements). We hypothesized that patients who did not adhere to the prescribed measurement frequency may be less adherent to antihypertensive drugs in that period than patients who performed the prescribed measurement frequency. Although non-significant, median adherence was lower in patients who adhered to the measurement frequency $(n=92)$ than in patients who did not adhere ( $n=22)$ : 98.0 vs. $95.9 \% ; P=0.30$.

The mean DDDs prescribed was 2.2 (SD 1.2), and differed significantly between the SP and OP group (1.9 vs. $2.4 ; P=0.0010$ ). As the DDDs could influence adherence to treatment, we adjusted for this potential confounder by performing a logistic regression analysis. Other variables included in the model were age, newly diagnosed hypertension and baseline BP. A small difference between the crude Odds Ratio (OR) and the adjusted OR (1.35 vs. 1.17) was observed. Nevertheless, patients randomised into the SP group had a slightly higher chance of a higher adherence. Subgroup 
analysis by the number of DDDs showed little differences in adherent patients between the SP group and OP group (Table 4.3; test for trend $P=0.35$ ).

Table 4.3 Subgroup analysis of DDDs on the association between randomization group and adherence category.

\begin{tabular}{lccc}
\hline & SP-group & OP-group & RR $(95 \% \mathrm{Cl})^{*}$ \\
\hline $\begin{array}{l}\text { <2 DDDs } \\
\text { Adherent [n (\%)] }\end{array}$ & $47(89)$ & $30(79)$ & $1.12(0.93-1.35)$ \\
$\begin{array}{l}\text { 2-3 DDDs } \\
\text { Adherent [n (\%)] }\end{array}$ & $28(68)$ & $34(74)$ & $0.92(0.70-1.21)$ \\
$\quad$ Adherent [n (\%)] & $16(80)$ & $21(70)$ & $1.14(0.83-1.57)$ \\
\hline
\end{tabular}

${ }^{*} \mathrm{RR}$ indicates relative risk; $\mathrm{Cl}$ indicates confidence interval

\section{Discussion}

The results from the present study suggest that patients may adhere somewhat better to antihypertensive treatment when they measure their BP themselves than when they do not. Nevertheless, the magnitude of this effect was too small to be clinically meaningful.

We used MEMS for adherence monitoring, which is momentarily considered to be the gold standard for measurement of adherence to treatment. MEMS allows a more accurate investigation of intake behaviour than other measures such as pill count, refill data or self-reports. Therefore, our conclusions are probably valid from a scientific point of view.

A few other studies have addressed the impact of SBPM on adherence. For instance, Ashida and colleagues ${ }^{11}$ performed a descriptive study in which patients answered questions whether they had a BP monitoring device at home or not and how many measurements they performed if they possessed one. They were further asked how many times they missed taking a drug and whether they could recognize the drugs they used. From the results of that study it appeared that patients who had a BP monitoring device at home and measured their BP daily missed less drug doses than patients who did not measure their blood pressure at all. Another study by MarquezContreras ${ }^{10}$ measured adherence in a randomised controlled setting. For a period of six months 250 patients with newly diagnosed or poorly controlled hypertension were randomised to perform SBPM three times a week or standard care. Follow-up visits were planned at week 4, 12 and 24 . The data from that study also suggest a better adherence in patients who perform SBPM than in those receiving routine care ${ }^{10}$. The lack of a major difference in favour of the SP group in our study probably is due to the fact that adherence in the OP group was already as high as $90 \%$. This has undoubtedly minimized our chances of finding greater differences. However, while we were unable to demonstrate a clinically significant impact of SBPM on adherence, the 
specific design of our study did allow us to describe the pattern of adherence relative to a scheduled visit to the hospital or GP office. We found that patients had a higher median adherence within the 7 days before a visit than on the remaining days. Furthermore, within the first 7 days after each visit adherence was significantly lower than on the remaining days. Patients from the SP group had to measure their blood pressure six times a day during seven days before an upcoming consultation. We hypothesized that patients in the SP group would be more inclined to take their drugs than patients in the OP group since they probably were more involved in the treatment of their high blood pressure. However, we did not observe differences in adherence between the OP and SP group during the seven days before the visit. The upcoming consultation probably acted as an important intervention for improving adherence to treatment in both the SP and OP group. The latter phenomenon is known as white-coat adherence and underscores the importance of clinical visits for patients with hypertension ${ }^{17}$. After the scheduled visit patients may have been relieved and temporarily less motivated to take their drugs. As patients in the present study visited their doctor more frequently than what is usual in regular healthcare, white-coat adherence may also have contributed to the high overall adherence.

Recently, Vrijens and colleagues ${ }^{18}$ performed a longitudinal database study in which dosing errors of patients with hypertension were investigated. From the results it appeared that almost half of the patients discontinued treatment within one year after prescription of antihypertensive medication. In addition, patients who took their medication in the morning (morning takers) were less likely to discontinue treatment than 'evening takers'. In our study, adherence remained high for both groups throughout the study period. The frequent visits to the physician probably ensured that patients adhered consistently. In addition, patients took their medication in the morning which probably attributed to the high adherence throughout the study as well.

In our study, patients had to take their drugs on a once daily basis, irrespective whether they used one or multiple drugs. Data from the literature show that for a twice daily drug regimen adherence is lower than for a once daily regimen ${ }^{19}$. In addition, there is increasing evidence that the number of tablets taken at one moment of the day influences adherence as well. This has been shown in comparisons of adherence rates with the use of fixed dose combinations versus single drug tablets $^{20-22}$. Even a minimally higher adherence in the SP group could be attributable to the fact that patients from the SP group used less antihypertensive drugs than patients from the OP group. Although we cannot entirely reject that possibility, adherence in the SP group remained somewhat better than in the OP group even after adjustment for the number of drugs used.

At this time there is no consensus on the definition of an optimal adherence level in the management of hypertension. Wetzels and colleagues ${ }^{19}$ showed that in previously performed studies cut-off values arbitrarily ranged between $80-100 \%$ when using days of correct dosing as adherence measurement. However, there are no data to support 
the notion that any of such levels is necessary for reaching adequate BP reduction. To avoid having to define yet another arbitrary cut-off value we have investigated the number of patients in the OP and SP group among different adherence levels as well. Although not significantly different, more patients with an adherence level $<70 \%$ were observed in the OP group whereas more patients with an adherence of $\geq 90 \%$ were observed in the SP group.

In our study we have chosen to take $140 / 90 \mathrm{mmHg}$ as the target of treatment for SBPM instead of the $135 / 85 \mathrm{mmHg}$ which is presently recommended ${ }^{23}$. As a result, patients in the SP group may have been slightly undertreated. However, at the time the HOMERUS protocol was written there was no consensus on what should be the upper limit for $\mathrm{SBPM}^{24}$. Secondly, in our study we used the same oscillometric automatic device for OBPM and SBPM. As a result differences between office based and home based BP would be less dependent of the measurement itself. Finally, in our study three OBPMs have been performed, instead of the recommended two ${ }^{25}$, which leads to lower average OBPM values ${ }^{26}$. Lower OBPM values tend to dilute the difference between OBPM and SBPM.

The results of our study must be interpreted within the context of its limitations. First of all, patients who received the MEMS-TrackCaps were aware that their drug intake was being monitored. This may have resulted in a greater adherence than what is usually seen in the general population and, hence, overestimation of the habitual adherence of these subjects. On the other hand, patients did not receive feedback about their adherence behaviour, so that positive reinforcement cannot have played a role. Although, ideally, one would prefer not to inform patients that their adherence is being measured, ethical considerations preclude such an approach. Secondly, the possibility exists that our study has preferentially attracted adherent patients, who do not represent the general population. Since all patients were aware of the adherence monitoring before they gave informed consent, the possibility exists that adherent patients responded to participate.

Taking our data and those from the literature together, we may conclude that SBPM probably increases adherence to antihypertensive medication, but the effect is very small and clinically not meaningful when the 'endogenous' adherence behaviour is already very good. Moreover, under the conditions of our present study it appears that white-coat adherence is frequently demonstrable in hypertensive patients. The practicing physician should be well aware of this phenomenon in order to avoid false overestimation of adherence. 


\section{References}

1. Osterberg L, Blaschke T. Adherence to medication. N Engl J Med 2005;353:487-97.

2. Sabate E. Adherence to long term therapies: evidence for action. Geneva:World Health Organization, 2003.

3. Mar J, Rodriguez-Artalejo F. Which is more important for the efficiency of hypertension treatment: hypertension stage, type of drug or therapeutic compliance? J Hypertens 2001;19:149-55.

4. Hughes DA, Bagust A, Haycox A, Walley T. The impact of non-compliance on cost-effectiveness of pharmaceuticals: a review of the literature. Health Economics 2001;10:601-15.

5. Urquhart J. Partial compliance in cardiovascular disease: risk implications. $\mathrm{Br}$ J Clin Pract Suppl 1994;73:2-12.

6. Urquhart J. Patient non-compliance with drug regimens: measurement, clinical correlates, economic impact. Eur Heart J 1996;17 Suppl A:8-15.

7. Carnahan JE, Nugent CA. The effects of self-monitoring by patients on the control of hypertension. Am J Med Sci 1975;269:69-73.

8. Feldman $\mathrm{R}$, Bacher $\mathrm{M}$, Campbell $\mathrm{N}$, Drover A, Chockalingam A. Adherence to pharmacologic management of hypertension. Can J Public Health 1998;89:I16-8.

9. Vrijens B, Goetghebeur E. Comparing compliance patterns between randomized treatments. Control Clin Trials 1997;18:187-203.

10. Marquez-Contreras E, Martell-Claros N, Gil-Guillen V, de la Figuera-Von Wichmann M, CasadoMartinez JJ, Martin-de Pablos L, Figueras M, Galera J, Serra A. Efficacy of a home blood pressure monitoring programme on therapeutic compliance in hypertension: the EAPACUM-HTA study. J Hypertens 2006;24:169-75.

11. Ashida T, Sugiyama T, Okuno S, Ebihara A, Fujii J. Relationship between home blood pressure measurement and medication compliance and name recognition of antihypertensive drugs. Hypertens Res 2000;23:21-4.

12. Verberk WJ, Kroon AA, Kessels AG, Dirksen C, Nelemans PJ, Lenders JWM, Thien ABM, van Montfrans GA, Smit AJ, de Leeuw PW. Home versus Office blood pressure MEasurements: Reduction of Unnecessary treatment Study: rationale and study design of the HOMERUS trial. Blood Press 2003;12:326-33.

13. Verberk WJ, Thien T, Kroon AA, Lenders JW, van Montfrans GA, Smit AJ, de Leeuw PW. Selfmeasurement of blood pressure at home reduces the need for antihypertensive drugs: a randomized, controlled trial. Hypertension 2007;50:1019-25.

14. O'Brien E, Mee F, Atkins N, Thomas M. Evaluation of three devices for self-measurement of blood pressure according to the revised British Hypertension Society Protocol: the Omron HEM-705CP, Philips HP5332, and Nissei DS-175. Blood Press Monit 1996;1:55-61.

15. Cramer JA, Mattson RH, Prevey ML, Scheyer RD, Ouellette VL. How often is medication taken as prescribed? A novel assessment technique. JAMA 1989;261:3273-7.

16. WHO Collaborating Centre for Drug Statistics Methodology. http://www.whocc.no/atcddd/. Consulted on 3 September 2008.

17. Feinstein AR. On white-coat effects and the electronic monitoring of compliance. Arch Intern Med 1990;150:1377-8.

18. Vrijens B, Vincze G, Kristanto P, Urquhart J, Burnier M. Adherence to prescribed antihypertensive drug treatments: longitudinal study of electronically compiled dosing histories. BMJ 2008;336:1114-7.

19. Wetzels GE, Nelemans P, Schouten JS, Prins MH. Facts and fiction of poor compliance as a cause of inadequate blood pressure control: a systematic review. J Hypertens 2004;22:1849-55.

20. Brixner DI, Jackson KC $2^{\text {nd }}$, Sheng $X$, Nelson RE, Keskinaslan A. Assessment of adherence, persistence, and costs among valsartan and hydrochlorothiazide retrospective cohorts in free- and fixed-dose combinations. Curr Med Res Opin 2008;24:2597-607.

21. Bangalore S, Kamalakkannan G, Parkar S, Messerli FH. Fixed-dose combinations improve medication compliance: a meta-analysis. Am J Med 2007;120:713-9.

22. Gerbino PP, Shoheiber O. Adherence patterns among patients treated with fixed-dose combination versus separate antihypertensive agents. Am J Health Syst Pharm 2007;64:1279-83. 
23. O'Brien E, Asmar R, Beilin L, Imai Y, Mancia G, Mengden T, Myers M, Padfield P, Palatini P, Parati G, Pickering T, Redon J, Staessen J, Stergiou G, Verdecchia P. Practice guidelines of the European Society of Hypertension for clinic, ambulatory and self blood pressure measurement. J Hypertens 2005;23:697-701.

24. Pickering T. Recommendations for the use of home (self) and ambulatory blood pressure monitoring. American Society of Hypertension Ad Hoc Panel. Am J Hypertens 1996;9:1-11.

25. O'Brien E, Asmar R, Beilin L, Imai Y, Mallion JM, Mancia G, Mengden T, Myers M, Padfield P, Palatini P, Parati G, Pickering T, Redon J, Staessen J, Stergiou G, Verdecchia P; European Society of Hypertension Working Group on Blood Pressure Monitoring. European Society of Hypertension recommendations for conventional, ambulatory and home blood pressure measurement. J Hypertens 2003;21:821-48.

26. Stergiou GS, Thomopoulou GC, Skeva II, Mountokalakis TD. Home blood pressure normalcy: the Didima study. Am J Hypertens 2000;13:678-85. 
82 


\section{Chapter 5}

\section{Assessing medication adherence simultaneously by electronic monitoring and pill count in patients with mild to moderate hypertension}

Hein AW van Onzenoort, Willem J Verberk, Alfons G Kessels, Abraham A Kroon, Cees Neef, Paul-Hugo $M$ van der Kuy, Peter $W$ de Leeuw

American Journal of Hypertension 2010;23:149-154 


\section{Abstract}

\section{Background}

Poor adherence is one of the major problems in the treatment of hypertension. Electronic monitoring is currently considered to be the gold standard for assessing adherence, but may trigger patients to open the pill bottle without taking medication from it or to pocket extra doses while not opening the pill bottle as often as prescribed. In adjunct to electronic monitoring, pill count could be a valuable tool for exploring adherence patterns, and their effects on blood pressure (BP) reduction.

\section{Methods}

Among a total of 228 patients with mild-to-moderate hypertension, adherence to treatment was measured by means of both the Medication Event Monitoring System (MEMS) and pill count. Patients were followed-up for seven visits over a period of 1 year. At each visit to the physician's office patient's adherence was assessed by both methods.

\section{Results}

Defined as the percentage of days with correct dosing, median adherence according to MEMS was lower than median adherence according to pill count (91.6 versus 96.1 ; $P<0.001)$. In 107 (47\%) and 33 (14\%) patients both methods agreed in defining adherence and non-adherence, respectively. Thirty-one (14\%) patients were adherent only by MEMS and 59 (25\%) patients only by pill count. At the end of the study, patients in the four categories reached comparable BP values and reductions.

\section{Conclusion}

Pill count could be a useful adjunct to electronic monitoring in assessing adherence patterns. Although deviant intake behaviour frequently occurred, the effect on achieved $\mathrm{BP}$ and $\mathrm{BP}$ reduction was not remarkable. 


\section{Introduction}

Insufficient adherence to antihypertensive medication remains a challenging and poorly understood phenomenon ${ }^{1}$. The World Health Organization estimated that half of the patients suffering from hypertension do not comply with the prescribed drug regimen ${ }^{2}$. Recently, a longitudinal study also demonstrated that after one year of treatment almost $50 \%$ of a large group of hypertensive patients discontinued treatment $^{3}$. In contrast, results of clinical trials show much better figures for adherence $^{4-8}$, suggesting that the degree of adherence found in clinical trials does not represent a 'real-life' situation.

A factor that complicates the interpretation of adherence data is the method of measurement and its unit of definition. Presently, electronic monitoring by means of a Medication Event Monitoring System (MEMS) is considered to be the gold standard $^{5,9-13}$. Other methods, such as patient self-reports, pharmacy refilling data, and pill-counts are easy to perform but lack reliability ${ }^{10,13}$. Several studies show that pill count overestimate adherence to medication ${ }^{11,14,15}$, whereas pharmacy refilling data only give information about the collection of the medication by the patient ${ }^{16}$.

Theoretically, the use of MEMS could trigger the patient to open the MEMS container each day without taking medication from it. As a result, adherence would appear to be sufficient, yet the outcome variable, i.e. effect on blood pressure (BP) control, will be disappointing. On the other hand, patients could open the pill bottle less than prescribed and spare up extra doses whilst ingesting the medication at the correct time (pocket dosing). This behaviour will lead to an underestimation of adherence determined by MEMS, even though BP may at times be better controlled.

So far, not much information is available with respect to these different behavioural patterns in relation to achieved BP. This prompted us to investigate adherence patterns in more detail by comparing and matching MEMS data with pill count data and by assessing the effect on BP reduction in patients with mild to moderate hypertension.

\section{Methods}

All patients in this study participated in the HOMERUS trial, the design and results of which have been described in detail elsewhere ${ }^{17,18}$. In brief, HOMERUS is a multicentre, prospective, randomised, double blind trial with a parallel-group design. Patients, aged 18 years and older whose office BP was above $139 \mathrm{mmHg}$ systolic and/or $89 \mathrm{mmHg}$ diastolic were recruited from the outpatient departments of four participating university hospitals and affiliated general practices. If the BP remained above $139 / 89 \mathrm{mmHg}$ at the second visit patients were randomly allocated (minimization procedure) to either the self pressure (SP) group or the office pressure (OP) group. If randomised to the SP group antihypertensive treatment was guided by 
the results of self $B P$ measurement (SBPM). In the OP group, treatment was titrated on the basis of office BP measurement (OBPM). Both previously treated and untreated patients qualified for inclusion. In all of them, secondary hypertension had been ruled out by laboratory investigation. Patients were followed-up for seven visits over a period of 1 year. After the third visit, patients were followed monthly; after the fifth visit patients were followed at a 2-months interval. The primary objective of the HOMERUS-study was to examine whether decisions concerning antihypertensive therapy based on SBPM would lead to less medication and associated costs, when compared to decisions based on OBPM. As a secondary objective, the effect of SBPM on adherence to medication within random subgroups of the SP and OP groups was investigated. All patients gave their informed consent and the study was approved by the ethical committees of all participating centres before inclusion of patients into the study.

\section{BP measurements}

At every visit, three consecutive OBPMs were performed in the hospital or at the general practitioners clinic. SBPM was performed six times a day (three in the morning and three in the evening) for a 7-day period, prior to every visit. Patients were requested to register their self-measurements on a form and to print out all results. Both OBPM and SBPM were always performed at the non-dominant arm in sitting position after at least 5 min of rest, and always using the same fully automated device (Omron HEM-705 CP) ${ }^{19}$.

\section{Study treatment}

At entry into the study, any existing antihypertensive therapy was discontinued whenever possible and patients entered a placebo run-in period of four weeks duration before study treatment was initiated.

Treatment was instituted stepwise according to the following schedule:

Step 1: Lisinopril $10 \mathrm{mg}$ once daily plus one tablet of placebo once daily; Step 2: Lisinopril $20 \mathrm{mg}$ once daily plus one tablet of placebo once daily; Step 3: Lisinopril $20 \mathrm{mg}$ once daily plus hydrochlorothiazide $12.5 \mathrm{mg}$; Step 4: Lisinopril $20 \mathrm{mg}$ once daily plus hydrochlorothiazide $12.5 \mathrm{mg}$ plus amlodipine $5 \mathrm{mg}$.

In both the OP and SP group, the goal BP ranged between 120 and $139 \mathrm{mmHg}$ systolic and between 80 and $89 \mathrm{mmHg}$ diastolic. In patients who were above the target BP (i.e. systolic $>139 \mathrm{mmHg}$ and/or diastolic $>89 \mathrm{mmHg}$ ), antihypertensive treatment was intensified by one step. If BP was lower than the target (systolic $<120 \mathrm{mmHg}$ and diastolic $<80 \mathrm{mmHg}$ ), treatment was reduced by one step, eventually until termination of treatment. If patients were on their target, treatment remained unchanged. In case 
of refractory hypertension, defined as a sitting BP systolic $>160 \mathrm{mmHg}$ or diastolic $>100 \mathrm{mmHg}$ while the patient was already on the maximum combination therapy (i.e. step 4), additional strategies from other drug classes were instituted in order to further decrease BP level. Treatment decisions were taken at each visit and at the coordinating centre so that both the doctor and the patient were blinded for all study medication drugs. All drugs were prescribed to be taken in the morning.

\section{Adherence}

From the patients recruited by the coordinating centre (Maastricht University Hospital) and surrounding general practitioners' practices adherence to antihypertensive medication was measured both by pill count and MEMS V TrackCaps (Aardex Corp., Zug, Switzerland). The MEMS-TrackCap is an electronic monitoring system designed to compile the dosing histories of ambulatory patients who are prescribed oral medications ${ }^{20}$. Microelectronics integrated into the cap of pill containers record the time and date that the container is opened or closed. Patients were not given feedback about their adherence behaviour.

\section{Statistical analysis}

Baseline characteristics were defined at enrollment of patients (visit 1), except for baseline BP which was determined at visit 3 after the placebo run-in period and before initiation of study treatment. Adherence measured by MEMS was expressed as 'percentage of days with correct dosing'; a drug was considered to have been taken correctly when the pill boxes were opened once every 24 hours (between 03.00 and $03.00 \mathrm{hr}$ at the next day). Adherence measured by pill count was calculated as the percentage of the number of prescribed pills corrected for the number of returned pills divided by the period (in days) multiplied by $100 \%$. For both methods, an adherence level of at least $90 \%$ was defined as acceptable. This indicates that patients could be classified as adherent or not on the basis of both MEMS and pill count. Four categories were identified: A. Non-adherent by both methods, B. Adherent by MEMS but not pill count, $C$. Adherent by pill count but not MEMS, and D. Adherent by both methods. The degree of agreement of adherence measured by MEMS and by pill count was evaluated by a Bland-Altman plot $^{21}$. Differences in adherence were calculated with the Wilcoxon Rank Test. Pair-wise comparisons (Tukey HSD) were performed for analyzing differences between the different categories of adherence and analysis of covariance was performed to investigate the association between adherence behaviour and BP reduction corrected for potential confounders. Defined Daily Doses (DDDs) of antihypertensive drugs were calculated according to data of the WHO Collaborating Centre for Drug Statistics Methodology. A $P$-value smaller than 0.05 was considered to be statistically significant. Analyses were done on an intentionto-treat basis using SPSS version 15.0 (SPSS, Inc. Chicago, Illinois). The last observation 
carried forward method was applied for missing values when data of $\geq 2$ consecutive visits were available.

\section{Results}

A total of 233 patients met the inclusion criteria and were considered eligible for the study. Of these, 5 did not start trial medication because they withdrew or refused consent for various reasons. Consequently, 228 patients were included in this adherence study of which 205 patients were recruited by the outpatient department of the coordinating centre (Maastricht University Hospital) and 23 patients by the surrounding general practitioners' practices. The baseline characteristics are shown in Table 5.1. Participants had a mean age of 57 years and an average BP value at the start of the study of $169 / 99 \mathrm{mmHg}$ (systolic/diastolic). In most participants ( $n=173$ ) hypertension had been present for almost 10 years.

Table $5.1 \quad$ Baseline characteristics.

\begin{tabular}{|c|c|c|c|c|c|c|}
\hline & $\begin{array}{c}\text { Total } \\
(n=228)\end{array}$ & $\begin{array}{c}\text { A } \\
(n=33)^{*}\end{array}$ & $\begin{array}{c}B \\
(n=31)^{*}\end{array}$ & $\begin{array}{c}C \\
(n=57)^{*}\end{array}$ & $\begin{array}{c}D \\
(n=107)^{*}\end{array}$ & $P$-value \\
\hline Age [years (SD)] & $57(10)$ & $55(10)$ & $56(9)$ & $58(11)$ & $57(10)$ & 0.53 \\
\hline Female sex [n (\%)] & $116(51)$ & $19(58)$ & $16(52)$ & $32(56)$ & $49(46)$ & 0.51 \\
\hline Self Pressure group [n (\%)] & $114(50)$ & $14(42)$ & $17(55)$ & $28(49)$ & $55(51)$ & 0.77 \\
\hline Smoking [n (\%)] & $41(18)$ & $8(24)$ & $6(19)$ & $15(26)$ & $12(11)$ & 0.077 \\
\hline Alcohol [n (\%)] & $174(76)$ & $28(85)$ & $22(71)$ & $45(79)$ & $79(74)$ & 0.55 \\
\hline Body Mass Index $\left[\mathrm{kg} / \mathrm{m}^{2}\right.$ (SD)] & $27(4)$ & $27(4)$ & $28(5)$ & $28(4)$ & $27(4)$ & 0.35 \\
\hline Diabetes Mellitus [n (\%)] & $14(6)$ & $0(0)$ & $2(7)$ & $5(9)$ & $7(7)$ & 0.41 \\
\hline Baseline fasting glucose level [mg/dl (SD)] & $103(20)$ & $101(22)$ & $101(14)$ & $104(27)$ & $103(20)$ & 0.83 \\
\hline Baseline total cholesterol level [mg/dl (SD)] & $220(43)$ & $240(35)$ & $217(46)$ & $224(50)$ & $217(43)$ & 0.050 \\
\hline Baseline creatinin level [mg/dl (SD)] & $0.93(0.2)$ & $0.92(0.2)$ & $0.93(0.3)$ & $0.89(0.2)$ & $0.95(0.2)$ & 0.39 \\
\hline \multicolumn{7}{|l|}{ Baseline office blood pressure [mmHg (SD)] } \\
\hline Systolic & $169(21)$ & $171(18)$ & $168(22)$ & $171(19)$ & $168(22)$ & 0.73 \\
\hline Diastolic & $99(11)$ & $102(12)$ & $97(9)$ & $100(11)$ & $98(11)$ & 0.15 \\
\hline Newly diagnosed hypertension [n (\%)] & $55(24)$ & $9(27)$ & $6(19)$ & $10(18)$ & $30(28)$ & 0.42 \\
\hline Time past since diagnosis of hypertension [years (SD)] & $9.6(8)$ & $7.7(5.9)$ & $9.6(8.4)$ & $11(9.3)$ & $9.2(7.8)$ & 0.42 \\
\hline
\end{tabular}

$\mathrm{A}=$ non-adherent according to MEMS and pill count; $\mathrm{B}=$ adherent according to MEMS, not to pill count; $\mathrm{C}=$ adherent according to pill count, not MEMS; D=adherent according to MEMS and pill count

On average, patients used the MEMS-containers for $311 \pm 81$ days with a median adherence expressed as days of correct dosing of 91.6\% (Inter Quartile Range (IQR) $85.7-94.0 \%$ ). Median adherence according to pill count was 96.1\% (IQR $88.8-98.4 \%$ ) which was significantly better than the adherence calculated on the basis of the MEMS-data $(P<0.001)$. Figure 5.1 shows the Bland-Altman plot of both estimates, with a bias of $-4.97 \%$ (95\% limit of agreement $-34.6-24.6 \%$ ), indicating great differences between MEMS and pill count results. 


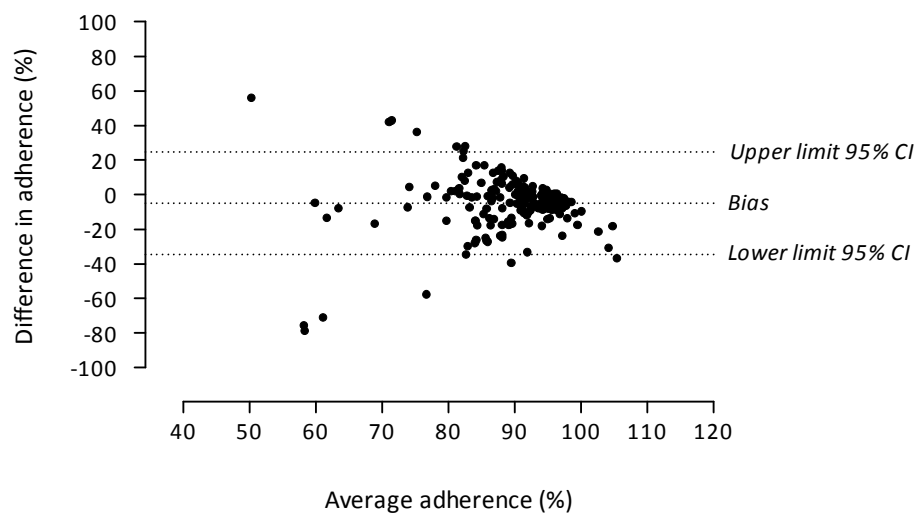

Figure 5.1 Bland-Altman plot of adherence as measured by MEMS and pill count.

Figure 5.2 shows the distribution of patients' adherences according to the four predefined categories. MEMS and pill count were concordant in classifying participants as adherent in $47 \%(n=107 ; D)$ and as non-adherent in $14 \%(n=33 ; A)$ of all patients. Of the 138 patients who were classified as adherent determined by MEMS, $31(22 \% ; B)$ patients showed a non-acceptable adherence by pill count. When pill count indicated adherence, non-adherence by MEMS occurred in 57 (35\%; $C$ ) patients. Table 5.1 presents the characteristics of the patients in the different categories. In category $A$, median adherence according to MEMS was comparable to the adherence according to pill count: $82 \%$ versus $81 \% ; p=0.79$, whereas in category $D$ adherence according to pill count was significantly higher (98\% versus $94 \% ; P<0.001)$. Mean number of DDDs used in each group was 2.1, 1.9, 2.5, and 2.1 for $A, B, C$, and $D$, respectively. Differences between group $B$ and $C$ and between $C$ and $D$ were significant ( $P=0.030$ and $P=0.045$, respectively).

At the end of the study, mean office BP had fallen from 169/99 $\mathrm{mmHg}$ to $146 / 86$ $\mathrm{mmHg}$. Patients who were categorized in $B$ had the smallest decrement in BP when compared to the other categories (15/8 versus $30 / 17,24 / 13$, and $23 / 13$ [systolic/diastolic] $\mathrm{mmHg}$ for $A, C$, and $D$, respectively), but differences were only significant between $A$ and $B: P=0.05$ and $P=0.03$ for systolic and diastolic $B P$, respectively (Table 5.2). We performed an analysis of covariance to examine the influence of confounding factors on the association between adherence patterns and net decrease in BP (Table 5.3). Systolic and diastolic BP values at the start of the study were the most important predictors, but the various different adherence patterns did not modify the effect on BP reduction. 


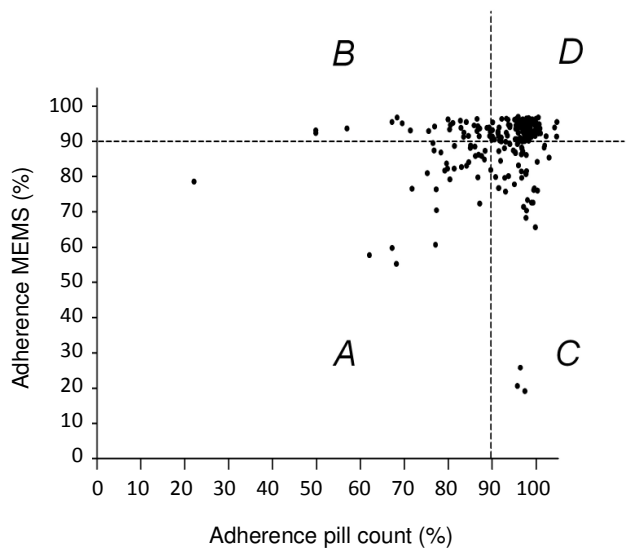

Figure 5.2 Distribution of adherences measured by IVItIVIS and pIII count.

Table 5.2 Achieved BP and BP reduction in subsets of patients.

\begin{tabular}{cccccc}
\hline & $\mathrm{A}(\mathrm{n}=33)$ & $\mathrm{B}(\mathrm{n}=31)$ & $\mathrm{C}(\mathrm{n}=57)$ & $\mathrm{D}(\mathrm{n}=107)$ & $P$-value \\
\hline Achieved BP [mm Hg (SD)] & & & & & \\
Systolic & $142(19)$ & $153(24)$ & $147(18)$ & $144(18)$ & 0.073 \\
Diastolic & $85(8)$ & $88(11)$ & $87(10)$ & $85(10)$ & 0.28 \\
Decrease in BP [mm Hg (SD)] & & & & & \\
Systolic & $30(26)$ & $15(25)$ & $24(21)$ & $23(22)$ & 0.085 \\
Diastolic & $17(13)$ & $8(13)$ & $13(12)$ & $13(13)$ & 0.048 \\
\hline
\end{tabular}

$A=$ non-adherent according to MEMS and pill count; $B=$ adherent according to MEMS, not to pill count; $C=$ adherent according to pill count, not MEMS; D=adherent according to MEMS and pill count.

Table 5.3 Analysis of co-variance on net decrease in systolic and diastolic BP.

\begin{tabular}{|c|c|c|c|}
\hline & Adjusted $\mathrm{R}^{2}$ & F-value & $P$-value \\
\hline Decrement in systolic BP & 0.42 & & \\
\hline Adherence pattern & & 2.1 & 0.10 \\
\hline Baseline systolic BP & & 44 & $<0.001$ \\
\hline Baseline diastolic BP & & 3.2 & 0.077 \\
\hline Age & & 0.6 & 0.45 \\
\hline Sex & & 0.5 & 0.46 \\
\hline Randomization into SP or OP group ${ }^{*}$ & & 2.0 & 0.16 \\
\hline Newly diagnosed hypertension & & 3.0 & 0.085 \\
\hline Decrement in diastolic BP & 0.44 & & \\
\hline Adherence pattern & & 2.1 & 0.11 \\
\hline Baseline systolic BP & & 1.9 & 0.17 \\
\hline Baseline diastolic BP & & 56 & $<0.001$ \\
\hline Age & & 1.3 & 0.25 \\
\hline Sex & & 1.8 & 0.18 \\
\hline Randomization into SP or OP group* & & 1.9 & 0.17 \\
\hline Newly diagnosed hypertension & & 0.2 & 0.62 \\
\hline
\end{tabular}

\footnotetext{
* SP indicates self pressure; OP indicates office pressure.
} 


\section{Discussion}

The results from the present study indicate that $22 \%$ of the patients who opened the MEMS containers daily did not take sufficient drugs and that $35 \%$ of all patients who seemed to take their pills appropriately did not open the MEMS containers as frequently as prescribed. Nevertheless, patients from the latter group had a slightly greater BP reduction than patients from the first group. Differences between groups were, however, not statistically significant, making the clinical importance of this behaviour questionable.

The discrepancies in the results between MEMS and pill count in our study suggest that despite the appropriate openings of the MEMS or the removal of the appropriate number of pills from the containers, the prescribed dosing schedule was often not followed. In our study, the interpretation of MEMS data solely, would lead to false negative and false positive outcomes in $39 \%$ of the patients. According to the MEMS data, participants in group $C$ are unfairly classified as non-adherers, since they do not open the MEMS container sufficiently. However, their adherence is sufficient according to the pill count. This indicates that patients remove more than the prescribed pills from the container. It is unclear whether these pills are taken at a later time or are discarded. The data from group $B$, on the other hand, show that some patients do adhere according to MEMS, while pill count indicate the opposite. This means that patients open the MEMS container, without removing the prescribed number of pills from the container. It is known that adherence monitoring by MEMS tends to overestimate adherence, especially in patients who open the MEMS container multiple times a day out of curiosity ${ }^{22}$. However, by expressing adherence as a percentage of days of correct dosing it is possible to obtain adherence rates more reliably. Multiple curiosity openings are then filtered out. An explanation for the deviant behaviour in group $B$ could be that patients did not recall taking a drug and verified whether the number of drugs had changed. This scenario relies on patient's remembrance about the number of pills that had been and should be in the container. Within the context of opening the MEMS container only once a day, this explanation is, however, difficult to support. Another explanation may be that patients, as they were all aware of the adherence monitoring, purposefully opened the container each day, without removing the prescribed pill. Therefore, counting the pills that are returned at each visit in adjunct to MEMS registration may gain more information about patient's intake behaviour and should be performed to identify true nonadherers.

Until now, only one study addressed the magnitude and impact of non-adherence calculated by pill count and $\mathrm{MEMS}^{23}$. In this study by Lee and colleagues, $19 \%$ of all patients were not adherent, $13 \%$ were adherent by MEMS alone, $32 \%$ were adherent by pill count alone, and $36 \%$ were adherent by both methods. In addition, $14 \%$ of the patients who were not adherent according to both methods reached a desired BP compared to $50 \%$ in patients who were adherent according to both methods. 
Although results were largely comparable with our results, the study by Lee differed in some aspects. First of all, adherence by MEMS was expressed as the percentage of time intervals between MEMS openings that were within $25 \%$ of the dosing interval, that is, within $24 \pm 6$ hours, whereas our study only allowed one opening each day. Secondly, an adherence level of at least $80 \%$ was considered acceptable as opposed to $90 \%$ in our study. We have chosen this cut-off value to better identify patient's behaviour and the effect on BP at the end of the study. Patients who were nonadherent according to both methods (group $A$ ) or adherent only according to one method (group $B$ or $C$ ) reached a $\mathrm{BP}$ reduction comparable to the patients who were categorized as true adherers (group $D$ ). Median adherence in group $A$ was approximately $82 \%$. This may indicate that, with a comparable number of DDDs, a higher adherence level does not lead to a further decrease in BP.

Some limitations should be addressed when interpreting the results of this study. First of all, using pill count data, in adjunct to MEMS data, is an indirect method for classifying patients as adherent or non-adherent. This may have resulted in false positive and false negative classifications, especially in those patients who only adhered according to one of both methods. Although, we cannot entirely reject this possibility, it is likely that these two indirect measures would yield the most information, since patient's self-reports are in general unreliable ${ }^{10,13}$ and pharmacy refill rates only give information about whether or not the medication has been collected by the patient ${ }^{16}$. Secondly, patients who received the MEMS-TrackCaps were aware that their drug intake was being monitored. In addition, patients had many appointments to attend with the physician within one year of follow-up. This may have resulted in a greater adherence than what is usually seen in the general population and, hence, overestimation of the habitual adherence of these subjects. Although, ideally, one would prefer not to inform patients that their adherence is being measured, ethical considerations preclude such an approach. Thirdly, the lack of significant differences between adherence pattern and BP in our study may be due to the small number of patients in each group. Although, our study was primarily not powered to detect differences further research is needed to investigate the consequences of deviant intake behaviour on BP.

Taking our data together, we may conclude that deviant intake behaviour frequently takes place. The effect on BP reduction is clinically not remarkable when the adherence behaviour is already very good. However, whether this is also true for patients whose adherence is lower remains unknown. 


\section{References}

1. McGavock H. A review of the literature on drug adherence. Queen's University:Belfast, 1996.

2. Sabate E. Adherence to long term therapies: evidence for action. Geneva:World Health Organization, 2003.

3. Vrijens B, Vincze G, Kristanto P, Urquhart J, Burnier M. Adherence to prescribed antihypertensive drug treatments: longitudinal study of electronically compiled dosing histories. BMJ 2008;336:1114-7.

4. Andrejak M, Genes N, Vaur L, Poncelet P, Clerson P, Carre A. Electronic pill-boxes in the evaluation of antihypertensive treatment compliance: comparison of once daily versus twice daily regimen. Am J Hypertens 2000;13:184-90.

5. Burnier M, Schneider MP, Chiolero A, Stubi CL, Brunner HR. Electronic compliance monitoring in resistant hypertension: the basis for rational therapeutic decision. J Hypertens 2001;19:335-41.

6. Girvin B, McDermott BJ, Johnston GD. A comparison of enalapril $20 \mathrm{mg}$ once daily versus $10 \mathrm{mg}$ twice daily in terms of blood pressure lowering and patient compliance. J Hypertens 1999;17:1627-31.

7. Nuesch R, Schroeder K, Dieterle T, Marina B, Battegay E. Relation between insufficient response to antihypertensive treatment and poor compliance with treatment: a prospective case-control study. BMJ 2001;323:142-6.

8. Santschi V, Rodondi N, Bugnon O, Burnier M. Impact of electronic monitoring of drug adherence on blood pressure control in primary care: A cluster 12-month randomized controlled study. Eur J Intern Med 2008;19:427-34.

9. Bertholet N, Favrat B, Fallab-Stubi CL, Brunner HR, Burnier M. Why objective monitoring of compliance is important in the management of hypertension. J Clin Hypertens (Greenwich) 2000;2:258-62

10. Farmer KC. Methods for measuring and monitoring medication regimen adherence in clinical trials and clinical practice. Clinical Therapeutics 1999;21:1074-90.

11. Cramer JA, Mattson RH, Prevey ML, Scheyer RD, Ouellette VL. How often is medication taken as prescribed? A novel assessment technique. JAMA 1989;261:3272-7.

12. Rudd P, Ahmed S, Zachary V, Barton C, Bonduelle D. Improved compliance measures: applications in an ambulatory hypertensive drug trial. Clin Pharmacol Ther 1990;48:676-85.

13. Urquhart J. The electronic medication event monitor. Lessons for pharmacotherapy. Clin Pharmacokinet 1997;32:345-56.

14. Pullar T, Kumar S, Tindall H, Feely M. Time to stop counting the tablets? Clin Pharmacol Ther 1989;47:547.

15. Matsui D, Hermann C, Klein JJ, Berkovitch M, Olivieri M, Koren G. Critical comparison of novel and existing methods of compliance assessment during a clinical trial of an oral iron chelator. J Clin Pharmacol 1994;34:944-9.

16. Steiner JF, Prochazka AV. The assessment of refill compliance using pharmacy records: methods, validity, and applications. J Clin Epidemiol 1997;50:105-16.

17. Verberk WJ, Kroon AA, Kessels AGH, Dirksen C, Nelemans PJ, Lenders JWM, Thien Th, van Montfrans GA, Smit AJ, de Leeuw PW. Home versus Office blood pressure MEasurements: Reduction of Unnecessary treatment Study: rationale and study design of the HOMERUS trial. Blood Press 2003;12: 326-33.

18. Verberk WJ, Thien T, Kroon AA, Lenders JW, van Montfrans GA, Smit AJ, de Leeuw PW. Selfmeasurement of blood pressure at home reduces the need for antihypertensive drugs: a randomized, controlled trial. Hypertension 2007;50:1019-25.

19. O'Brien E, Mee F, Atkins N, Thomas M. Evaluation of three devices for self-measurement of blood pressure according to the revised British Hypertension Society Protocol: the Omron HEM-705CP, Philips HP5332, and Nissei DS-175. Blood Press Monit 1996;1:55-61.

20. Urquhart J, De Klerk E. Contending paradigms for the interpretation of data on patient compliance with therapeutic drug regimens. Stat Med 1998;17:251-67.

21. Bland JM, Altman DG. Statistical methods for assessing agreement between two methods of clinical measurement. Lancet 1986;1:307-10.

22. Wetzels GEC, Nelemans PJ, Schouten JSAG, Prins MH. Facts and fiction of poor compliance as a cause of inadequate blood pressure control: a systematic review. J Hypertens 2004;22:1849-55. 
23. Lee JY, Kusek JW, Greene PG, Bernard S, Norris K, Smith D, Wilening B, Wright JT. Assessing medication adherence by pill count and electronic monitoring in the African American Study of Kidney Disease and Hypertension (AASK) pilot study. Am J Hypertens 1996;9:719-25. 


\section{Chapter 6}

\section{Participation in a clinical trial enhances adherence and persistence to treatment}

A retrospective cohort study

Hein AW van Onzenoort, Frederique E Menger, Cees Neef, Willem J Verberk, Abraham A Kroon, Peter $\mathrm{W}$ de Leeuw, Paul-Hugo $\mathrm{M}$ van der Kuy

Hypertension 2011;58:573-578 


\section{Abstract}

\section{Background}

Poor adherence to treatment is one of the major determinants of an uncontrolled blood pressure. Participation in a clinical trial may increase patient's adherence to treatment. This prompted us to investigate adherence and persistence profiles in patients with hypertension who had participated in a clinical trial, by collecting pharmacy refill data before, during, and after participation in the trial.

\section{Methods}

Pharmacy refill data of one-hundred-and-eighty-two patients with hypertension who participated in the Home versus Office blood pressure Measurements: Reduction of Unnecessary treatment Study between 2001-2005 were obtained from 1999 until 2010. Refill adherence to treatment was compared for the periods before, during, and after this trial. Persistence to medication was investigated for the period after termination of the trial.

\section{Results}

Refill data were available of 22,600 prescriptions. Participation into the trial significantly increased refill adherence: from 90.6 to $95.6 \%(P<0.001)$. After the trial period refill adherence decreased again to $91.8 \%(P<0.001)$, which did not differ from the adherence before the start of the trial $(P=0.45)$. Except for adherence to trial medication, adherence to non-trial related drugs also increased as a consequence of trial participation: from 77.6 to $89.6 \%(P<0.001)$. After termination of the trial, median persistence was 1424 days. Participants classified as adherent (adherence>90\%) were less likely to discontinue treatment compared to non-adherent participants (Odds ratio $=0.66 ; 95 \%$ confidence interval 0.45-0.98).

\section{Conclusion}

Participation in a clinical trial significantly increases adherence to both trial related and non-trial related treatment, suggesting that participants in a trial are more involved with their conditions and treatments. 


\section{Introduction}

Poor adherence to treatment is one of the major determinants of an uncontrolled blood pressure (BP). According to the World Health Organization only $50 \%$ of the patients with hypertension do take medication as prescribed ${ }^{1}$. Moreover, up to $50 \%$ of the patients with hypertension discontinue treatment within one year after initiation $^{2-5}$.

Despite these alarming figures, several observations indicate that adherence to treatment is fairly high in patients who participate in a clinical trial ${ }^{6}$. So, there seems to exist a difference in adherence rates between 'real-life' practice and clinical practice under experimental conditions ${ }^{7}$, suggesting that participation in a clinical trial increases adherence, at least to treatment. This positive reinforcement could be explained by the specific design of the study in which patients usually have to attend the clinic more often than usual. Indeed, we recently demonstrated that adherence rates increase significantly prior to an upcoming visit ${ }^{8}$. Alternatively, patients who are more engaged with their condition and treatment may be more willing to participate in a trial in which adherence is monitored. Consequently, patients may be more adherent upfront as compared to what is observed in a general population. All these considerations may compromise the generalizibility of trial-derived adherence results. For the interpretation of adherence data it is important to distinguish between two important aspects of drug intake behaviour: the quality of execution and the degree of continuation of patients' dosing regimen ${ }^{2}$. The effectiveness and clinical power of pharmacotherapy in chronic diseases depend greatly on the degree of continuation (or persistence). However, when patients are engaged with treatment for a certain period of time, the quality of execution of the dosing regimen determine drug action. To date, no information is available with respect to the effect of a clinical trial itself on adherence to treatment. This prompted us to investigate adherence and persistence profiles in patients with hypertension who had participated in a clinical trial, by collecting refill data before, during, and after participation in the trial. We hypothesized that during the trial adherence would be better as compared to that in the period before and after the trial. In this analysis, we also included non-trial related medication and investigated whether a possible increase in adherence during the trial period resulted in better BP control.

\section{Methods}

\section{Study population}

We recruited participants who participated in the Home versus Office blood pressure Measurements: Reduction of Unnecessary treatment Study (HOMERUS) ${ }^{9,10}$ between 2001 and 2005. The HOMERUS trial was a multi-centre, prospective, randomised, 
double blind trial with a parallel-group design in which patients aged 18 years or older and whose office BP was above $139 \mathrm{mmHg}$ systolic and/or $89 \mathrm{mmHg}$ diastolic were included. Participants were recruited from the outpatient departments of four participating university hospitals and affiliated general practices. Both previously treated and untreated patients qualified for inclusion. In all of them, secondary hypertension had been ruled out by laboratory investigation. At entry into the study, any existing antihypertensive therapy was discontinued whenever possible and participants entered a placebo run-in period of four weeks duration before study treatment was initiated. Study treatment was instituted stepwise based on BP according to the following schedule:

Step 1: Lisinopril $10 \mathrm{mg}$ once daily plus one tablet of placebo once daily;

Step 2: Lisinopril $20 \mathrm{mg}$ once daily plus one tablet of placebo once daily;

Step 3: Lisinopril $20 \mathrm{mg}$ once daily plus hydrochlorothiazide $12.5 \mathrm{mg}$;

Step 4: Lisinopril $20 \mathrm{mg}$ once daily plus hydrochlorothiazide $12.5 \mathrm{mg}$ plus amlodipine $5 \mathrm{mg}$.

Atenolol was prescribed to participants intolerant for lisinopril. The goal BP ranged between 120 and $139 \mathrm{~mm} \mathrm{Hg}$ systolic and between 80 and $89 \mathrm{~mm} \mathrm{Hg}$ diastolic. In participants who were above the target BP (i.e. systolic $>139 \mathrm{mmHg}$ and/or diastolic $>89 \mathrm{mmHg}$ ), antihypertensive treatment was intensified by one step. If BP was lower than the target (systolic $<120 \mathrm{mmHg}$ and diastolic $<80 \mathrm{mmHg}$ ), treatment was reduced by one step. All drugs were prescribed to be taken in the morning. Participants were followed-up for seven visits over a period of 1 year ${ }^{9}$.

\section{Adherence measurement}

The total number of participants in the HOMERUS trial was 470 . Of these, 228 participants, recruited by the coordinating centre (Maastricht University Hospital) and surrounding general practitioners' practices, were included in the present study. Participants' filled prescriptions from computerized pharmacy systems were obtained from 1999 until 2010 (Figure 6.1). In the case patients did not collect their drugs at the same pharmacy department during that period, other pharmacy departments were contacted to retrieve as many data if possible. Accordingly, we collected data for the two-year period prior to the trial until five years after its completion. During the HOMERUS trial, proper adherence to antihypertensive medication was concurrently measured by both pill count and Medication Event Monitoring System (MEMS) V TrackCaps (Aardex Corp., Zug, Switzerland). The MEMS-TrackCap is an electronic monitoring system designed to compile the dosing histories of ambulatory participants who are prescribed oral medications ${ }^{11}$. Microelectronics integrated into the cap of pill containers record the time and date that the container is opened or closed. As this is true for all indirect adherence monitoring systems, MEMS does not register pill consumption. 


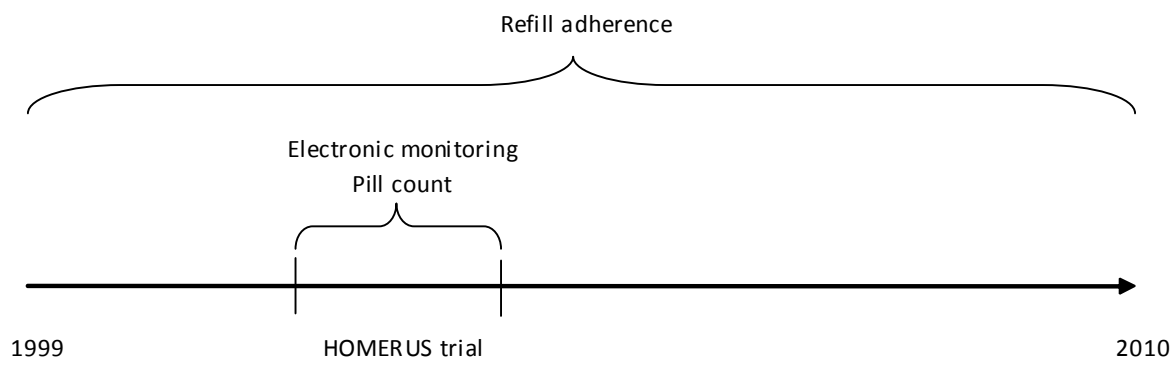

Figure 6.1 Timeframe of adherence measurements.

\section{Filled prescriptions}

Prescription records obtained from the pharmacies included the names of all dispensed drugs, Anatomical Therapeutic Chemical (ATC) classification system, prescribed daily dose, quantity dispensed at each pharmacy fill and the dates of the prescription fills. A prescription fill covered a 90 day drug intake. We considered participants as continuous users when at least three consecutive prescriptions were filled. In addition, a gap between two consecutive prescriptions of 90 days or less after the theoretical duration of the prescription was allowed ${ }^{12}$. Participants who obtained their medications after this allowed treatment gap were considered as noncontinuous users for that specific drug.

\section{Informed consent}

This study was approved by the Review Board of the University Hospital of Maastricht, The Netherlands. Participants gave written informed consent prior to collection of the prescription records. Of the 228 participants who were invited to participate, 46 declined participation (Figure 6.2). Consequently, prescription records were obtained from 182 participants. Procedures were followed in accordance with institutional guidelines.

\section{Statistical analyses}

Refill adherence was calculated for each ATC code ${ }^{13}$ as the theoretical duration divided by the period between the start date and the date of the last prescription filled. The theoretical duration was calculated by dividing the number of units dispensed by the prescribed daily dose. Filled prescriptions in which no daily dose was registered or no theoretical duration could be calculated were excluded from the analysis. Arbitrarily, an adherence level of at least $90 \%$ was defined as acceptable. 
Participants with an adherence of $90 \%$ or more were then classified as adequate adherers, whereas participants with an adherence of less than $90 \%$ were classified as poor adherers. Adherence rates are presented as mean values, including standard deviations. Differences between the three periods (i.e. before, during, and after the trial) in adherence rates were analyzed by pair-wise comparisons with Bonferroni correction. Risk estimates on BP control were calculated for adherent participants before and throughout the study period. We considered continuation of the HOMERUS medication after the trial period in the case participants filled these prescriptions within 90 days after termination of the trial. Persistence of these drugs was calculated as the length of time during which medication was taken. We used Kaplan-Meier curves to display persistence over time. To distinguish persistence for the different antihypertensive drugs used we constructed Kaplan-Meier plots, which were formally tested with a Cox's proportional hazards model.

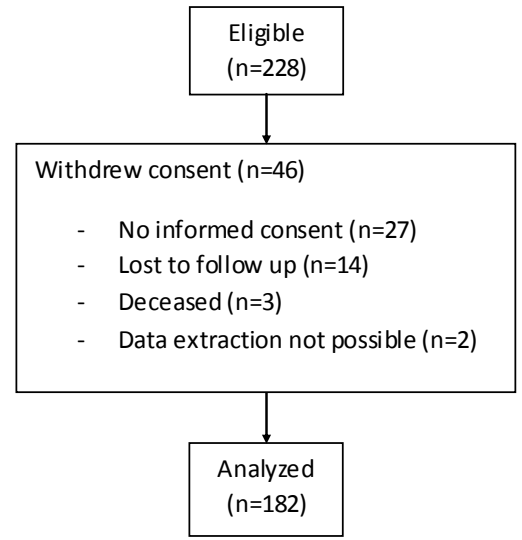

Figure 6.2 Flow diagram of study subjects.

We also analyzed whether adherence rates obtained by pill count differed between participants whose adherence had been monitored electronically by MEMS and those in whom only pill count were used. During the clinical trial, adherence rates based on pill count were calculated both in participants originating from the Maastricht region $(n=228)$ and other centres $(n=242)$, whereas MEMS monitoring was performed only in participants from the Maastricht region. Adherence rates obtained by pill count were calculated for the aforementioned antihypertensive drugs which were used in the HOMERUS trial. Adherence measured by pill count was calculated as the percentage of the number of prescribed pills corrected for the number of returned pills divided by the period (in days) multiplied by $100 \%$. A $P$-value smaller than 0.05 was considered to be statistically significant. We used SPSS version 15.0 (SPSS, Inc. Chicago, Illinois) for all statistical analyses. 


\section{Results}

Altogether, 228 participants who participated in the HOMERUS trial and whose adherence had been monitored both electronically and by pill count during the trial were eligible for this study. Of these, 46 withdrew or refused consent for various reasons (Figure 6.2). Consequently, pharmacy refill data from 1999 until 2010 were obtained from 182 participants. Participants' baseline characteristics at the time of inclusion into the trial are presented in Table 6.1. Baseline characteristics of the 46 participants who did not sign informed consent did not differ from those in this study.

Table 6.1 Baseline characteristics of patients participating $(n=182)$ and of patients who declined participation $(n=46)$.

\begin{tabular}{lcc}
\hline & $\begin{array}{c}\text { Participating patients } \\
(\mathrm{n}=182)\end{array}$ & $\begin{array}{c}\text { Not participating } \\
\text { patients }(\mathrm{n}=46)\end{array}$ \\
\hline Age [years (SD)] & $57(10)$ & $56(11)$ \\
Male [n (\%)] & $93(51)$ & $19(41)$ \\
Smoking [n (\%)] & $32(18)^{*}$ & $9(20)^{\dagger}$ \\
Alcohol [n (\%)] $_{\text {Diabetes Mellitus [n (\%)] }}^{\ddagger}$ & $142(78)^{\dagger}$ & $32(70)^{+}$ \\
Time past since diagnosis of hypertension [years (SD)] $^{+}$ & $12(7)$ & $2(4)$ \\
\hline
\end{tabular}

Data missing for $*=2, \dagger=1$ and $\ddagger=3$ participants

Refill data were available for 22,600 prescriptions. The monitored periods covered an average of 993 (standard deviation (SD) 517) days, 250 (SD 71) days, and 1695 (SD 475) days respectively for the periods before, during, and after the trial. The mean number of drugs prescribed was 3.2, 3.6, and 5.2 for the periods before, during, and after the trial. Participation into the trial significantly increased refill adherence: from 90.6 to $95.6 \%(P<0.001$; Table 6.2).

Table 6.2 Effect of a clinical trial on adherence to treatment.

\begin{tabular}{ccccc}
\hline & Before trial & During trial & After trial & $P$-value \\
\hline $\begin{array}{c}\text { Mean adherence, overall (\% [SD]) } \\
\text { Mean adherence, per ATC-code }{ }^{*} \text { (\% [SD]) }\end{array}$ & $90.6(11)$ & $95.6(7)$ & $91.8(10)$ & $<0.001$ \\
A & $88.5(17)$ & $90.8(16)$ & $86.8(20)$ & 0.59 \\
B & $92.8(9)$ & $89.8(13)$ & $96.3(8)$ & 0.025 \\
C & $95.1(9)$ & $97.9(7)$ & $95.6(9)$ & $<0.001$ \\
G & $82.6(28)$ & $89.7(20)$ & $93.3(15)$ & 0.20 \\
H & $90.9(12)$ & $95.5(7)$ & $87.1(27)$ & 0.67 \\
L & $99.0(-)$ & - & $84.2(22)$ & 0.55 \\
M & $65.1(33)$ & $69.0(36)$ & $69.9(33)$ & 0.61 \\
N & $74.2(31)$ & $74.9(32)$ & $76.4(28)$ & 0.93 \\
R & $26.9(-)$ & $46.6(-)$ & $84.0(24)$ & 0.079 \\
\hline
\end{tabular}

*Anatomical Therapeutic Code; A=Alimentary tract and metabolism; B=Blood and blood forming organs; $\mathrm{C}=$ Cardiovascular system; $\mathrm{G}=$ Genito-urinary system and sex hormones; $\mathrm{H}=$ Systemic hormonal preparations, excluding sex hormones and insulins; L=Antineoplastic and immunomodulating agents; M=Musculo-skeletal system; N=Nervous system; R=Respiratory system. 
After the trial period, refill adherence decreased again to $91.8 \%(P<0.001)$, a level which did not differ from the adherence before the start of the trial $(P=0.45)$. When we stratified for cardiovascular (ATC-code C) and non-cardiovascular drugs (i.e. the remaining ATC codes) participation in the clinical trial increased adherence to noncardiovascular treatment as well from 77.6 to $89.6 \%(P<0.001)$. After the trial period, refill adherence fell back to $84.1 \%$, which did not differ from the adherence observed before and during the trial period. Differences in adherence to treatment between the periods for each ATC-code were only significant for cardiovascular (C) medication and for drugs related to blood and blood forming organs (B; Table 6.2). Drugs in the latter category were acetic salicylic acid, folic acid, and ferric salts.

We analyzed whether adherent participants were more likely to achieve BP control (BP $<140 / 90 \mathrm{mmHg}$ ) at the end of the trial period. Before the start of the clinical trial, 139 participants were prescribed cardiovascular medication. Of these, 106 participants (76\%) were classified as adherent (adherence $>90 \%$ ) to cardiovascular medication and remained so during the trial period. Despite an adequate adherence level, 63 (59\%) participants did not reach BP control during the trial, compared to 43 (41\%) participants who did (Figure 6.3). The chance of having a participant's BP controlled under the observation of an adequate adherence level was 0.68 (95\% confidence interval $(\mathrm{Cl})=0.46-1.00)$.

We also analyzed whether the effect of participation in a clinical trial which aimed to study adherence to treatment was confounded by the use of MEMS monitoring. For this analysis we used pill count derived from the entire HOMERUS population. Mean adherence as determined by pill count during the trial was comparable in participants whose adherence had been monitored electronically by MEMS and by pill count together $(n=182)$ and in participants whose adherence had been monitored by pill count only ( $\mathrm{n}=242)$ : 94.0 vs. $92.6 \%(P=0.20)$.

During the HOMERUS trial cardiovascular drugs with ATC code C03 (hydrochlorothiazide), C07 (atenolol), C08 (amlodipine), and C09 (lisinopril) were prescribed. Before the start of the trial, 57 participants (31\%) were using drugs with the same ATC-code as used during the HOMERUS trial. The mean number of drugs used was 1.4 (SD 0.73). After the trial period, 150 participants (82\%) continued using the HOMERUS medication for a mean period of 3.6 years (SD 1.9). Of the remaining 32 participants, 13 subjects (41\%) were switched directly from HOMERUS medication to other antihypertensive drugs, 4 participants (13\%) dropped-out during the trial, and 1 patient filled the prescription more than 90 days after termination of the trial. In 9 participants (28\%) refill data were not available for the period after the trial and in 5 participants (16\%) antihypertensive medication was no longer indicated based on blood pressure. The mean number of drugs used was 1.9 (SD 0.83). 


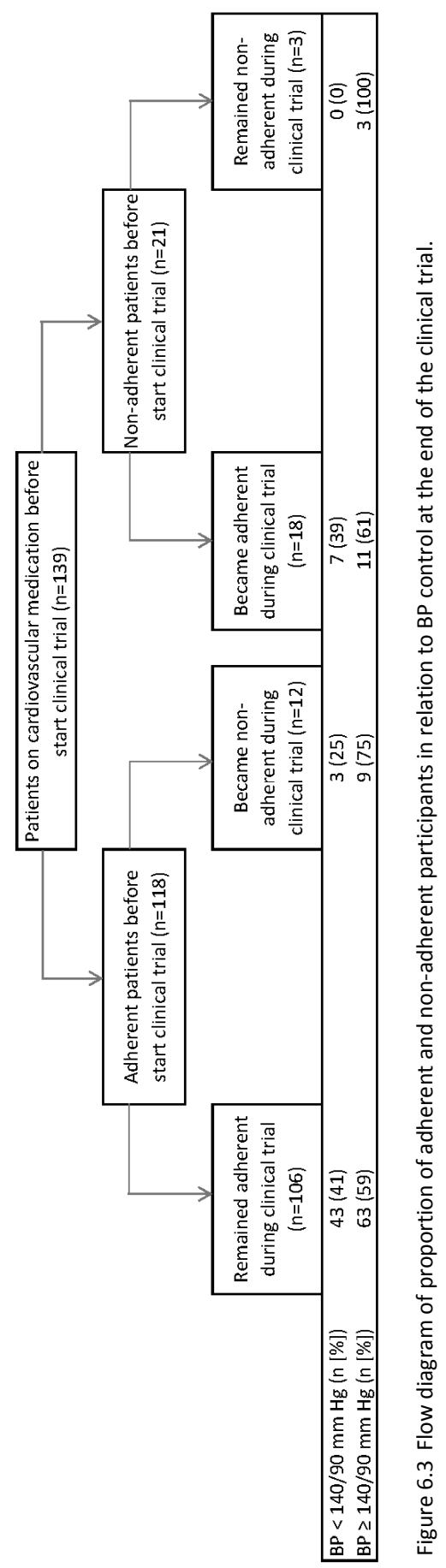


Figure 6.4 shows a Kaplan-Meijer estimate of persistence after the trial period for the HOMERUS drugs. Median duration of continuation was 1424 days after termination of the trial. Persistence decreased during the first one, two, and three years after termination of the trial to 83,74 , and $68 \%$, respectively. No differences in duration of continuation between the different drugs used were observed $\left(X^{2}=2.21 ; P=0.70\right)$. Participants who were classified as adherent (adherence $>90 \%$ ) based on refill data showed a longer persistence (Figure 6.5). Median duration of continuation was 1000 days for non-adherent participants as compared to 1440 days for adherent participants. The chance that a patient would discontinue treatment early was 0.66 (Odds ratio) for participants classified as adherent $(95 \%$ confidence interval 0.45-0.98).

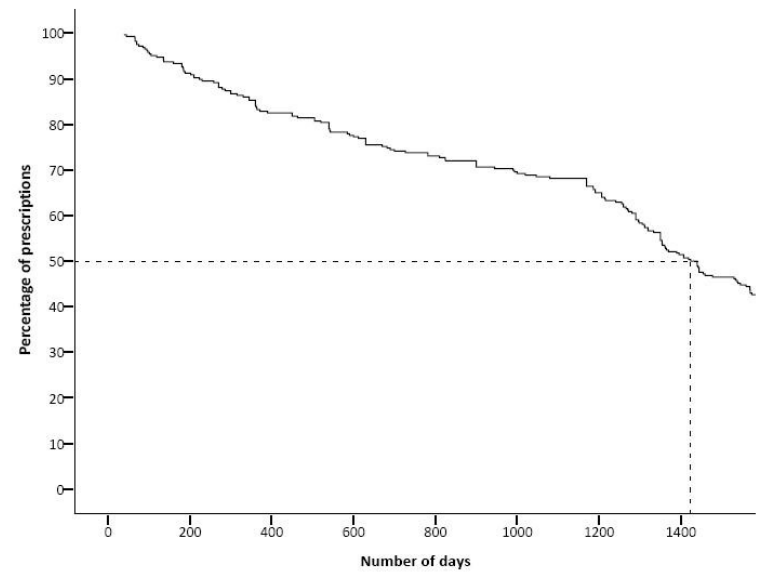

Figure 6.4 Time course of persistence after the clinical trial of the antihypertensive drugs started during the HOMERUS trial.

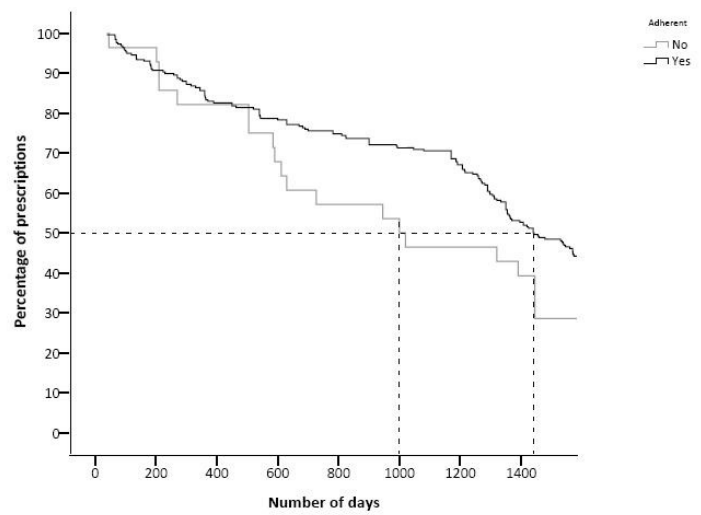

Figure 6.5 Time course of persistence after the clinical trial of the antihypertensive drugs started during the HOMERUS trial stratified by adherence status (adherent if adherence rate $>90 \%$ ). 


\section{Discussion}

The results from the present study in patients with hypertension demonstrate that participation in a clinical trial increases adherence to both study and non-study medication. In addition, continuation of study medication after termination of the trial seems to persist for a relatively long period.

Early discontinuation of treatment and poor adherence form a major barrier for long term treatment of hypertension. Indeed, the World Health Organization stated that poor adherence severely compromises the effectiveness of treatment ${ }^{1}$. It is, however, remarkable that adherence levels as found in clinical trials are substantially higher than what is observed in 'real life' settings ${ }^{6}$. There are several explanations for the differences in adherence rates as observed in observational studies and clinical trials. Firstly, the specific study protocol of the clinical trial may motivate patients to follow their prescriptions more accurately. Especially when patients have to visit the clinic more often than usual, white-coat adherence may have a positive effect on overall adherence to treatment ${ }^{8}$. Secondly, patients who are more concerned about their health and treatment may be more willing to participate in a clinical trial in which adherence is monitored. Finally, patients who are already adherent upfront may be more inclined to participate in a clinical trial. Our study shows that refill adherence before participation in the HOMERUS trial was already as high as $91 \%$. For cardiovascular drugs the adherence rate was 95\%. These findings support the latter explanation for the difference in adherence rates found between clinical trials and observational studies. Despite the high adherence rate before the HOMERUS trial, participation resulted in a further increase in adherence. Interestingly, this effect was also observed with non-cardiovascular drugs, suggesting that patients' perception of illnesses and their treatments are positively influenced by participation in a clinical trial. The relatively long period of continuation of the HOMERUS drugs and the high adherence rate after termination of the clinical trial support this hypothesis.

Poor adherence to treatment is still considered a major determinant of an uncontrolled BP control $^{14-16}$. The results of our study showed that despite a high adherence rate before and during the trial, the number of participants with an uncontrolled blood pressure remained fairly high. This suggests that failure to reach BP control using a given drug regimen is not necessarily due to a problem of poor adherence to treatment. Treating physicians should be aware of this when being confronted to patients with an uncontrolled blood pressure.

Although several studies have investigated persistence rates of antihypertensive drugs based on refill data ${ }^{3-5}$, comparing the results is difficult since studies used different methodologies for calculating persistence rates $^{17}$. Despite these differences, a consistent observation is that persistence decreases rapidly (up to 50\%) within one year after initiation of antihypertensive treatment and continues to decrease in the following years. These data emphasize the importance of supporting and motivating patients to adhere to the prescribed treatment, especially in the early phase of 
treatment. Although, our study also indicates that it is difficult for patients to continue the prescribed medication, the fall in persistence during the first year after termination of our trial was only $15 \%$, which is below that what is usually observed ${ }^{3-5}$. This suggests that a positive study effect on persistence to treatment is sustained for a short period of time.

We defined participants as adherent when adherence rates were $90 \%$ or higher. Although this degree of adherence is considered fairly high for antihypertensive treatment, participants who were classified as non-adherent were significantly less persistent than those who were classified as adherent. These results underscore the importance of presenting data on adherence not exclusively for the supervised treatment period ${ }^{2}$.

In this study, we used refill data from computerized pharmacy databases to calculate adherence rates. Refill adherence rates have been used extensively for the assessment of drug acquisition and dispensing. Compared to electronic monitoring, refill data provide researchers with a relatively simple method for investigating exposure to medication in large populations ${ }^{18-20}$. Moreover, this method is suitable for investigating long-term persistence to treatment and gaps in medication supply ${ }^{19-21}$. Therefore, our conclusions are probably valid from a scientific point of view.

The results of our study must be interpreted within the context of its limitations. First of all, an effect of participation in a clinical trial on adherence to treatment may be compromised by the MEMS monitoring as performed in our population. Several studies show that electronic monitoring increases adherence to treatment ${ }^{22-26}$. However, most of these studies had followed patients for only a short period of time, making it difficult to predict sustainability of a monitoring effect ${ }^{23-25}$. In our study, adherence rates based on pill count were comparable for participants whose adherence had been monitored electronically by MEMS as well as by pill count and for those in whom adherence had been monitored by pill count only. These results may suggest that electronic monitoring has a limited effect on adherence to treatment during a trial. Consequently, the effect on adherence may be attributable solely to participation in the trial. Whether this is true for patients who are less adherent than what is observed in our study is not clear. Secondly, and this is true for all methods of adherence measurement, discarding of drugs is difficult to prove when using refill data. Thirdly, generalizability of the results might be compromised by the specific selection of study subjects. We included participants from a population that had already participated in a clinical trial. The possibility exists that these patients are more inclined to participate in another study than patients who have not participated in a trial yet.

\section{Perspectives}

Generalizability of adherence results is an important issue in research. The results of our study underscore the difficulties in interpretation and implications of adherence 
data into clinical practice. Participants in our study showed high adherence rates upfront and during the trial. Treating physicians should be aware that adherence rates observed in clinical trials do not represent a 'real-life setting'. In addition, selection of highly adherent patients may confound the effectiveness of intervention strategies for improving adherence. Whether improvement in adherence could be more substantial in populations with adherence rates that are lower than the high adherence rates we observed should be subject to further research. Since these patients are probably less inclined to participate in a trial, it will be a challenge for researchers and physicians to include them into a trial. 


\section{References}

1. Sabate E. Adherence to long term therapies: evidence for action. Geneva:World Health Organization, 2003.

2. Vrijens B, Vincze G, Kristanto P, Urquhart J, Burnier M. Adherence to prescribed antihypertensive drug treatments: longitudinal study of electronically compiled dosing histories. BMJ 2008;336:1114-7.

3. Van Wijk BL, Shrank WH, Klungel OH, Schneeweiss S, Brookhart MA, Avorn J. A cross-national study of the persistence of antihypertensive medication use in the elderly. J Hypertens 2008;26:145-53.

4. Caro JJ, Salas M, Speekman JL, Raggio G, Jackson JD. Persistence with treatment for hypertension in actual practice. Can Med Assoc J 1999;160:31-7.

5. Bourgault C, Sénécal M, Brisson M, Marentette MA, Grégoire JP. Persistence and discontinuation patterns of antihypertensive therapy among newly treated patients: a population-based study. J Hum Hypertens 2005;19:607-13.

6. Wetzels GE, Nelemans P, Schouten JS, Prins MH. Facts and fictions of poor compliance as a cause of inadequate blood pressure control: a systematic review. J Hypertens 2004;22:1849-55.

7. Prado jr JC, Mion jr D. Adherence to medication: the importance of research in primary care. Am J Hypertens 2010;23:109.

8. Van Onzenoort HAW, Verberk WJ, Kroon AA, Kessels AG, Nelemans PJ, van der Kuy PH, Neef C, de Leeuw PW. Effect of self-measurement of blood pressure on adherence to treatment in patients with mild to moderate hypertension. J Hypertens 2010;28:622-7.

9. Verberk WJ, Kroon AA, Kessels AGH, Dirksen C, Nelemans PJ, Lenders JWM, Thien TA, van Montfrans GA, Smit AJ, de Leeuw PW. Home versus Office blood pressure MEasurements: Reduction of Unnecessary treatment Study: rationale and study design of the HOMERUS trial. Blood Press 2003;12:326-33.

10. Verberk WJ, Kroon AA, Lenders JW, Kessels AG, van Montfrans GA, Smit AJ, van der Kuy PH, Nelemans PJ, Rennenberg RJ, Grobbee DE, Beltman FW, Joore MA, Brunenberg DE, Dirksen C, Thien T, de Leeuw PW. Self-measurement of blood pressure at home reduces the need for antihypertensive drugs: a randomized, controlled trial. Hypertension 2007;50:1019-25.

11. Urquhart J, De Klerk E. Contending paradigms for the interpretation of data on patient compliance with therapeutic drug regimens. Stat Med 1998;17:251-67; discussion 387-9.

12. Van Wijk BL, Klungel OH, Heerdink ER, de Boer A. Refill persistence with chronic medication assessed from a pharmacy database was influenced by method of calculation. J Clin Epidemiol 2006;59:11-7.

13. Vink NM, Klungel OH, Stolk RP, Denig P. Comparison of various measures for assessing medication refill adherence using prescription data. Pharmacoepidemiol Drug Saf 2009;18:159-65.

14. Mar J, Rodriguez-Artalejo F. Which is more important for the efficiency of hypertension treatment: hypertension stage, type of drug or therapeutic compliance? J Hypertens. 2001;19:149-55.

15. Urquhart J. Partial compliance in cardiovascular disease: risk implications. $\mathrm{Br} \mathrm{J}$ Clin Pract Suppl 1994;73:2-12.

16. O'Rorke JE, Richardson WS. Evidence based management of hypertension: what to do when blood pressure is difficult to control. BMJ 2001;322:1229-32.

17. Van Wijk BL, Klungel OH, Heerdink ER, de Boer A. Refill persistence with chronic medication assessed from a pharmacy database was influenced by method of calculation. J Clin Epidemiol 2006;59:11-7.

18. Farmer KC. Methods for measuring and monitoring medication regimen adherence in clinical trials and clinical practice. Clinical Therapeutics 1999;21:1074-90.

19. Steiner JF, Prochazka AV. The assessment of refill compliance using pharmacy records: methods, validity, and applications. J Clin Epidemiol 1997;50:105-16.

20. Andrade SE, Kahler KH, Frech F, Chan KA. Methods for evaluation of medication adherence and persistence using automated databases. Pharmacoepidemiol Drug Saf 2006;15:565-74.

21. Choo PW, Rand CS, Inui TS, Lee ML, Cain E, Cordeiro-Breault M, Canning C, Platt R. Validation of patient reports, automated pharmacy records, and pill count with electronic monitoring of adherence to antihypertensive therapy. Med Care 1999;37:846-57.

22. Burnier M, Schneider MP, Chiolero A, Stubi CL, Brunner HR. Electronic compliance monitoring in resistant hypertension: the basis for rational therapeutic decisions. J Hypertens 2001;19:335-41. 
23. Bertholet N, Favrat B, Fallab-Stubi CL, Brunner HR, Burnier M. Why objective monitoring of compliance is important in the management of hypertension. J Clin Hypertens (Greenwich) 2000;2:258-62.

24. Waeber B, Vetter W, Darioli R, Keller U, Brunner HR. Improved blood pressure control by monitoring compliance with antihypertensive therapy. Int J Clin Pract 1999;53:37-8.

25. Wetzels GE, Nelemans PJ, Schouten JS, Dirksen CD, van der Weijden T, Stoffers HE, Janknegt R, de Leeuw PW. Prins MH. Electronic monitoring of adherence as a tool to improve blood pressure control. A randomized controlled trial. Am J Hypertens 2007;20:119-25.

26. Santschi V, Rodondi N, Bugnon O, Burnier M. Impact of electronic monitoring of drug adherence on blood pressure control in primary care: A cluster 12-month randomized controlled study. Eur J Int Med 2008;19:427-34. 


\section{Chapter 7}

Objective adherence measurement with a smart blister

A feasibility study in primary care

Hein AW van Onzenoort, Cees Neef, Willem J Verberk, H Peter van Iperen, Peter W de Leeuw, Paul-Hugo M van der Kuy Accepted by American Journal of Health-System Pharmacy 


\section{Abstract}

\section{Background}

To date, several methods are available for measuring adherence to treatment. However, no method fulfils all requirements for valid adherence measurement.

\section{Methods}

In this feasibility study, the functionality, robustness, and adherence to treatment determined by the smart blister were investigated in 115 participants. Functionality was determined by variables that could influence the interpretation of registered events, and as a result the interpretation of adherence rates. The robustness of the smart blister was determined by calculating the percentage of blisters that registered multiple events at the same time as a consequence of breaking multiple conductive tracks. Adherence was expressed as taking and timing adherence, and days of correct dosing.

\section{Results}

In total, 245 smart blisters were used during a mean period of 60 days. The registration of handing-out date and time of the smart blister took place in $72 \%$ of all smart blisters. Registration of patient number or name, identification number of the smart blister, identification of the event (i.e. date and time of pushing the pill through the smart blister), and handing-in date and time of the smart blister was $100 \%$. Fortytwo smart blisters (17\%) registered multiple events at the same time as a consequence of breaking multiple conductive tracks. Mean intake adherence was 97.6\% (SD 11\%).

\section{Conclusion}

The smart blister may be a valuable tool for measuring adherence to treatment. However, functionality and robustness of the smart blister need further development. 


\section{Introduction}

Insufficient adherence to treatment remains one of the major limitations in the management of cardiovascular diseases and may contribute to increased morbidity, mortality and $\operatorname{costs}^{1-10}$. Several studies have shown that persistence with treatment decreases with time ${ }^{11-18}$. In hypertension, discontinuation rates of antihypertensive drugs vary from $22 \%$ to almost $50 \%$ in one year after initiation of therapy ${ }^{11-14}$. For lipid lowering drugs ${ }^{15-17}$ and antidiabetics ${ }^{17,18}$, comparable rates have been observed. In order to develop strategies aimed at improving adherence to treatment and, hence, minimize the risk of an cardiovascular event, insight into patient's adherence to medication is therefore necessary.

To date, several methods are available for measuring adherence to treatment ${ }^{19-25}$. However, no method fulfils all requirements for valid adherence measurement. Although easy to perform, pill count, pharmacy refilling data, and patient self-reports lack reliability ${ }^{21,24}$. Studies show that pill count overestimate adherence to treatment ${ }^{22,26,27}$, whereas pharmacy refilling data only give information about the collection of the medication by the patient ${ }^{28}$. Until now electronic adherence monitoring by the Medication Event Monitoring System (MEMS) has been considered to be the most reliable method to evaluate patient adherence ${ }^{19-24}$. Recently, a few other methods have been developed for measuring adherence electronically ${ }^{29-31}$. The Intelligent Drug Administration System (IDAS) is an electronic device that accommodates blister packs, and is able to record date and hour at which a drug was removed from the blister. Furthermore, it reminds patients when to take their medications with a visual and audible warning ${ }^{30}$. Yamada et al. ${ }^{31}$ designed a device with press-through-packaging sheets holding 28 tablets. This device largely resembles the IDAS.

Although these new developments are promising, dedicated devices have to be designed to accommodate medication blisters. Recently, a smart blister (The Compliers Group, Veldhoven, The Netherlands) which can be attached to an existing, commercially available standard blister package has been developed. This blister could be promising since no dedicated system needs to be developed and it does not alter the medication blister package. In addition, compared to MEMS any removal of a tablet causes an event, whereas an opening of the MEMS bottle does not necessarily mean a single removal of a tablet. Recently, Jekle et al. presented the functionality and reliability of the smart blister in an experimental setting ${ }^{32}$. In this report, we present the first clinical experiences of the smart blister in patients. 


\section{Methods}

\section{Participants}

In this open-label study among twenty pharmacies in The Netherlands, patients were invited to participate during a three month follow-up period in which the feasibility of the smart blister was investigated. Although participants could use multiple drugs, we monitored only one drug (in our study valsartan) which had to be taken once daily. We hypothesized that this would minimize the variation and hence increase generalizability of the results. All participants using valsartan were eligible for participation. Each time when participants collected their tablets at the pharmacy department, two original medication blisters of 14 pills valsartan each were provided with a smart blister that was placed in a cardboard wallet. The smart blister has to be attached to the backside of the original medication blister before it can be placed in the cardboard wallet. When returning to the pharmacy department, participants had to hand-over the empty smart blister to the pharmacist who read out the adherence data and discussed patient's intake behaviour with the patient. The study was performed between November 2005 and June 2006. Participants gave consent prior to participation and were aware that their adherence was measured.

\section{Design smart blister}

We designed an exact copy of the backside of the medication blister in which valsartan is packaged. This copy is provided with an electronic detection circuit and printed on an adhesive label (i.e. smart blister; Figure 7.1). The smart blister also contains a non-volatile storage chip which incorporates a Radio Frequency IDentification (RFID) interface, detector inputs, a counter and a clock generator. The printed label uses conductive tracks, which detect when (date and time) a pill is pushed out of the blister pack. In addition, the pack incorporates a copper aerial and an energy cell to supply the electronic circuit. The information gathered at the blister can be transferred via the Near Field Communication (NFC) interface to an internet accessible database. A reader of these data was designed (DataTaker, TCG, Eindhoven, The Netherlands) to pick-up the data stored in the blister. The DataTaker is able to send the data via the General Packet Radio Service (GPRS) network to a database which is located on a server.

Before the smart blister can register data, and consequently be handed over to the patient, the chip has to be activated first by the DataTaker. The DataTaker programs patient's identification number into the memory of the smart blister so that the blister is correctly identified by the internet database. After activation it is possible to register the time and date that a pill is pushed through the blister. When the patient returns to the pharmacy to obtain new medication, the empty smart blister has to be handed over to read out the stored data. As outlined below, the system calculates 
adherence to the prescribed medication and shows patient's intake behaviour over time graphically.

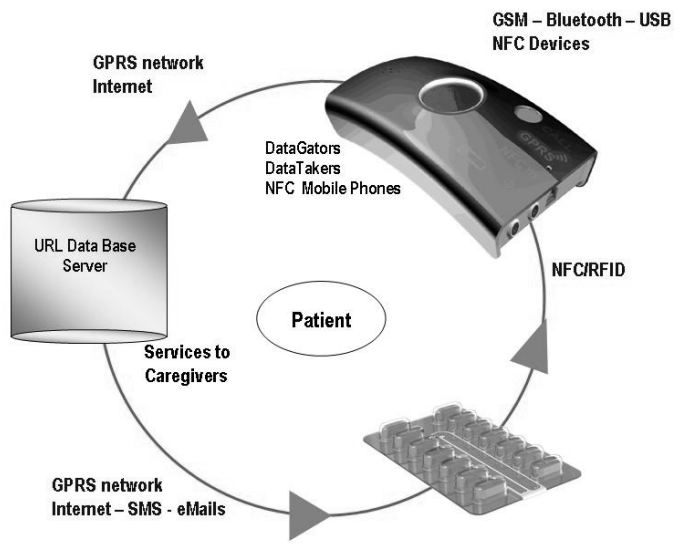

Figure 7.1 Design of the smart blister.

\section{Feasibility}

To determine the feasibility of the smart blister we registered the functionality and the robustness of the smart blister. Functionality was determined by variables that could influence the interpretation and analysis of registered events, and thereby limiting the applicability of the smart blister in practice. For example, the smart blister should be possible to identify the correct patient in order to present patient's specific adherence data. The variables included were patient number or name, identification number of the smart blister, identification of the event (i.e. date and time of pushing the pill through the smart blister), and handing-out or handing-in date and time of the smart blister. The percentage of smart blisters in which registration of these variables took place was calculated. The robustness of the smart blister was determined by calculating the percentage of blisters that registered multiple events at exactly the same time as a consequence of breaking multiple conductive tracks. By pushing a pill through the blister the possibility existed that multiple conductive tracks of horizontally positioned pills broke. As a result multiple events were registered at exactly the same time. In the situation this happened, future objective registrations were impossible. 


\section{Adherence}

Adherence to treatment was calculated as intake adherence, timing adherence and days of correct dosing. Intake adherence was defined as the total number of pills that were pushed through the smart blister divided by the theoretical number of days multiplied by $100 \%$. The theoretical number of days was calculated as the number of pills dispensed divided by the number of pills to be taken each day. Timing adherence was defined as the total number of pills that were pushed through the smart blister within the timeframe of $2 \mathrm{AM}$ and $2 \mathrm{PM}$ divided by the total number of pills multiplied by $100 \%$. Participants were prescribed valsartan to be taken at 8 in the morning. For calculating timing adherence, registered events between 2 AM and 2 PM were classified as adherent events. Days of correct dosing was calculated as the number of pills that were pushed through the smart blister correctly every 24 hours divided by the total number of pills multiplied by $100 \%$. In this study, participants were prescribed valsartan once daily. Consequently, correct dosing could only be achieved if a pill was pushed through the blister once daily. In the situation that participants pushed multiple pills through the smart blister on the same day, the registered events were classified as non-adherent. Analyses were done using SPPS version 15.0 (SPSS, Inc. Chicago, Illinois).

\section{Results}

A total of 115 participants prescribed valsartan agreed to participate in this feasibility study. Thirty-nine participants used the smart blister for one episode of 28 days and declined further participation. Of the remaining 76 participants, 32 used the smart blister for 56 days, 39 for 84 days, two for 112 days, one for 140 days, and two for 168 days. In total, 245 smart blisters were used during a mean follow-up period of 60 days (standard deviation [SD] 29 days). Figure 7.2 shows chronology plots of within-day timing of drug intake of different participants included into the study.

In general, participating pharmacists considered the smart blister suitable for implementation into daily routine. Of the twenty pharmacies that were invited, two found the implementation of the smart blister into daily routine too difficult and consequently declined participation. Participants who used the smart blister found pharmacist's involvement into patient's treatment a possible advantage.

\section{Feasibility}

The feasibility was determined by registration of the functionality and the robustness of the smart blister. The registration of patient number or name, identification number of the smart blister, identification of the event (i.e. date and time of pushing the pill through the smart blister), and handing-in date and time of the smart blister was $100 \%$. However, handing-out date and time were registered in only 176 (72\%) 
smart blisters. Registration of the handing-out date and time of the remaining 69 smart blisters was not performed, because the pharmacy simply forgot to do so.

Of the 245 smart blisters, $42(17 \%)$ had at least one occurrence where it registered multiple simultaneous events. The majority (52\%) of the 42 smart blisters registered two multiple events. Six smart blisters (14\%) registered 22 to 24 multiple events.
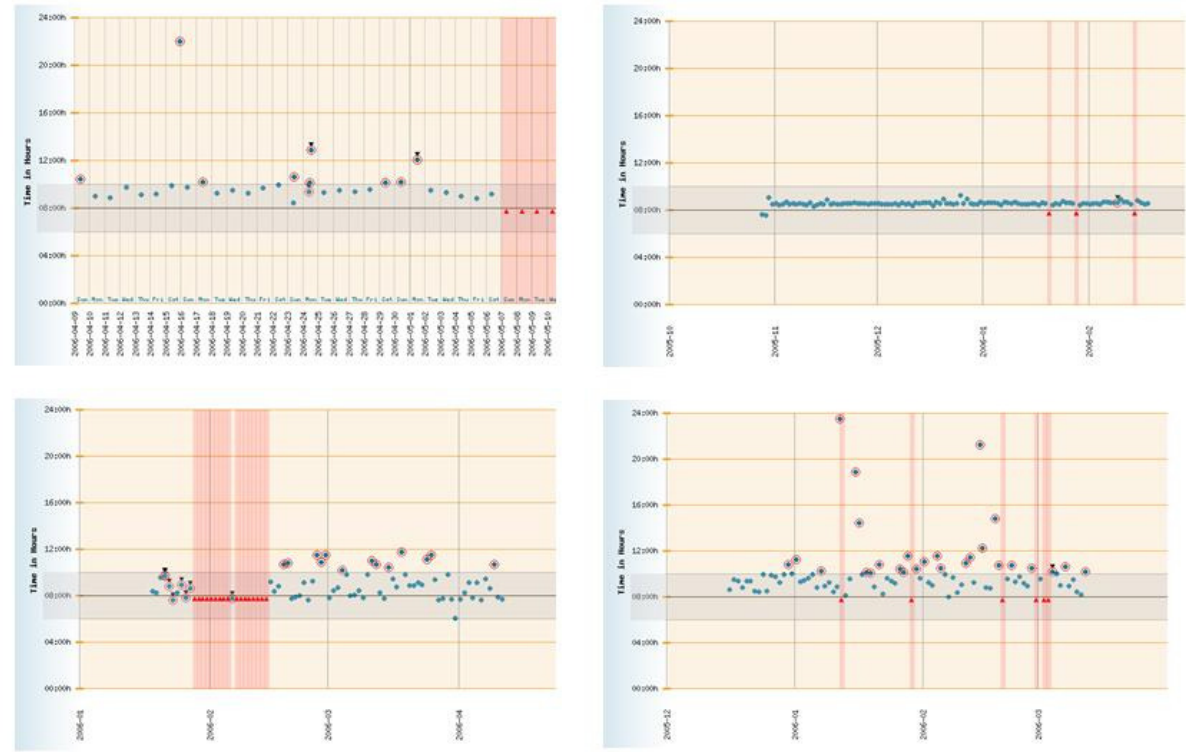

- represents dose taken; $\boldsymbol{\nabla}$ represents

multiple doses taken; $\boldsymbol{\Delta}$ represents missed

dose; O represents non compliant

Figure 7.2 Chronology plots of within-day timing of drug intake.

\section{Adherence to treatment}

For the calculation of adherence rates, we did not consider the adherence data obtained by the 42 smart blisters that registered multiple events. As a result, 203 smart blisters used by 104 participants were analyzed. Table 7.1 summarizes three different measures of adherence: intake adherence, timing adherence, and days of correct dosing. For all measures the calculated adherence rate was $>85 \%$. During the follow-up period adherence rates remained high in all participants. However, days of correct dosing and timing adherence decreased to $72 \%$ in the two participants who had been using the smart blister for 140 days. Adherence rates were comparable when stratified for the weeks of treatment (Figure 7.3). 
Table 7.1 Patient's adherence to medication.

\begin{tabular}{lc}
\hline & Mean adherence (\% [SD]) \\
\hline Intake adherence & $97.6(11)$ \\
Timing adherence & $86.9(29)$ \\
Days of correct dosing & $94.3(14)$ \\
\hline
\end{tabular}

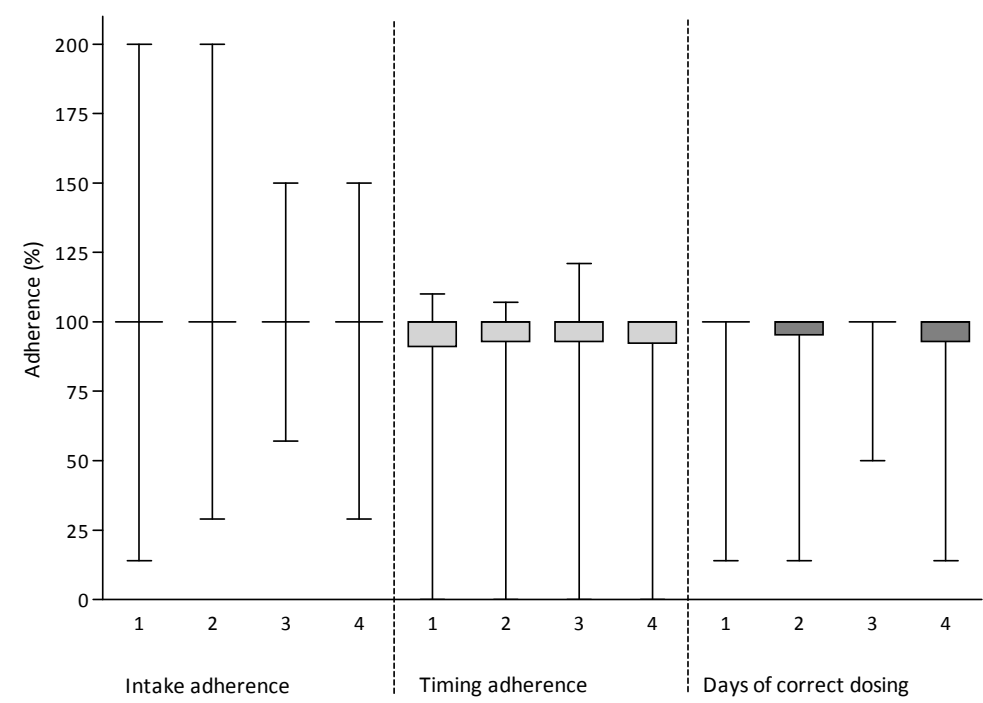

Figure 7.3 Different adherence rates stratified by weeks.

\section{Discussion}

This report is the first one to describe the application of the smart blister in a clinical setting. The results from the present study suggest that the smart blister may be a valuable tool for the measurement of adherence to medication. Nevertheless, robustness and functionality deserve further attention in order to make the smart blister a practical device.

Up till now, electronic monitoring by means of MEMS is considered to be the gold standard for assessing adherence. However, the MEMS has some drawbacks, thereby limiting the interpretation of adherence data. Theoretically, the use of MEMS could trigger the patient to open the MEMS container each day without taking medication from it (curiosity openings). On the other hand, participants could open the pill bottle less than prescribed and remove more than one dose at a time for later use (pocket dosing). Curiosity openings and pocket dosing result into adherence rates that do not reflect patient's actual intake behaviour. Recently, we showed that despite the 
appropriate openings of the MEMS or the removal of the appropriate number of pills from the MEMS containers, deviant intake behaviour was still frequently observed ${ }^{33}$. In order to interpret adherence data correctly it is therefore necessary to develop new methods for adherence monitoring.

Although a direct comparison of the smart blister with other electronic devices has not been performed yet, theoretically the smart blister may have several advantages compared to MEMS. Interpretation of possible advantages should be within the context of the applicability of the smart blister. In some countries the blister pack is normal for product packaging, the pill bottle is normal in others. A possible advantage of the smart blister could be the resemblance with the normal medication blister. The smart blister can be delivered in the normal product packaging. As a result patients may be less aware of the adherence monitoring. The measured adherence will then reflect actual adherence more precisely. Secondly, curiosity openings will be minimized. Thirdly, the smart blister makes it possible to have insight into patient's intake behaviour more precisely. In the case that a patient pushes multiple pills through the blister, the time and date of these events are registered. The MEMS, on the other hand, only registers the time and date that the pill bottle is opened, but it is unclear how many pills were removed from the bottle. Future studies are needed to examine these possible advantages.

The use of electronic devices accommodating blisters for adherence monitoring has been described earlier ${ }^{30,31}$. Those devices were able to record date and time at which a drug was removed from the blister. In addition, patients were reminded with a visual and/or audible warning when a drug was not taken, making it possible to increase adherence to treatment. The smart blister we used did not possess such a feature. Although this could be considered as a disadvantage of the smart blister, the smart blister was not designed to increase adherence to treatment. A possible advantage of the smart blister compared to the other devices may be the absence of need to design a dedicated wallet for accommodating the blisters.

In this feasibility study we found that in $17 \%$ of all smart blisters multiple events were registered. These events resulted from breaking multiple conductive tracks that were positioned horizontally in the smart blister. By pushing one pill through the blister it was possible that other conductive tracks were damaged. In six smart blisters more than 22 events were registered at the exact same time. An explanation for this finding could be that the smart blister was fully ruptured by the patient from the cardboard wallet. These findings indicate that the electronics of the smart blister are the weakest part in the design and should be ameliorated to make this blister a reliable tool for assessing adherence to treatment.

The results of this study should be interpreted within the context of its limitations. First of all, selection of participants may have limited the generalizibility of the results. Since our population was recruited among twenty pharmacies in The Netherlands, we tried to recruit a population that resembled the general population at best. Nevertheless, the possibility exists that the introduction of new, electronic devices in 
patient's treatment attracted participants, who do not represent the general population. Secondly, patients in our study had used the smart blister for a mean period of 60 days. Thirty-four percent of the patients had used the smart blister for only 28 days. This may imply that the data are weighed to those who continued the study with further refills of the medication. Although it is questionable whether both limitations had an effect on the feasibility of the smart blister, the effect on adherence rates should be explored in future studies that follow patients for a longer period than in our study.

\section{Conclusion}

Taking our data together, we may conclude that the smart blister is a promising method for adherence measurement. The smart blister may be a valuable tool for drugs of which missed doses have an enormous influence on efficacy, such as antineoplastic drugs, antiretroviral drugs, and antibiotics. However, in order to produce robust and easy to use smart blisters the blister needs further improvement. 


\section{References}

1. Mar J, Rodriguez-Artalejo F. Which is more important for the efficiency of hypertension treatment: hypertension stage, type of drug or therapeutic compliance? J Hypertens 2001;19:149-55.

2. Hughes DA, Bagust A, Haycox A, Walley T. The impact of non-compliance on cost-effectiveness of pharmaceuticals: a review of the literature. Health Economics 2001;10:601-15.

3. Urquhart J. Partial compliance in cardiovascular disease: risk implications. Br J Clin Pract Suppl 1994;73:2-12.

4. Urquhart J. Patient non-compliance with drug regimens: measurement, clinical correlates, economic impact. Eur Heart J 1996;17 Suppl A:8-15.

5. The sixth report of the joint national committee on prevention, detection, evaluation, and treatment of high blood pressure. Arch Int Med 1997;157:2413-56.

6. Ho PM, Magid DJ, Shetterly SM, Olson KL, Maddox TM, Peterson PN, Masoudi FA, Rumsfeld JS. Medication nonadherence is associated with a broad range of adverse outcomes in patients with coronary artery disease. Am Heart J 2008;155:772-9.

7. Ho PM, Magid DJ, Masoudi FA, McClure DL, Rumsfeld JS. Adherence to cardioprotective medications and mortality among patients with diabetes and ischemic heart disease. BMC Cardiovasc Disord 2006;6:48-56.

8. Ho PM, Rumsfeld JS, Masoudi FA, McClure DL, Plomondon ME, Steiner JF, Magid DJ. Effect of medication nonadherence on hospitalization and mortality among patients with diabetes mellitus. Arch Intern Med 2006;166:1836-41.

9. Gehi AK, Ali S, Na B, Whooley MA. Self-reported medication adherence and cardiovascular events in patients with stable coronary heart disease: the heart and soul study. Arch Intern Med 2007;167:1798-803.

10. Rasmussen JN, Chong A, Alter DA. Relationship between adherence to evidence-based pharmacotherapy and long-term mortality after acute myocardial infarction. JAMA 2007;297:177-86.

11. Vrijens B, Vincze G, Kristanto P, Urquhart J, Burnier M. Adherence to prescribed antihypertensive drug treatments: longitudinal study of electronically compiled dosing histories. BMJ 2008;336:1114-7.

12. Van Wijk BL, Shrank WH, Klungel OH, Schneeweiss S, Brookhart MA, Avorn J. A cross-national study of the persistence of antihypertensive medication use in the elderly. J Hypertens 2008;26:145-53.

13. Caro JJ, Salas M, Speekman JL, Raggio G, Jackson JD. Persistence with treatment for hypertension in actual practice. Can Med Assoc J 1999;160:31-7.

14. Bourgalt $C$, Sénécal M, Brisson M, Marentette MA, Grégoire JP. Persistence and discontinuation patterns of antihypertensive therapy among newly treated patients: a population-based study. J Hum Hypertens 2005;19:607-13.

15. Bates TR, Connaughton VM, Watts GF. Non-adherence to statin therapy: a major challenge for preventive cardiology. Expert Opin Pharmacother 2009;10:2973-85.

16. Liberopoulos EN, Florentin M, Mikhailidis DP, Elisaf MS Compliance with lipid-lowering therapy and its impact on cardiovascular morbidity and mortality. Expert Opin Drug Saf 2008;7:717-25.

17. Cramer JA, Benedict A, Muszbek N, Keskinaslan A, Khan ZM. The significance of compliance and persistence in the treatment of diabetes, hypertension and dyslipidaemia: a review. Int J Clin Pract 2008;62:76-87.

18. Schmittdiel JA, Uratsu CS, Karter AJ,. Why don't diabetes patients achieve recommended risk factor targets? Poor adherence versus lack of treatment intensification. J Gen Intern Med 2008;23:588-94.

19. Burnier M, Schneider MP, Chioléro A, Stubi CL, Brunner HR. Electronic compliance monitoring in resistant hypertension: the basis for rational therapeutic decision. J Hypertens 2001;19:335-41.

20. Bertholet N, Favrat B, Fallab-Stubi CL, Brunner HR, Burnier M. Why objective monitoring of compliance is important in the management of hypertension. J Clin Hypertens (Greenwich) 2000;2:258-62.

21. Farmer KC. Methods for measuring and monitoring medication regimen adherence in clinical trials and clinical practice. Clinical Therapeutics 1999;21:1074-90.

22. Cramer JA, Mattson RH, Prevey ML, Scheyer RD, Ouellette VL. How often is medication taken as prescribed? A novel assessment technique. JAMA 1989;261:3272-77. 
23. Rudd P, Ahmed S, Zachary V, Barton C, Bonduelle D. Improved compliance measures: applications in an ambulatory hypertensive drug trial. Clin Pharmacol Ther 1990;48:676-85.

24. Urquhart J. The electronic medication event monitor. Lessons for pharmacotherapy. Clin Pharmacokinet 1997;32:345-56.

25. Osterberg L, Blaschke T. Adherence to medication. New Eng J Med 2005;353:487-97.

26. Pullar T, Kumar S, Tindall H, Feely M. Time to stop counting the tablets? Clin Pharmacol Ther. 1989;46:163-8.

27. Matsui D, Hermann C, Klein J, Berkovitch M, Olivieri N, Koren G. Critical comparison of novel and existing methods of compliance assessment during a clinical trial of an oral iron chelator. J Clin Pharmacol 1994;34:944-49.

28. Steiner JF, Prochazka AV. The assessment of refill compliance using pharmacy records: methods, validity, and applications. J Clin Epidemiol 1997;50:105-16.

29. Oakley D, Potter L, de Leon-Wong E, Visness C. Oral contraceptive use and protective behaviour after missed pills. Fam Plann Perspect 1997;29:277-9, 287.

30. Santschi V, Wuerzner G, Schneider MP, Bugnon O, Burnier M. Clinical evaluation of IDAS II, a new electronic device enabling drug adherence monitoring. Eur J Clin Pharmacol 2007;63:1179-84.

31. Yamada H, Nakashima M. New electronic device for monitoring medication compliance. Am J Health Syst Pharm 2003;60:1910-1.

32. Jekle C, Krämer I. OtCM (Objective therapy Compliance Measurement): smart blister packages for measuring patient compliance. Hospital Pharmacy Europe 2008;40:47-50.

33. van Onzenoort HA, Verberk WJ, Kessels AG, Kroon AA, Neef C, van der Kuy PH, de Leeuw PW. Assessing medication adherence simultaneously by electronic monitoring and pill count in patients with mild to moderate hypertension. Am J Hypertens 2010;23:149-54. 


\section{Chapter 8}

The importance of adherence data for the approval of antihypertensive drugs by regulatory authorities

A review of marketing authorization applications

Hein AW van Onzenoort, Peter GM Mol, Christine C Gispen-de Wied, Willem J Verberk, Paul-Hugo M van der Kuy, Cees Neef, Peter W de Leeuw Submitted 


\section{Abstract}

\section{Background}

The evaluation of benefit and risk of antihypertensive drugs in marketing authorization application (MAA) files may be affected by non-adherence in the clinical trial setting.

\section{Methods}

We searched the Dutch Medicines Evaluation Board (CBG-MEB) database for antihypertensive drugs approved between January 1, 2000 and March 2011. Drugs of interest were new active substances and fixed dose combinations of two or more known active substances. Potentially relevant registration files were screened for clinical information regarding drugs' efficacy and safety profiles with respect to adherence data.

\section{Results}

Searches identified ten registered antihypertensive drugs. In all clinical trials adherence was measured by pill count. When reported mean adherence was nearly perfect (>98\%). However, in 43 of the 83 clinical trials (52\%), a history of nonadherence was an exclusion criterion for a patient's participation. In eight registration files a minimal adherence level was defined (range 70-80\%). Patients with an adherence level below this minimal level were classified as protocol violators and were excluded from randomization (43 clinical trials), were excluded from the per protocol (PP) analysis (32 clinical trials) or withdrawn from further participation (25 clinical trials).

\section{Conclusion}

Drugs' efficacy and safety data for MAAs are not confounded by adherence levels. The excellent adherence rates observed in clinical trials for MAAs are a consequence of the specific study design of those trials. Including patients in clinical trials who represent a real-life setting should be made mandatory for pharmaceutical companies. 


\section{Introduction}

Poor adherence to treatment remains one of the major challenges in the management of hypertension and may contribute to increased morbidity, mortality and $\operatorname{costs}^{1-5}$. It is estimated that at least $50 \%$ of the patients with hypertension do not take their antihypertensive medication as prescribed ${ }^{6}$. Moreover, up to $50 \%$ of the patients with hypertension discontinue treatment within one year after initiation ${ }^{7-10}$. Regulatory authorities rely on randomised controlled trials (RCTs) for the benefit/risk evaluation of new drugs. In such trials, non-adherence can be a major threat for obtaining statistical power to detect intervention effects. Patients in the experimental arm who discontinue treatment before the assigned protocol ends often experience more adverse drug events (ADEs) or fewer benefits than patients in the control arm ${ }^{11}$. As a consequence, patient groups remaining on the assigned treatment may become imbalanced with confounded results as the trial progresses ${ }^{11-14}$.

Statistical approaches such as intention-to-treat (ITT), on-treatment, and per-protocol (PP) analyses are available to minimize the influence of non-adherence in the analysis of data from RCTs ${ }^{11-14}$. However, these approaches do not answer the question why and to which extent patients are non-adherent, which is important for regulatory authorities when reviewing a new drug for its efficacy and safety. So far, no information is available with respect to the availability of adherence data in marketing authorization application (MAA) files, nor is it clear whether the obtained adherence results in RCTs influence study outcomes. To investigate this, we reviewed MAA files of antihypertensive drugs approved by the Dutch Medicines Evaluation Board (CBGMEB), with particular emphasis on adherence data.

\section{Methods}

\section{Data sources and extraction}

We searched the CBG-MEB database for all antihypertensive drugs that received market approval between January 1, 2000 and March 2011. Antihypertensive drugs were identified through their Anatomical Therapeutic Chemical (ATC) classification code. The ATC-codes of interest were C02 (antihypertensive drugs), C03 (diuretics), C04 (peripheral vasodilators), C07 (beta blocking agents), C08 (calcium channel blockers), C09 (agents acting on the renin-angiotensin system). The drugs of interest consisted of new active substances and fixed dose combinations of two or more new or known active substances. Thus, generic medicinal products of which the branded drugs had been registered before Jan 12000 were excluded. Drugs for which no efficacy and safety data were generated were excluded as well. 


\section{Review of registration dossiers}

Potentially relevant MAA files were screened for clinical information regarding drugs' efficacy and safety profiles. We screened the clinical overview, the Integrated Summary of Efficacy (ISE), and the Integrated Summary of Safety (ISS) of each drug. The ISE and ISS are detailed integrated analyses that comprehensively examine the effectiveness and safety data from individual clinical studies ${ }^{15,16}$. Data were extracted from these files according to a structured collection form (Appendix 8.1). Study characteristics, including protocol for analyses of data, measurement of adherence and, if applicable, adherence results were extracted from the clinical overview section and the ISE. The number of adverse drug events and discontinuation rates due to adverse drugs events and non-adherence were extracted from the pooled safety analysis in the clinical overview section and the ISS. Any updates in clinical data were further screened according to the above mentioned form.

\section{Adherence and discontinuation rate}

We distinguished between two aspects of drug intake behaviour: the quality of execution and the degree of continuation of patients' dosing regimen ${ }^{7}$. The former is expressed by adherence to drug treatment, and can eventually lead to discontinuation of study treatment (i.e. the latter aspect). We hypothesized that non-adherence may result into early withdrawal from the trial.

As fixed dose combinations of two or more active substances may increase adherence to treatment, when compared to individual drugs ${ }^{17-19}$, we also reviewed whether clinical trials investigated this hypothesis.

\section{Results}

Searches identified 18 antihypertensive drugs that received market approval between January 1, 2000 and March 2011. Of these, eight drugs were excluded (Figure 8.1). Seven of these were known active substances, of which five were fixed dose combinations of two known active substances. These seven products received market approval on bioequivalence data only while no efficacy and safety data had been generated. Of one drug no information could be found in the CBG-MEB database. Consequently, ten complete registration files were available. Two new active substances were marketed after January 1, 2000. The remaining drugs were single pill combinations of two $(n=6)$ or three active substances $(n=2)$.

Table 8.1 shows the characteristics of the included drugs. The number of trials available for the evaluation of clinical efficacy ranged between 1 and 19 trials per drug, totalling 83 clinical trials. The trials had been performed in six continents, though most of them in Europe $(n=59)$ and North America $(n=33)$. All dossiers contained data on long-term follow-up, to a maximum of 24 months. Sixty-five trials 
were Phase III trials. Twenty-eight trials investigated drug's efficacy compared to placebo; 31 trials involved an active comparator. In 43 of the 83 clinical trials (52\%), a history of non-adherence was an exclusion criterion for patient's participation. All patients randomised to treated groups were encouraged to adhere to the prescribed treatment regimen. In eight registration files a minimal adherence level was prespecified (in general between 70 and $80 \%$, which was verified by pill count; Table 8.2 ). Patients whose adherence level was below this minimal level were classified as protocol violators and were excluded from randomization when the study design included a (placebo) run-in phase ( 43 clinical trials). In 32 clinical trials, poor adherers were excluded from the per protocol (PP) analysis, or could be withdrawn from further participation if already randomised and treated ( 25 clinical trials). Some trials dealt with adherence in more than one way, which is why the numbers do not add up to 83 trials. In the remaining ones, poor adherers were not taken into account.

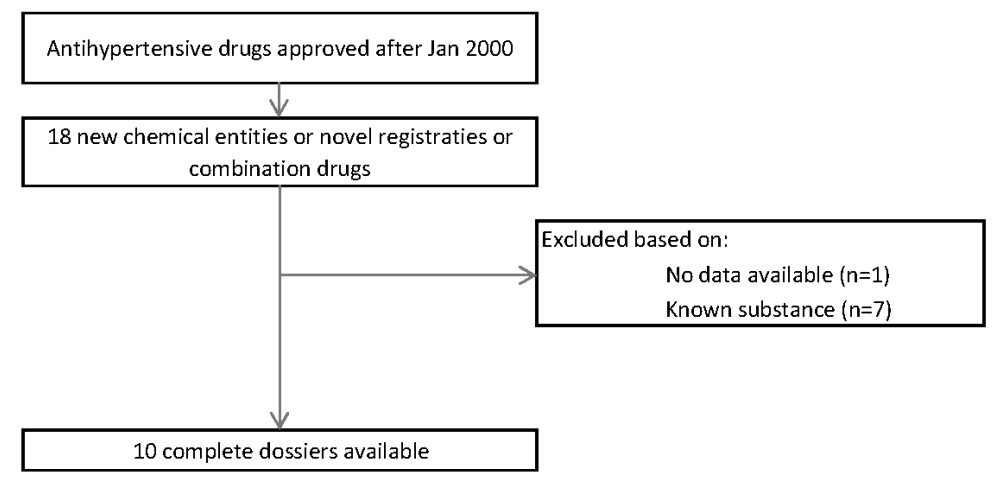

Figure 8.1 Flow diagram of included medicinal products.

In the clinical overview section of the MAA files no information regarding adherence was presented, except for the application of lercanidipine/enalapril in which adherence was reported as high (98\%) during the long-term phase of the pivotal trials. Adherence results were, however, presented in the ISE and ISS sections. In all clinical trials adherence was measured by pill count. Although mean adherence was not specified in all clinical trials, mean adherence across trials was at least $98 \%$ (standard deviation (SD) $=0.82 \%$; Table 8.2 ).

Of the ten included drugs, eight were fixed dose combinations of two or three active substances. In the registration files of these drugs, increasing adherence by combining different substances in a fixed dose was hypothesized as a possible advantage compared to the individual drugs. We investigated whether this hypothesis was subject to research in the clinical trials. No single trial investigated this subject specifically. 


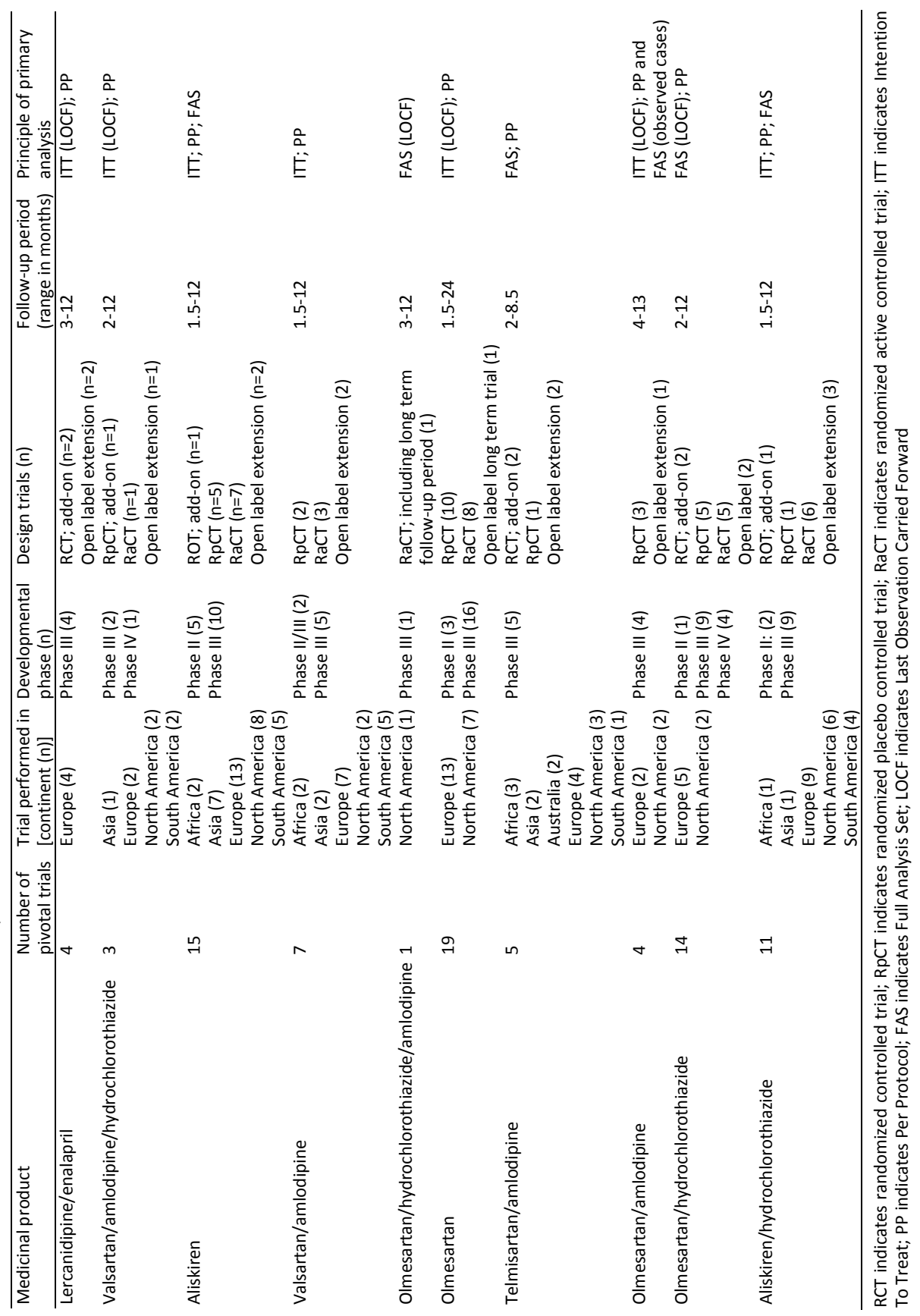


Table 8.2 Adherence results.

\begin{tabular}{|c|c|c|c|}
\hline Medicinal product & $\begin{array}{l}\text { Method of } \\
\text { adherence } \\
\text { measurement }\end{array}$ & $\begin{array}{l}\text { Mandatory minimal } \\
\text { adherence level for PP } \\
\text { analysis }\end{array}$ & $\begin{array}{l}\text { Adherence } \\
\text { level }\end{array}$ \\
\hline Lercanidipine/enalapril & Pill count & $80 \%$ & $98.5 \%{ }^{*}$ \\
\hline Valsartan/amlodipine/ hydrochlorothiazide & $\begin{array}{l}\text { Pill count } \\
\text { Self-report }\end{array}$ & $\begin{array}{l}80 \% \text { or drug } \\
\text { interruption }<3 \\
\text { consecutive days }\end{array}$ & $98.5 \% "$ \\
\hline Aliskiren & $\begin{array}{l}\text { Pill count } \\
\text { Self-report }\end{array}$ & $70 \%$ to $80 \%$ & $\begin{array}{l}99.8 \% \text { with an } \\
\text { adherence } \\
\text { level }>70 \%\end{array}$ \\
\hline Valsartan/amlodipine & Pill count & Not specified & Not specified \\
\hline Olmesartan/hydrochlorothiazide/amlodipine & Pill count & $\begin{array}{l}\text { No minimal level } \\
\text { specified for PP analysis }\end{array}$ & $98.3 \%$ \\
\hline Olmesartan & $\begin{array}{l}\text { Pill count } \\
\text { Self-report }\end{array}$ & $80 \%$ & $100.7 \%^{ \pm}$ \\
\hline Telmisartan/amlodipine & Pill count & $80 \%$ & $98.9 \%^{ \pm}$ \\
\hline Olmesartan/amlodipine & Pill count & $70 \%$ & $98.6 \%^{\zeta}$ \\
\hline Olmesartan/hydrochlorothiazide & Pill count & $75 \%$ to $80 \%$ & $98.8^{\zeta}$ \\
\hline Aliskiren/hydrochlorothiazide & Pill count & $70 \%$ to $80 \%$ & $\begin{array}{l}99.7 \% \text { with an } \\
\text { adherence } \\
\text { level }>70 \%\end{array}$ \\
\hline
\end{tabular}

"Data derived from two trials; " data derived from one trial; ${ }^{ \pm}$data derived from five trials; ${ }^{\zeta}$ data derived from six trials

Table 8.3 shows a summary of the incidence of ADEs and discontinuation rates related to non-adherence. These data were derived from the clinical overview sections. According to the pooled safety analysis, the incidence of ADEs of five drugs was higher in the experimental group than in the comparator group. Discontinuation rates for six drugs were higher in the experimental group than in the comparator group. Only one registration file specified non-adherence as a cause for discontinuation. Of five other drugs (telmisartan/amlodipine, olmesartan/hydrochlorothiazide/amlodipine, lercanidipine/enalapril, olmesartan, olmesartan/hydrochlorothiazide) the clinical overview section did not report discontinuation rates related to non-adherence. The ISE and ISS did, however, report discontinuation rates. For telmisartan/amlodipine, olmesartan/hydrochlorothiazide/amlodipine, lercanidipine/enalapril, olmesartan, and olmesartan/hydrochlorothiazide) it was reported that 13 patients ( $0.9 \%$; based on one trial), eight patients $(1.2 \%)$, one patient $(0.6 \%$; based on one trial), 12 patients $(0.5 \%$; based on six trials), and three patients (0.3\%; based on 2 trials) respectively, prematurely discontinued treatment. 


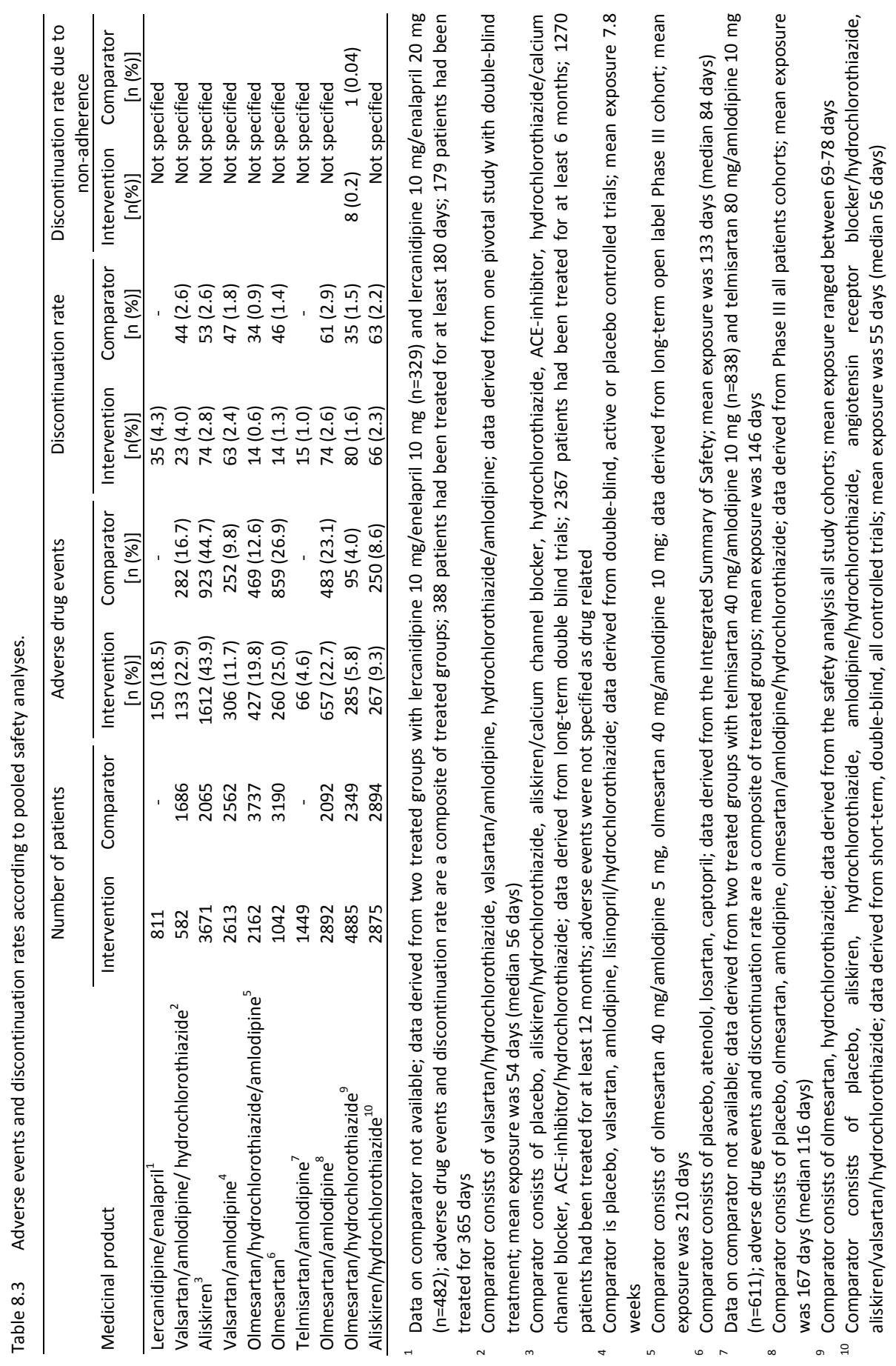




\section{Discussion}

We reviewed MAA files of antihypertensive drugs on the availability of adherence data. Adherence data were reported in $90 \%$ of all marketing authorization files. When reported, mean adherence to treatment was at least $98 \%$. In a substantial number of trials, patients with a history of non-adherence were excluded from participation, patients who were classified as non-adherent during the run-in phase were excluded from randomization, and patients who were non-adherent during the clinical trial were withdrawn from the PP analysis.

RCTs are crucial for the scientific evaluation of therapies, and they are mandatory for drug approvals by regulatory authorities. Preferably, new drugs should be compared to an active control group which is in line with recommended therapy ${ }^{20}$. This is important for demonstrating efficacy and safety of a new drug, but also for assessing its place in therapy in comparison with existing drugs ${ }^{20}$. From this respect it is important that patients who participate in a clinical trial fully adhere to prescribed study treatment. The results of our review indicate that non-adherence was unlikely to occur. Consequently, efficacy effects likely reflect the true drug effect in the treated participants.

In contrast, it is generally acknowledged that non-adherence and early discontinuation of treatment form a major barrier for long-term hypertension treatment. Indeed, the World Health Organization stated that non-adherence severely compromises the effectiveness of treatment ${ }^{6}$. It is, therefore, questionable whether the observed efficacy in the clinical trials submitted for MAA can be extrapolated to the population who we know is less adherent than the participants in clinical trials as shown in our review. Uijen and colleagues also showed that participants in a hypertension trial are more adherent than hypertensive patients in general practice ${ }^{21}$. Moreover, we recently showed that patients with hypertension who participated in a clinical trial showed a high adherence rate before the start of the trial ${ }^{22}$. So there seems to be a methodological struggle between external and internal validity. As our review indicates, several methodological aspects compromise external validity. First of all, the majority of the trials excluded patients with a history of non-adherence from participation. Secondly, clinical trials in which a placebo run-in phase preceded randomization excluded patients who were non-adherent during the run-in phase. An advantage of applying a run-in period may be that the number of drop-outs after randomization is reduced. It allows patients to reconsider their participation and it permits researchers to gauge to what extent participants will adhere ${ }^{23,24}$. However, run-in periods have been criticized as being non-ethical, limiting successful masking, and confounding treatment effects with withdrawal effects ${ }^{24,25}$. Thirdly, patients who were non-adherent during the clinical trial period were possibly ineligible for further participation. So, treating physicians should be aware that adherence rates observed in clinical trials do not represent a 'real-life setting' and that selection of highly adherent patients may overestimate benefits but likely also harm of new drugs. 
Although the results showed high adherence rates, non-adherence could be a major threat for obtaining statistical power to detect intervention effects. Patients in the experimental arm who discontinue treatment before the assigned protocol ends often experience more ADEs or fewer benefits than patients in the control $\mathrm{arm}^{11}$. As a consequence, patient groups remaining on the assigned treatment will become imbalanced and the primary analysis of data can then be severely confounded when the trial progresses ${ }^{11-14}$. In the clinical overview of only one drug non-adherence was reported as a reason for early trial withdrawal. The number of patients who were withdrawn from further treatment was, however, very small and clinically not meaningful.

Of the ten included drugs, eight were fixed dose combinations of two or more active substances. We excluded five fixed dose combinations of two active substances from our review since only bio-equivalence data were available. An advantage of fixed dose combinations may be a higher adherence rate than what is observed with the individual substances ${ }^{17-19}$. All MAA files underscore the importance of adherence to treatment and the possible positive effect of a single pill combination on adherence. However, MAA files do not support this with data.

Post-marketing surveillance is an important aspect for drugs to become more universally recommended. If side-effects of a drug result into early discontinuation of treatment, efficacy of that drug will be influenced adversely. So, the expected gain in effectiveness of a new drug compared to usual treatment may be very limited. The current practice of registration trials may, therefore, even violate ethical standards. We recommend that pharmaceutical companies should make every effort to include patients in clinical trials for MAAs who represent a real-life setting. In addition, MEBs should take adherence results more into consideration when assessing MAAs.

A limitation of our study is that we investigated antihypertensive drugs only. Whether our results are also applicable to other drugs and conditions in which non-adherence is a determinant of uncontrolled disease status is not known. This should be elucidated in future research.

Taking our data together, we may conclude that a drug's efficacy and safety profile is not confounded by non-adherence. The excellent adherence rates observed in clinical trials for MAAs are a consequence of the specific study design of those trials. These observations limit the extrapolation of efficacy and safety results into clinical practice. In terms of MAAs, including patients in clinical trials who represent a real-life setting should be made mandatory for pharmaceutical companies. 


\section{References}

1. Mar J, Rodriguez-Artalejo F. Which is more important for the efficiency of hypertension treatment: hypertension stage, type of drug or therapeutic compliance? J Hypertens 2001;19:149-55.

2. Hughes DA, Bagust A, Haycox A, Walley T. The impact of non-compliance on cost-effectiveness of pharmaceuticals: a review of the literature. Health Economics 2001;10:601-15.

3. Urquhart J. Partial compliance in cardiovascular disease: risk implications. $\mathrm{Br} \mathrm{J}$ Clin Pract Suppl 1994;73:2-12.

4. Urquhart J. Patient non-compliance with drug regimens: measurement, clinical correlates, economic impact. Eur Heart J 1996;17 Suppl A:8-15.

5. The sixth report of the joint national committee on prevention, detection, evaluation, and treatment of high blood pressure. Arch Int Med 1997;157:2413-56.

6. Sabate E. Adherence to long term therapies: evidence for action. Geneva:World Health Organization, 2003.

7. Vrijens B, Vincze G, Kristanto $P$, Urquhart J, Burnier M. Adherence to prescribed antihypertensive drug treatments: longitudinal study of electronically compiled dosing histories. BMJ 2008;336:1114-7.

8. Van Wijk BL, Shrank WH, Klungel OH, Schneeweiss S, Brookhart MA, Avorn J. A cross-national study of the persistence of antihypertensive medication use in the elderly. J Hypertens 2008;26:145-53.

9. Caro JJ, Salas M, Speekman JL, Raggio G, Jackson JD. Persistence with treatment for hypertension in actual practice. Can Med Assoc J 1999;160:31-7.

10. Bourgalt $C$, Sénécal $M$, Brisson M, Marentette MA, Grégoire JP. Persistence and discontinuation patterns of antihypertensive therapy among newly treated patients: a population-based study. J Hum Hypertens 2005;19:607-13.

11. Greenland S, Lanes S, Jara M. Estimating effects from randomized trials with discontinuations: the need for intent-to-treat design and G-estimation. Clin Trials 2008;5:5-13.

12. Fergusson D, Aaron SD, Guyatt G, Hébert P. Post-randomisation exclusions: the intention to treat principle and excluding patients from the analysis. BMJ 2002;325:652-4.

13. Jo B. Statistical power in randomized intervention studies with noncompliance. Psychol Methods 2002;7:178-93.

14. Sheng D, Kim MY. The effects of non-compliance on intent-to-treat analysis of equivalence trials. Statist Med 2006;25:1183-99.

15. http://www.fda.gov/downloads/Drugs/GuidanceComplianceRegulatoryInformation/Guidances/UCM 136174.pdf. Consulted on October 16, 2011.

16. http://www.ema.europa.eu/docs/en_GB/document_library/Scientific_guideline/2009/09/WC500002 724.pdf. Consulted on October 16, 2011.

17. Brixner DI, Jackson KC $2^{\text {nd }}$, Sheng X, Nelson RE, Keskinaslan A. Assessment of adherence, persistence, and costs among valsartan and hydrochlorothiazide retrospective cohorts in free- and fixed-dose combinations. Curr Med Res Opin 2008;24:2597-607.

18. Bangalore S, Kamalakkannan G, Parkar S, Messerli FH. Fixed-dose combinations improve medication compliance: a meta-analysis. Am J Med 2007;120:713-9.

19. Gerbino PP, Shoheiber O. Adherence patterns among patients treated with fixed-dose combination versus separate antihypertensive agents. Am J Health Syst-Pharm 2007;64:1279-83.

20. Van Luijn JC, van Loenen AC, Gribnau FW, Leufkens HG. Choice of comparator in active control trials of new drugs. Ann Pharmacother 2008;42:1605-12.

21. Uijen AA, Bakx JC, Mokkink JGA, van Weel C. Hypertension patients participating in trials differ in many aspects from patients treated in general practices. J Clin Epidemiol 2007;60:330-5.

22. Van Onzenoort HAW, Menger FE, Neef C, Verberk WJ, Kroon AA, de Leeuw PW, van der Kuy P-HM. Participation in a clinical trial enhances adherence and persistence to treatment. Hypertension 2011;58:573-8.

23. Ulmer M, Robinaugh D, Friedberg JP, Lipsitz SR, Natarajan S. Usefulness of a run-in period to reduce drop-outs in a randomized controlled trial of a behavioural intervention. Contemp Clin Trials 2008;29:705-10.

24. Berger VW, Vali B. Intent-to-randomize corrections for missing data resulting from run-in selection bias in clinical trials for chronic conditions. J Biopharm Stat 2011;21:263-70. 
25. Britton A, McKee M, Black N, McPherson K, Sanderson C, Bain C. Threats to applicability of randomized trials: exclusions and selective participation. J Health Serv Res Policy 1999;4:112-21. 


\section{Appendix 8.1 Data collection form}

Name of drug:

Study ..... of .....

Generic name of drug:

\section{Research:}

$\square$ Phase II $\square$ Phase III $\square$ Phase IV

Is adherence measured in the submitted study? $\quad \square$ Yes $\square$ No If Yes, - which method is used?

$\square$ Electronic monitoring $\square$ Pill counts $\square$ Self-report $\square$ Other: ...

- how high is the adherence in the study?

Intervention(\%) Comparison(\%) P-value

How high is the drop-out rate in the study?

Intervention[n(\%)] Comparison[n(\%)] P-value

Is non-adherence the reason for drop-out? $\quad \square$ Yes $\square$ No $\square$ Not mentioned

How many ADEs are registered in the study?

Intervention[n(\%)] Comparison[n(\%)] P-value

Are ADEs the reason for non-adherence? $\quad \square$ Yes $\square$ No

Which protocol is followed for the analysis of data?

$\square$ intention-to-treat $\square$ per-protocol $\square$ on-treatment $\square$ as-treated $\square$ other:...

Are adherence data taken into account when analyzing the results?

Are adherence data taken into account when interpreting the results? $\quad \square$ Yes $\square$ No If Yes, how? ... 


\section{Chapter 9}

General discussion 
$138 \mid$ Chapter 9 
The objectives of this thesis were to assess the methodological aspects and the consequences of (non-)adherence in patients with hypertension and to provide suggestions for new strategies to measure adherence and for interventions aimed at improving adherence. We performed several studies to investigate strategies for increasing adherence to treatment (Chapter 2 and 4) and blood pressure control (Chapter 3). The methodological aspects of adherence measurement and nonadherence are part of all chapters, though these are investigated more specifically in Chapter 5, 6, 7, and 8.

In this general discussion, we will first focus on methods for improving adherence. Subsequently, we describe a few methods which are available for adherence measurement and the level of adherence that is minimally required to obtain an adequate blood pressure reduction. Finally, we will discuss the methodological aspects of the studies in this thesis and provide suggestions for further research.

\section{Interventions for improving adherence to treatment and blood pressure control}

The aim of Chapter 2 was to systematically review the literature on successful intervention strategies for improving adherence to treatment in patients with hypertension. Several systematic reviews and meta-analyses found that some interventions were successful in improving adherence, whilst others had only a limited effect ${ }^{1-6}$. We found many studies that addressed the effectiveness of adherence improving strategies in hypertension. However, most of these strategies did not result into better adherence. An important observation of our review was that most interventions were complex and consisted of multiple intervention strategies. This makes it difficult to assess the effect of single interventions.

In Chapter 2, we also hypothesized that the complexity of non-adherence could be explained better by applying the conceptual distinction of 'unintentional' and 'intentional' non-adherence in patients who are non-adherent'. Unintentional nonadherence refers to barriers to patients taking medicines as prescribed; intentional adherence refers to deliberate decisions patients may take to adjust their medication use. In the latter case, patients may modify the prescribed drug regimen by altering the dose or frequency of the medication or only take medication when having symptoms of the disease, or discontinue treatment at all. These reasoned actions, or behavioural intentions, are influenced by attitudes and subjective norms ${ }^{8}$ and may be reliable predictors for non-adherence. Barriers to patients taking medicines resulting in unintentional non-adherence arise from capacity and resource limitations of the patient, such as memory, knowledge or dexterity deficiencies ${ }^{7}$. Ideally, changing patients' health behaviour makes them more apt to adhere and persist to prescribed medication. In all likelihood, this works better when there is an external incentive that moderates patients' perception of the disease and its treatment than when this 
external incentive is wanting. Unfortunately, we did not find effective interventions targeting intentional or unintentional non-adherence. The number of interventions that was considered to be successful was comparable in all categories. Therefore, we believe that interventions targeting unintentional non-adherence may modify intentional non-adherence as well. Consequently, differences between intentional and unintentional non-adherence may be difficult, and perhaps even impossible, to distinguish. On the other hand, we believe that the conceptual distinction between unintentional and intentional non-adherence may be better applied to individual patients, since they have different perceptions about the disease and its treatment. Therefore, it may be difficult to apply adherence improving strategies to the general population. Future studies should focus on the individual patient's behavioural intentions, barriers and subjective norms.

In Chapter 3 and 4 we evaluated in our own clinic the effect of two single intervention strategies: the effect of electronic monitoring on blood pressure control (Chapter 3) and the effect of self-measurement of blood pressure (SBPM) on adherence to treatment (Chapter 4).

Several reports suggest that electronic monitoring could improve adherence and, consequently, blood pressure control as well ${ }^{9-13}$. We found that adherence levels between the intervention group, in which adherence was measured both electronically and by pill count, and the control group, in which adherence was measured by pill count only, were comparable. In both groups adherence was $>90 \%$. In addition, blood pressure reductions were comparable in both groups. We concluded that the effect of electronic monitoring of adherence on blood pressure control is limited.

In Chapter 4 we investigated the effect of SBPM on adherence to treatment. Implementation of SBPM in the routine diagnostic and therapeutic follow-up could be of great value in the management of hypertension. Several reports suggest that SBPM may increase adherence to prescribed drugs ${ }^{14-18}$ and the results of our study seem to corroborate that notion. However, the clinical significance of our observations was limited since adherence levels among participants were already as high as $90 \%$.

\section{Which method should be used for adherence measurement?}

At present there are numerous methods available for measuring adherence to treatment. Although more than 30 years ago Rudd ${ }^{19}$ already described the criteria which an ideal method should meet, still no single measurement fulfils all these criteria. Nevertheless, measuring adherence to treatment by electronic monitoring is generally considered to be the gold standard ${ }^{12,13,20-23}$. Therefore, we measured adherence to treatment electronically by means of the Medication Event Monitoring System (MEMS, Aardex, Switzerland). However, the use of MEMS could trigger the 
patient to open the MEMS container each day without taking medication from it. As a result, adherence would appear to be sufficient, yet the outcome variable, e.g. effect on blood pressure control, will be disappointing. On the other hand, patients could open the pill bottle less than prescribed and spare up extra doses whilst ingesting the medication at the correct time (pocket dosing). This behaviour will lead to an underestimation of adherence determined by MEMS, even though blood pressure may at times be better controlled. The aim of the study which is described in Chapter 5 was to investigate adherence patterns in more detail by comparing and matching MEMS data with pill count data and by assessing the effect on blood pressure reduction in patients with mild to moderate hypertension. The results from that study indicate that the interpretation of MEMS data only would lead to false negative and false positive conclusions in $39 \%$ of the patients. Deviant intake behaviour had no effect on the degree of blood pressure reductions, which in turn could be explained by the high adherence rate observed among the patients. We conclude that besides MEMS registration counting of pills is required to identify the true non-adherers.

It is important to realize that MEMS data refer to the monitoring of the exact dates and times the patient is concerned with his or her medication. It does not give insight into the actual taking of the medication. Given the results described in Chapter 5 , we investigated the feasibility of the smart blister, a newly developed electronic method for adherence measurement, in Chapter 7. Theoretically, the smart blister may have some advantages when compared to MEMS. First of all, the smart blister can be delivered in the normal product packaging. As a result patients may be less aware that they are being monitored and curiosity openings may be minimized. The measured adherence may therefore reflect actual adherence more precisely. Secondly, the smart blister makes it possible to get a more thorough insight into the patient's intake behaviour. In case a patient pushes multiple pills through the blister, the time and date of these events are registered. The MEMS, on the other hand, only registers the time and date the pill bottle is opened, but it is unclear how many pills were removed from the bottle. As is true for all indirect methods, also the smart blister does not measure actual drug intake.

So, which method then should preferably be used for adherence measurement? All strategies, including the newly developed ones ${ }^{24-26}$, have their own specific advantages and limitations. In our opinion, the choice for a particular method depends on the information one wants to obtain with it. However, subjective measures, such as self-report, that are sensitive to fraught should not be used. Electronic monitoring by MEMS provides accurate, detailed information about the opening and closing of the MEMS container. Likewise, only counting pills alone has limited value in the measurement of adherence. Indeed, several reports show that pill count tend to overestimate adherence ${ }^{22,27,28}$. On the other hand, the combination of MEMS with pill count will probably lead to more reliable conclusions than either one alone (Chapter 5). Pharmacy refill data give information about the collection of the medication by the patient ${ }^{29}$ and provide researchers with a relatively simple method 
for investigating exposure to medication in large populations ${ }^{22,29,30}$. In our opinion this method is potentially suitable for investigating long-term persistence to treatment and gaps in medication supply (Chapter 6).

\section{What level of adherence is sufficient for clinical effectiveness?}

In the past, many studies tried to answer this question and numerous recommendations have been made. When we compared MEMS data with pill count data (Chapter 5) we found that patients who were classified as non-adherent according to both methods still had a mean adherence of $82 \%$. Given that the patients had adequate blood pressure control, this suggests that an adherence of at least $80 \%$ should be sufficient for an adequate BP reduction, at least in our population. This notion is further supported by the results of several recently performed studies in which the effect of non-adherence on clinical outcomes were investigated ${ }^{31-33}$. Although these studies were observational and carried out only in primary care settings using refill data for adherence calculations, they strengthen our view that an adherence level of approximately $80 \%$ may already be sufficient for a satisfying BP reduction. This means that missing one or perhaps even a few doses will have no demonstrable effect on outcome. Indeed, from a pharmacological point of view one could argue that missing one dose will have limited or no pharmacodynamic consequences. It is, in fact, the plasma half-life of antihypertensive drugs that determines whether a pharmacodynamic effect persists when a patient misses a single dose. Despite these considerations, it remains difficult to define an adherence level that is absolutely necessary for reaching adequate BP reduction. Although our results and those of others suggest that $80 \%$ or more may be sufficient, the data of Chapter 6 in which we investigated the effect of participation in a clinical trial on adherence indicate that failure to reach BP control is not necessarily due to a problem of poor adherence to treatment. The results of that study showed that despite a high adherence rate before and during the trial, the number of participants with an uncontrolled blood pressure remained fairly high. In other words, it is not only poor adherence that may compromise BP control and clinical outcome. Certainly, patient factors such as the degree of resistance to treatment also play a role. Consequently, in controlled settings, such as randomized controlled trials, poor adherence may only be a minor determinant of treatment efficacy. 


\section{Other methodological aspects}

An important observation in the majority of our studies was that adherence to treatment was $>90 \%$. This high adherence rate was probably the result of the specific study design of the HOMERUS trial in which patients had to attend the clinic seven times in one year of follow-up. An advantage of the high adherence was that the primary conclusion of the HOMERUS trial, i.e. that decisions concerning antihypertensive therapy based on SBPM lead to a reduction in the prescription of antihypertensive drugs used and associated costs as compared to decisions based on OBPM, was not confounded by insufficient adherence. However, our results with respect to adherence are not in line with data of the World Health Organization $(\mathrm{WHO})^{34}$ and of studies reporting that patients not only adhere poorly to the prescribed treatment regimen but also discontinue treatment prematurely ${ }^{35-37}$. To some extent, this discrepancy may be explained by the specific study conditions. The results of Chapter 4 and 6 underscore the possible effect of an experimental study on adherence to treatment. In Chapter 4, we found that patients displayed a higher adherence within the 7 days before a visit to the clinic than on the remaining days. Furthermore, within the first 7 days after each visit adherence was significantly lower than on the remaining days. In addition, the results of Chapter 6 showed that participation in a clinical trial increases patient's adherence to treatment. When comparing the observations of the WHO with our results, it is tempting to conclude that participants of clinical trials do not represent real-life patients. This is further reinforced by the data in Chapter 8 . In this chapter we reviewed the marketing authorization applications of all antihypertensive drugs which had been approved for registration in the last 10 years. In particular, we searched for adherence data. The results from our analysis clearly show that inclusion selection bias plays a major role in all applications. Three observations support this notion. First of all, the majority of the trials excluded patients with a history of non-adherence from participation. Secondly, clinical trials in which a placebo run-in phase preceded randomization excluded patients who were non-adherent during the run-in phase. Thirdly, patients who were non-adherent during the clinical trial period were possibly not eligible for further participation, and could be withdrawn from the study. So, how should we interpret the efficacy and safety data of new drugs? Apparently, those data are severely confounded by the excellent adherence rates patients displayed during the trials.

Post-marketing surveillance is an important aspect for drugs to become more universally recommended. If side-effects of a drug result into early discontinuation of treatment, efficacy of that drug will be influenced adversely. So, the expected gain in effectiveness of a new drug compared to usual treatment may be very limited. The current practice of registration trial may, therefore, even violate ethical standards. We recommend that pharmaceutical companies should make every effort to include patients in clinical trials for marketing authorization applications who represent a real- 
life setting. In addition, Medicines Evaluation Boards should take adherence results more into consideration when assessing marketing authorization applications.

So, do we measure what we really want to know about adherence? The results from the present thesis suggest that under experimental conditions adherence rates are sensitive to bias. In our opinion, the methodological limitations need to be solved adequately. Only then we can objectively assess the effectiveness of drugs in a representative population, investigate interventions for increasing adherence to treatment and determine which adherence measure is unobtrusive, objective, and preferably used in adherence research.

\section{Limitations}

A limitation of the present thesis is that many of the studies used data from the HOMERUS trial, and more specifically, from one specific subpopulation. We tried to answer several questions by nesting studies in the randomized controlled trial. Although this may have affected the generalizibility of our results to some extent, we think that our approach resulted in specific information on participants in a clinical trial. Additionally, the studies in our thesis showed that methodological issues may compromise the interpretation and transferability of adherence results into clinical practice. Another limitation of this thesis is that we studied only patients with mild to moderate hypertension. Whether the limited effect of the different interventions studied is similar in patients with other conditions should be subject for further research.

\section{Implications for further research}

An important area for further research that was identified in this thesis concerns the selection of only (highly) adherent patients into clinical trials and its consequences on the assessment of the efficacy and safety of antihypertensive drugs. If adherence plays a role in blood pressure control, more information about a patient's intake behaviour is necessary in order to evaluate the generalizibility of the results of clinical trials. In addition, more studies should be undertaken in which a representative sample of the population is included in the trial. We doubt whether randomized controlled trials should be continued when all too positive adherence measurements show that the included population cannot be representative. In such studies, selection bias is a major threat that limits the extrapolation of the results to broader populations. In addition, the mere participation in a clinical trial already increases patients' adherence to a level that is even less comparable to that found in the general population. Comparative effectiveness research in which large populations 
are investigated by exploring health databases may be an effective strategy when poor adherence plays an important role and when selection bias limits the correct interpretation of trial derived results. This approach should be elucidated in further research. However, this approach will not be suitable for pharmaceutical companies in their research on new chemical entities. To overcome the possible problems that we have identified, we suggest that pharmaceutical companies should make every effort to include patients in clinical trials who represent a real-life setting. In terms of marketing authorization applications, this seems to be a condition sine qua non. In addition, Medicines Evaluation Boards should take adherence results more into consideration when assessing marketing authorization applications.

\section{Conclusion}

Overall, the results of this thesis indicate that (poor) adherence to antihypertensive medication is still a complex topic which is difficult to unravel. Treating physicians and other health care workers should be well aware of these difficulties when incorporating adherence improving strategies into clinical practice. 


\section{References}

1. Haynes RB, Ackloo E, Sahota N, McDonald HP, Yao X. Interventions for enhancing medication adherence. Cochrane Database Syst Rev 2008(2):CD000011.

2. Chapman RH, Ferrufino CP, Kowal SL, Classi P, Roberts CS. The cost and effectiveness of adherenceimproving interventions for antihypertensive and lipid-lowering drugs*. Int J Clin Pract 2010;64: 169-81.

3. Morgado MP, Morgado SR, Mendes LC, Pereira LJ, Castelo-Branco M. Pharmacist interventions to enhance blood pressure control and adherence to antihypertensive therapy: Review and metaanalysis. Am J Health Syst Pharm 2011 ;68:241-53.

4. Schroeder K, Fahey T, Ebrahim S. Interventions for improving adherence to treatment in patients with high blood pressure in ambulatory settings. Cochrane Database Syst Rev 2004(3):CD004804.

5. van Dulmen S, Sluijs E, van Dijk L, de Ridder D, Heerdink R, Bensing J. Patient adherence to medical treatment: a review of reviews. BMC Health Serv Res 2007;7:55.

6. Van Wijk BL, Klungel $\mathrm{OH}$, Heerdink ER, de Boer A. Effectiveness of interventions by community pharmacists to improve patient adherence to chronic medication: a systematic review. Ann Pharmacother 2005;39:319-28.

7. Horne R, Weinman J, Barber N, Elliott R, Morgan M. Concordane, adherence and compliance in medicine taking. London: National Co-ordinating Centre for NHS Service Delivery and Organisation NCCSDO, 2005.

8. Horne R, Weinman J, Hankins M. The beliefs about medicines questionnaire: the development and evaluation of a new method for assessing the cognitive representation of medication. Psychology and Health 1999;14:1-24.

9. Burnier M, Schneider MP, Chiolero A, Stubi CL, Brunner HR. Electronic compliance monitoring in resistant hypertension: the basis for rational therapeutic decisions. J Hypertens 2001;19:335-41.

10. Bertholet N, Favrat B, Fallab-Stubi CL, Brunner HR, Burnier M. Why objective monitoring of compliance is important in the management of hypertension. J Clin Hypertens (Greenwich) 2000;2: 258-62.

11. Waeber B, Vetter W, Darioli R, Keller U, Brunner HR. Improved blood pressure control by monitoring compliance with antihypertensive therapy. Int J Clin Pract 1999;53:37-8.

12. Wetzels GE, Nelemans PJ, Schouten JS, Dirksen CD, van der Weijden T, Stoffers HE, Janknegt R, de Leeuw PW, Prins $\mathrm{MH}$. Electronic monitoring of adherence as a tool to improve blood pressure control. A randomized controlled trial. Am J Hypertens 2007;20:119-25.

13. Santschi V, Rodondi N, Bugnon O, Burnier M. Impact of electronic monitoring of drug adherence on blood pressure control in primary care: A cluster 12-month randomized controlled study. Eur J Int Med 2008;19:427-34.

14. Carnahan JE, Nugent CA. The effects of self-monitoring by patients on the control of hypertension. Am J Med Sci 1975; 269: 69-73.

15. Feldman R, Bacher M, Campbell N, Drover A, Chockalingam A. Adherence to pharmacologic management of hypertension. Can J Public Health 1998; 89: I16-8.

16. Vrijens B, Goetghebeur E. Comparing compliance patterns between randomized treatments. Control Clin Trials 1997;18:187-203.

17. Marquez-Contreras E, Martell-Claros N, Gil-Guillen V, de la Figuera-Von Wichmann M, CasadoMartinez JJ, Martin-de Pablos L, Figueras M, Galera J, Serra A. Efficacy of a home blood pressure monitoring programme on therapeutic compliance in hypertension: the EAPACUM-HTA study. J Hypertens 2006;24:169-75.

18. Ashida T, Sugiyama T, Okuno S, Ebihara A, Fujii J. Relationship between home blood pressure measurement and medication compliance and name recognition of antihypertensive drugs. Hypertens Res 2000;23:21-4.

19. Rudd P. In search of the gold standard for compliance measurement. Arch Intern Med 1979;139: 627-9.

20. Farmer KC. Methods for measuring and monitoring medication regimen adherence in clinical trials and clinical practice. Clin Ther 1999;21:1074-90. 
21. Urquhart J. The electronic medication event monitor. Lessons for pharmacotherapy. Clin Pharmacokinet 1997;32(5):345-56.

22. Cramer JA, Mattson RH, Prevey ML, Scheyer RD, Ouellette VL. How often is medication taken as prescribed? A novel assessment technique. JAMA 1989;261:3272-7.

23. Rudd P, Ahmed S, Zachary V, Barton C, Bonduelle D. Improved compliance measures: applications in an ambulatory hypertensive drug trial. Clin Pharmacol Ther 1990;48:676-85.

24. Oakley D, Potter L, de Leon-Wong E, Visness C. Oral contraceptive use and protective behaviour after missed pills. Fam Plann Perspect 1997;29:277-9, 287.

25. Santschi V, Wuerzner G, Schneider MP, Bugnon O, Burnier M. Clinical evaluation of IDAS II, a new electronic device enabling drug adherence monitoring. Eur J Clin Pharmacol 2007;63:1179-84.

26. Yamada H, Nakashima M. New electronic device for monitoring medication compliance. Am J Health Syst Pharm 2003;60:1910-1.

27. Pullar T, Kumar S, Tindall H, Feely M. Time to stop counting the tablets? Clin Pharmacol Ther 1989;46:163-8.

28. Matsui D, Hermann C, Klein J, Berkovitch M, Olivieri N, Koren G. Critical comparison of novel and existing methods of compliance assessment during a clinical trial of an oral iron chelator. J Clin Pharmacol 1994;34:944-9.

29. Steiner JF, Prochazka AV. The assessment of refill compliance using pharmacy records: methods, validity, and applications. J Clin Epidemiol 1997;50:105-16.

30. Andrade SE, Kahler KH, Frech F, Chan KA. Methods for evaluation of medication adherence and persistence using automated databases. Pharmacoepidemiol Drug Saf. 2006;15:565-74.

31. Mazzaglia G, Ambrosioni E, Alacqua M, Filippi A, Sessa E, Immordino V, Borghi C, Brignoli O, Caputi AP, Cricelli C, Mantovani L. Adherence to antihypertensive medications and cardiovascular morbidity among newly diagnosed hypertensive patients. Circulation 2009;120:1598-1605.

32. Dragomir A, Côté R, Roy L, Blais L, Lalonde L, Bérard A, Perreault S. Impact of adherence to antihypertensive agents on clinical outcomes and hospitalization costs. Med Care 2010;48:418-25.

33. Kettani FZ, Dragomis A, Côté R, Roy L, Bérard A, Blais L, Lalonde L, Moreau P, Perreault S. Impact of a better adherence to antihypertensive agents on cerebrovascular disease for primary prevention. Stroke 2009;40:213-20.

34. Sabate E. Adherence to long term therapies: evidence for action. Geneva:World Health Organization, 2003.

35. The sixth report of the joint national committee on prevention, detection, evaluation, and treatment of high blood pressure. Arch Int Med 1997;157:2413-56.

36. Vrijens B, Vincze G, Kristanto P, Urquhart J, Burnier M. Adherence to prescribed antihypertensive drug treatments: longitudinal study of electronically compiled dosing histories. BMJ 2008;336:1114-7.

37. Van Wijk BL, Shrank WH, Klungel OH, Schneeweiss S, Brookhart MA, Avorn J. A cross-national study of the persistence of antihypertensive medication use in the elderly. J Hypertens 2008;26:145-53. 
Summary 


\section{Chapter 1}

Hypertension is a major risk factor for the development of cardiovascular morbidity and mortality, and continues to be a major health problem since its prevalence is increasing worldwide. Hypertension affects approximately 1 billion adults, a number that is expected to have increased by $60 \%$ in 2025 . Despite the availability of several effective blood pressure lowering drugs, data indicate that $30 \%$ of the Americans with hypertension are unaware of their high blood pressure, and of those who are being treated for hypertension only 34-50\% reach a controlled blood pressure below 140/90 $\mathrm{mmHg}$.

It is generally acknowledged that poor adherence to antihypertensive drugs compromises treatment of high blood pressure. Estimated adherence rates in patients with hypertension range from 20 to more than $90 \%$. Moreover, up to $50 \%$ of the patients with hypertension discontinue treatment within one year after initiation. Differences in study design, method of adherence measurement, follow-up period, drug regimens used, and patient groups may explain this large variation in adherence results.

Many studies have addressed the complexity of adherence to treatment and tried to identify factors related to adherence and non-adherence. Despite that, there is paucity of research on methodological aspects of adherence measures and the impact of interventions to improve adherence. In this thesis we focused on these two issues in general and provided suggestions for new strategies in adherence measurement.

\section{Chapter 2}

In this chapter we systematically reviewed the literature to identify successful interventions aimed at improving adherence to antihypertensive treatment. In the last decade several systematic reviews on this topic have been published. It appears that generalizability of successful interventions for improving adherence to treatment in patients with hypertension is limited by the variety and complexity of different interventions that were subject to research. Furthermore, the complexity of nonadherence limits the applicability of these interventions into clinical practice. We tried to categorize the interventions into those that determine intentional (internal factors) and unintentional (external factors) non-adherence. This conceptual framework refers to barriers to patients taking medicines (unintentional non-adherence) and to deliberate decisions patients make to adjust their medication use (intentional nonadherence).

We included 78 studies of which 64 were randomized controlled trials. In general, the methodological quality of the included studies was poor. Only 33 studies showed a significant increase in adherence to treatment. Successful randomized controlled trials $(n=27)$ showed an increase in adherence level of 0.5 to $62 \%$ compared to 15 to $17.2 \%$ 
in non-randomized controlled trials $(n=6)$. Interventions targeting both internal and external factors were not more successful than interventions targeting internal or external factors only. Almost all interventions were complex, including combinations of education, self measurement of blood pressure, motivational interviewing, and establishing a health behaviour change.

We concluded that current methods of improving adherence are complex and not consistently effective. The conceptual framework of non-adherence may be unsuitable for the population at large. Future studies should therefore focus on patient's behavioural intentions, barriers and subjective norms.

\section{Chapter 3}

In this chapter we focused on the effect of electronic monitoring of adherence to treatment by means of Medication Event Monitoring System (MEMS) on blood pressure control in a population with mild to moderate hypertension. Compared to other adherence measures, electronic monitoring has the advantage that more detailed and accurate information can be obtained. In addition, electronic monitoring may improve adherence to treatment, as patients are aware of adherence monitoring. Hence, it may reduce the number of drugs used and improve blood pressure control. There is, however, little information available on the long-term effect of this intervention on blood pressure control.

In this observational study among 470 patients with mild to moderate hypertension adherence was measured in 228 patients by means of both the MEMS and pill count (intervention group), and in 242 patients by means of pill count alone (control group). Patients had been followed for 1 year.

On the basis of pill count, median adherence to treatment did not differ between the intervention group and the control group. In both groups, systolic and diastolic blood pressure decreased similarly: $23 / 13$ vs. $22 / 12 \mathrm{mmHg}$ in the intervention and control group respectively. Drug changes and the number of drugs used were associated with blood pressure at the start of study, but not with electronic monitoring.

We concluded that electronic monitoring of adherence to treatment by means of MEMS does not lead to better long-term blood pressure control nor does it result in less drug changes and drug use.

\section{Chapter 4}

We evaluated the effect of self blood pressure measurement (SBPM) on adherence to treatment. Several reports suggest that SBPM may increase adherence to prescribed drugs. Indeed, patients are more aware of their elevated blood pressure as they will 
notice a rise in pressure when they fail to take their medication. Implementation of self-measurements in the routine diagnostic and therapeutic follow-up could, therefore, be of great value in the management of hypertension.

In this prospective, randomized controlled study a total of 228 mild-to-moderate hypertensive patients were randomized to either a group that performed selfmeasurements at home in addition to office blood pressure measurements (OPBM) or a group that only underwent OBPM. We measured adherence by means of MEMS.

Although median adherence was significantly higher in the SBPM group (92.3\%) than in the OPBM group (90.9\%), differences were small and clinically not relevant. We also investigated whether adherence to treatment varied over time between two subsequent visits to the hospital or general practitioners' office. Although identical among both groups, in the week directly after each visit to the physician's office adherence was significantly lower than at the last seven days prior to each visit.

The upcoming consultation probably acted as an important intervention for improving adherence to treatment.

\section{Chapter 5}

In Chapter 3 we evaluated a potential advantage of MEMS monitoring on adherence to treatment. As patients become more aware of the adherence measurement, adherence levels may increase and, hence, blood pressure control. This positive reinforcement may also be a limitation of electronic monitoring. The use of MEMS could trigger the patient to open the MEMS container each day without taking medication from it. As a result, adherence would appear to be sufficient, yet the outcome variable, i.e. blood pressure control, will be disappointing. On the other hand, patients could open the pill bottle less often than prescribed and spare up extra doses whilst ingesting the medication at the correct time (pocket dosing). This behaviour will lead to an underestimation of adherence determined by MEMS, even though blood pressure may at times be better controlled.

In this observational study we compared MEMS data with pill count data among a total of 228 patients with mild-to-moderate hypertension. For both methods, an adherence level of at least $90 \%$ was defined as acceptable. This indicates that patients could be classified as adherent or not on the basis of both MEMS and pill count. Four categories were identified: A. Non-adherent by both methods, B. Adherent by MEMS but not pill count, $C$. Adherent by pill count but not MEMS, and D. Adherent by both methods.

It appeared that in 107 (47\%) and 33 (14\%) patients both methods agreed in defining adherence and non-adherence, respectively. Thirty-one (14\%) patients were adherent only by MEMS and 59 (25\%) patients only by pill count. At the end of the study, patients in the four categories reached comparable blood pressure values and reductions. Adherence in patients who were categorized as non-adherent according 
to both methods was $>80 \%$. So, this suggests that an adherence level of at least $80 \%$ may be sufficiently effective in reducing blood pressure. Nevertheless, pill count could be a useful adjunct to electronic monitoring in assessing deviant intake behaviour.

\section{Chapter 6}

Although poor adherence is considered to be a major determinant of uncontrolled blood pressure, several observations indicate that adherence to treatment is fairly high in patients who participate in a clinical trial. So, there seems to exist a difference in adherence rates between 'real-life' practice and clinical practice under experimental conditions, suggesting that participation in a clinical trial increases adherence to treatment. This positive reinforcement could be explained by the specific design of the study in which patients usually have to attend the clinic more often than usual. Alternatively, patients who are more engaged with their condition and treatment may be more willing to participate in a trial in which adherence is monitored. Consequently, patients may be more adherent upfront as compared to what is observed in a general population.

We performed a retrospective, cohort study among 182 patients who participated in the Home versus Office blood pressure Measurements: Reduction of Unnecessary treatment Study (HOMERUS) between 2001 and 2005. Pharmacy refill data were obtained from 1999 until 2010. Refill adherence to treatment was compared for the periods before, during, and after the HOMERUS trial. Persistence to medication was investigated for the period after termination of the trial.

The results showed that participation in a clinical trial significantly increased adherence to treatment. After the trial period, refill adherence decreased again to a level that did not differ from the adherence before the study. Except for adherence to trial medication, adherence to non-trial related drugs also increased as a consequence of trial participation. Participants classified as adherent (adherence $>90 \%$ ) were less likely to discontinue treatment compared to non-adherent participants in the period after termination of the trial.

The results of this study suggest that participants are more involved with their conditions and treatments when they participate in a clinical trial.

\section{Chapter 7}

To date, several methods are available for measuring adherence to treatment. Though electronic monitoring of adherence is considered to be the gold standard, no method fulfils all requirements for valid adherence measurement. 
In this study we investigated the feasibility of a recently developed 'smart blister' in clinical practice. The smart blister is an exact copy of the backside of a regular medication blister. This copy is provided with an electronic detection circuit and printed on an adhesive label (i.e. the smart blister). The smart blister uses conductive tracks that detect when (date and time) a pill is pushed out of the blister pack. This information is stored on a chip and can be transferred via the Near Field Communication interface to an internet accessible database.

To determine the feasibility of the smart blister we registered the functionality and the robustness of the smart blister. Functionality was determined by variables that could influence the interpretation and analysis of registered events. The robustness of the smart blister was determined by calculating the percentage of blisters that registered multiple events at exactly the same time as a consequence of breaking multiple conductive tracks. During a period of 60 days, 115 patients used 245 smart blisters. Functionality of the smart blister was adequate (72-100\%). However, fortytwo smart blisters (17\%) registered multiple events at the same time as a consequence of breaking multiple conductive tracks. In general, participating pharmacists considered the smart blister suitable for implementation into daily routine. Participants who used the smart blister found pharmacist's involvement into patient's treatment a possible advantage.

We concluded that the smart blister is a promising method for adherence measurement. However, in order to produce robust and easy to use smart blisters the blister needs further improvement.

\section{Chapter 8}

In this chapter we focussed on the availability of adherence data for the evaluation of a drug's efficacy and safety in the treatment of hypertension. Randomized controlled trials are crucial to the scientific evaluation of therapies, and are mandatory for drug approvals by Medicines Evaluation Boards (MEBs). In such trials, poor adherence can be a major threat for obtaining statistical power to detect intervention effects.

We searched the Dutch MEB database for all antihypertensive drugs approved between January 1, 2000 and March 2011. The drugs of interest consisted of new chemical entities and single pill combinations of two or more generic medicinal products or generic medicinal product(s) combined with branded drugs. Potentially relevant registration files were screened for clinical information regarding drugs' efficacy and safety profiles with respect to adherence data.

Our search identified 10 antihypertensive drugs that were approved for registration between January 1, 2000 and March 2011. In all clinical studies adherence was measured by pill count. When reported mean adherence was nearly perfect ( $>98 \%)$. In the majority of the trials, a history of non-adherence was an exclusion criterion for participation. Patients whose adherence level was below a minimal pre-defined level 
were classified as protocol violators and were excluded from randomization, were excluded from the per protocol analysis, or could be withdrawn from further participation.

We concluded that a drug's efficacy and safety profile is not confounded by nonadherence. The excellent adherence rates observed in clinical trials for marketing authorization appilications are a consequence of the specific study design of those trials. Including patients in clinical trials who represent a real-life setting should be made mandatory for pharmaceutical companies.

\section{Chapter 9}

We discussed the conclusion with regard to the practical implications of measuring adherence to treatment, interpreting and generalizing adherence results, and implementing interventions strategies to improve adherence to treatment. In summary, the main implications of our research are the following:

- Health care workers should take notice of possible unrepresentative adherence results derived from clinical trials for their own population

- To improve the generazilibility of trial derived adherence results, more patients who represent the general population should be included in clinical trials

- MEBs should take adherence results more into account when interpreting drugs' efficacy and safety.

- As long as there is a paucity in the implementation of new methods for adherence measurement, different measures should be combined to obtain more reliable adherence data

- Interventions for improving adherence to treatment should be evaluated in relation to patients' specific needs. Attention should be paid to patients' involvement and responsibility in their treatments.

Implications for further research were discussed. Future research should focus on the selection of (highly) adherent patients into clinical trials and its consequences on drugs' efficacy and safety in hypertension. In addition, more studies should be undertaken in which a representative sample of the population is included in the trial. Further research should elucidate whether comparative effectiveness research in which populations are investigated by exploring health databases is an effective strategy when poor adherence plays an important role and when selection bias limits the correct interpretation of trial derived results. 
Samenvatting 
158 Chapter 1 


\section{Hoofdstuk 1}

Hypertensie is een belangrijke risicofactor voor cardiovasculaire morbiditeit en mortaliteit. Het aantal patiënten met hypertensie wordt geschat op 1 miljard en zal de komende jaren verder stijgen. De laatste decennia is veel aandacht besteed aan de preventie en behandeling van hoge bloeddruk. Ondanks een toegenomen bewustzijn onder de bevolking en het beschikbaar zijn van effectieve bloeddrukverlagende geneesmiddelen is $30 \%$ van de Amerikanen zich niet bewust van het feit dat zij een hoge bloeddruk hebben en blijkt dat 30-50\% van de patiënten met hypertensie geen adequate bloeddrukcontrole bereikt.

Een verminderde therapietrouw wordt verondersteld als belangrijke determinant voor het niet bereiken van voldoende bloeddrukdaling. Geschat wordt dat therapietrouw aan antihypertensiva varieert tussen de $20 \%$ en $90 \%$. Daarnaast stopt ongeveer $50 \%$ van de patiënten met de behandeling binnen 1 jaar na start hiervan. Grote verschillen met betrekking tot therapietrouw worden gesignaleerd tussen de studies. Dit komt met name doordat de studies verschillen in opzet, in de methode waarmee therapietrouw wordt gemeten, in de duur van de studie, in de behandelschema's die worden onderzocht en in de populatie die wordt onderzocht.

In de afgelopen decennia hebben veel studies de complexiteit van therapietrouw aan antihypertensiva onderzocht. Desondanks is nog relatief weinig onderzoek gedaan naar de methodologische aspecten van onderzoek naar therapietrouw en het effect van verschillende interventies op therapietrouw. In dit proefschrift richten we ons op deze twee aspecten en geven we suggesties voor nieuwe benaderingen voor het meten en verbeteren van therapietrouw.

\section{Hoofdstuk 2}

In dit hoofdstuk hebben we de literatuur systematisch verzameld en beoordeeld. Primaire doelstelling van dit literatuuronderzoek was het identificeren van succesvolle interventies met als doel het verbeteren van de therapietrouw aan antihypertensiva. In het afgelopen decennium zijn verschillende literatuuroverzichten gepubliceerd waarin het effect van dergelijke interventies is onderzocht. Uit deze onderzoeken kan geconcludeerd worden dat het toepassen van succesvolle interventies in de praktijk beperkt is doordat de onderzochte interventies complex zijn. Daarnaast blijkt dat op het oog vergelijkbare interventies niet consistent effectief zijn.

In dit literatuuroverzicht hebben we getracht een onderverdeling te maken in de interventies door ze te categoriseren naar interventies die intentionele therapieontrouw beïnvloeden en interventies die niet-intentionele therapietrouwontrouw beïnvloeden. Barrières voor patiënten die ertoe leiden dat geneesmiddelen niet worden ingenomen leiden tot niet-intentionele therapieontrouw; vooringenomen 
acties van patiënten om geneesmiddelen niet in te nemen worden beschouwd als intentionele therapieontrouw.

We includeerden 78 studies, waarvan 64 gerandomiseerde, gecontroleerde studies waren. Slechts 33 studies lieten een significante verbetering in therapietrouw zien. De verbetering die werd gezien in gerandomiseerde, gecontroleerde studies was 0.5 tot $62 \%$. In niet-gerandomiseerde studies was de verbetering in therapietrouw 15 tot 17.2\%. Interventies die zowel intentionele als niet-intentionele therapieontrouw aanpakten waren niet meer succesvol dan interventies die een van de twee aspecten onderzochten. Over het algemeen werden de interventies als complex beschouwd. Het combineren van educatie, zelf meten van de bloeddruk, beïnvloeding van perceptie over hypertensie en de behandeling hiervan waren de meest voorkomende interventies.

We concludeerden dat de huidige methoden om therapietrouw te bevorderen complex en niet consistent effectief zijn. Het categoriseren van de interventies naar intentionele en niet-intentionele aspecten lijkt niet geschikt te zijn om verder onderscheid te maken in effectiviteit van de verschillende interventies. In toekomstige studies dient aandacht besteed te worden aan de patiënt als individu zodat op basis van patiëntkarakteristieken een individueel interventieprogramma opgesteld kan worden.

\section{Hoofdstuk 3}

In dit hoofdstuk onderzochten we het effect van het electronisch meten van therapietrouw met behulp van de 'Medication Event Monitoring System' (MEMS) op het bereiken van bloeddrukcontrole. Vergeleken met andere methoden om therapietrouw te meten, heeft het gebruik van MEMS voor het meten van therapietrouw een aantal voordelen. Ten eerste kan gedetailleerde en accurate informatie verkregen worden. Ten tweede zijn er aanwijzingen dat het gebruik van MEMS de therapietrouw bevordert, waardoor het aantal geneesmiddelen dat een patiënt gebruikt en de bloeddruk dalen. Er is hieromtrent echter weinig bekend over de effecten op langere termijn.

We voerden een observationeel onderzoek uit onder 470 patiënten met hoge bloeddruk. Therapietrouw werd in 228 patiënten gemeten met behulp van zowel MEMS als door het tellen van pillen (de interventiegroep); in de overige 242 patiënten werd de therapietrouw alleen gemeten door het tellen van de pillen (de controlegroep). Patiënten werden gevolgd gedurende 1 jaar. Op basis van het tellen van de pillen werd geen verschil in therapietrouw gevonden tussen beide groepen. In beide groepen werd een vergelijkbare daling gezien in systolische en diastolische bloeddruk: 23/13 (interventiegroep) versus 22/12 (controlegroep) $\mathrm{mm} \mathrm{Hg}$. Het gebruik van MEMS had geen effect op het aantal wijzigingen in geneesmiddelen en het aantal gebruikte geneesmiddelen. 
We concludeerden dat het gebruik van MEMS na 1 jaar niet tot een betere bloeddrukcontrole leidt, noch dat het leidt tot minder geneesmiddelengebruik en het aantal wijzigingen in geneesmiddelen.

\section{Hoofdstuk 4}

We onderzochten het effect van zelf meten van de bloeddruk door patiënten op therapietrouw aan antihypertensiva. Het zelf meten van de bloeddruk zou de therapietrouw bevorderen, hetgeen verklaard kan worden door een grotere betrokkenheid van de patiënt bij de behandeling. Routinematige implementatie van zelfmetingen in de behandeling van hypertensie zou dan ook van toegevoegde waarde kunnen zijn in de behandeling.

In dit prospectieve, gerandomiseerde onderzoek werden 228 patiënten met hoge bloeddruk gerandomiseerd naar een groep patiënten die als aanvulling op ambulante bloeddrukmetingen zelfstandig de bloeddruk maten en een groep waarbij alleen ambulante bloeddrukmetingen plaatsvonden. De therapietrouw werd gedurende 1 jaar waarin 7 visites plaatsvonden gemeten met behulp van MEMS.

De mediane therapietrouw was in de zelfmetingen groep significant hoger dan in de groep waarbij alleen ambulante metingen werden verricht: $92.3 \%$ versus $90.9 \%$. Het verschil was echter klein en klinisch niet relevant. We onderzochten ook of de therapietrouw varieerde tussen twee visites in. Hieruit bleek dat in de week voorafgaand aan een visite met de medisch specialist of huisarts de therapietrouw significant hoger was dan in de week na de visite. Het aankomende bezoek aan de arts fungeerde mogelijk als een belangrijke interventie om de therapietrouw te verhogen.

\section{Hoofdstuk 5}

In hoofdstuk 3 evalueerden we een mogelijk voordeel van electronische monitoring van de therapietrouw met behulp van MEMS. Het gebruik van MEMS kan leiden tot een verhoging van de therapietrouw, omdat patiënten op de hoogte zijn van de metingen die worden gedaan. Deze verhoging in therapietrouw kan vervolgens leiden tot een verbetering van de bloeddruk. Deze positieve beïnvloeding kan ook een nadeel zijn van MEMS metingen. De mogelijkheid bestaat dat patiënten dagelijks de MEMS container openen zonder dat ze er een tablet uithalen. Dit leidt er toe dat de therapietrouw adequaat lijkt, terwijl dit mogelijk niet wordt teruggezien in de bereikte bloeddruk. Daarnaast kunnen patiënten de MEMS container minder vaak openen, maar wel per opening meer tabletten uit de container halen. Deze tabletten zouden op een later moment ingenomen kunnen worden. Het gevolg hiervan is dat de therapietrouw laag is, terwijl mogelijk een adequate bloeddrukdaling wordt bereikt. 
In dit observationele onderzoek vergeleken we van 228 patiënten MEMS data met gegevens over het tellen van pillen. Voor beide methoden werd een therapietrouw van $90 \%$ als voldoende beschouwd om te worden geclassificeerd als therapietrouw. Uiteindelijk werden 4 groepen gevormd: 1 groep die volgens beide methoden therapietrouw was, 2 groepen die volgens een van beide methoden therapietrouw was en 1 groep die volgens beide methoden niet-therapietrouw was.

Honderdenzeven (47\%) patiënten werden volgens beide methoden geclassificeerd als therapietrouw; 33 (14\%) patiënten werden volgens beide methoden geclassificeerd als niet-therapietrouw. Eenendertig (14\%) patiënten waren therapietrouw volgens MEMS gegevens, maar niet volgens het tellen van pillen, terwijl 59 (25\%) patiënten therapietrouw waren volgens het tellen van pillen, maar niet volgens de MEMS gegevens. Patiënten in alle vier de categorieën bereikten aan het einde van de studie een vergelijkbare bloeddrukdaling. De therapietrouw van patiënten die volgens beide methoden werden geclassificeerd als niet-therapietrouw was $>80 \%$. Dit suggereert dat een therapietrouw van ten minste $80 \%$ voldoende is om een effectieve bloeddrukdaling te bereiken. Desalniettemin, het tellen van pillen als methode om therapietrouw te meten naast het gebruik van eletronische metingen lijkt zinvol voor het inzichtelijk maken van een afwijkend innamegedrag.

\section{Hoofdstuk 6}

Ondanks dat een verminderde therapietrouw beschouwd wordt als een belangrijke determinant voor een slechte bloeddrukcontrole, laten verschillende onderzoeken zien dat therapietrouw over het algemeen voldoende is bij patiënten die deelnemen aan een klinische studie. Het lijkt er dus op dat er een verschil bestaat tussen de therapietrouw bij patiënten in de eerste-lijn en bij patiënten die deelnemen aan een klinische studie. Dit verschil kan mogelijk verklaard worden doordat deelname aan een studie de therapietrouw verhoogt. Daarnaast bestaat de mogelijkheid dat patiënten die betrokken zijn bij de aandoening en behandeling meer geneigd zijn om deel te nemen aan een studie. Mogelijkerwijs is de therapietrouw van deze laatste categorie patiënten voor aanvang van de studie al hoger dan wat normaal gesproken gezien wordt in de eerste-lijns zorg.

We voerden een retrospectief, cohort onderzoek uit onder 182 patiënten die tussen 2001 en 2005 hadden deelgenomen aan de Home versus Office blood pressure Measurements: Reduction of Unnecessary treatment Study (HOMERUS) studie. Van deze patiënten werden bij de openbare apotheek over de periode 1999-2010 aflevergegevens van geneesmiddelen opgevraagd. Op basis van deze gegevens werd de therapietrouw berekend en vergeleken voor de perioden vóór, tijdens en na deelname aan de HOMERUS studie. Continuering van medicatie werd na einde van de klinische studie onderzocht. 
Deelname aan een klinische studie verhoogde de therapietrouw significant. $\mathrm{Na}$ de studieperiode daalde de therapietrouw weer naar waardes vergelijkbaar aan de periode vóór de studie. De stijging in therapietrouw als gevolg van deelname aan de studie was ook zichtbaar voor geneesmiddelen die niet in studieverband waren voorgeschreven. Patiënten die werden geclassificeerd als niet-therapietrouw $(<90 \%)$ hadden een grotere kans op het eerder stoppen met medicatie in de periode na beëindiging van de studie.

De resultaten van de studie suggereren dat deelnemers aan een studie meer betrokken zijn danwel worden bij hun aandoening en de behandeling hiervan.

\section{Hoofdstuk 7}

Op dit moment zijn verschillende methoden beschikbaar voor het meten van therapietrouw. Het electronisch meten van therapietrouw wordt op dit moment beschouwd als de gouden standaard. Desalniettemin blijkt dat geen enkele methode voldoet aan alle eisen die gesteld worden aan een objectief meetinstrument.

In deze studie onderzochten we de bruikbaarheid van een recent ontwikkelde medicatieblister, de 'smart blister', voor het electronisch meten van de therapietrouw. De 'smart blister' is een exacte kopie van de achterkant van een reguliere medicatieblister, waarop electronische banen zijn geprint. De 'smart blister' is in staat om het moment (dag en tijd) van het doordrukken van een tablet door de blister te registreren. Deze informatie wordt in een chip opgeslagen en kan op ieder moment worden verstuurd naar een database op het internet.

De bruikbaarheid van de 'smart blister' werd gedefinieerd als representanten van de functionaliteit en de robuustheid van de blister. De functionaliteit werd bepaald door variabelen die de interpretatie en analyse van de geregistreerde data konden beïnvloeden. De robuustheid werd bepaald door het percentage van de blisters te berekenen waarbij op het exact hetzelfde moment meerdere registraties plaatsvonden. Bij het uitdrukken van de tablet uit de blister worden electronische banen verbroken. De mogelijkheid bestaat dat meerdere banen tegelijkertijd worden verbroken. Dit leidt tot meerdere registraties op hetzelfde moment, terwijl slechts 1 tablet uit de blister is verwijderd.

Gedurende een gemiddelde periode van 60 dagen zijn door 115 patiënten 245 'smart blisters' gebruikt. De functionaliteit van de 'smart blister' was voldoende. De robuustheid was beperkt. Over het algemeen beschouwden de openbare apothekers de 'smart blister' als geschikt voor implementatie in de routinematige zorg. Patiënten beschouwden de intensievere begeleiding door de apotheker als mogelijk voordeel van de 'smart blister'.

We concludeerden dat de 'smart blister' een veelbelovende methode kan zijn voor het inzichtelijk maken van de therapietrouw. Echter, verdere ontwikkeling dient nog plaats te vinden. 


\section{Hoofdstuk 8}

In dit hoofdstuk is gekeken naar de beschikbaarheid van therapietrouwgegevens bij de beoordeling van de effectiviteit en veiligheid van antihypertensiva. Voordat een geneesmiddel in de handel gebracht mag worden moet het middel geregistreerd worden door het College ter Beoordeling van Geneesmiddelen (CBG). Het CBG beoordeelt of de voordelen van het gebruik aantoonbaar opwegen tegen de nadelen (effectiviteit - veiligheid balans). Gerandomiseerde, gecontroleerde onderzoeken zijn noodzakelijk om deze balans inzichtelijk te maken. Een verminderde therapietrouw kan er echter toe leiden dat deze balans verstoord wordt.

We doorzochten de CBG database naar antihypertensiva, zowel nieuwe chemische entiteiten als combinatiepreparaten, geregistreerd tussen 1 januari 2000 en maart 2011. Registratiedossiers die in aanmerking kwamen voor inclusie werden onderzocht op klinische informatie betreffende effectiviteit en veiligheid en de rol van therapietrouw hierin.

De zoekactie leverde 10 registraties op van zowel nieuwe chemische entiteiten als combinatiepreparaten. In alle klinische studies die de registratiedossiers vormden werd therapietrouw gemeten met behulp van het tellen van pillen. Therapietrouw gegevens waren niet in alle onderzoeken beschikbaar. In de onderzoeken waarin therapietrouw wel was weergegeven was deze tenminste $98 \%$. In de meerderheid van de studies werden patiënten met een verleden van verminderde therapietrouw geëxcludeerd voor deelname. Patiënten die gedurende de studie niet voldoende therapietrouw waren, werden geëxcludeerd voor randomisatie, werden geëxcludeerd voor de per-protocol analyse of mochten niet verder meer deelnemen aan de studie. We concludeerden dat de effectiviteit en veiligheid van een nog te registreren geneesmiddel niet wordt beïnvloed door een verminderde therapietrouw. De hoge therapietrouw die geobserveerd werd in de klinische studies wordt veroorzaakt door de methodologie van de studies. Farmaceutische bedrijven zouden meer patiënten die de algehele populatie representeren moeten includeren.

\section{Hoofdstuk 9}

We bespraken de conclusies met betrekking tot de praktische implicaties van het meten van therapietrouw, de interpretatie en generaliseerbaarheid van therapietrouwgegevens en de mogelijkheden om therapietrouw te verbeteren. 
Samenvattend zijn de belangrijkste implicaties van ons onderzoek:

- Zorgverleners zouden zich goed moeten realiseren dat therapietrouwgegevens voortkomend uit klinische hypertensie studies mogelijk niet representatief zijn voor hun eigen populatie

- Om de generaliseerbaarheid van therapietrouwgegevens uit klinische hypertensie studies te verbeteren zou meer aandacht besteed moeten worden aan de inclusie van patiënten die representatief zijn voor de totale populatie

- Geneesmiddel registratieautoriteiten zouden bij het beoordelen van registratiedossier van (nieuwe) antihypertensiva, therapietrouwgegevens meer in overweging moeten nemen bij de interpretatie van de effectiviteit en veiligheid van deze middelen

- Zolang nieuwe methoden om therapietrouw te meten nog niet geïmplementeerd zijn, zouden meerdere, bestaande meetmethodes gecombineerd moeten worden om een betrouwbaarder innamepatroon van een patiënt te kunnen krijgen

- Interventies voor het verbeteren van de therapietrouw zouden op individueel patiënt niveau geëvalueerd moeten worden, waarbij de betrokkenheid en verantwoordelijkheid van patiënten in hun eigen behandeling aandacht moet krijgen

Implicaties voor verder onderzoek werden besproken, waarbij vervolgonderzoek zich zou moeten richten op de selectie van patiënten die (zeer) therapietrouw zijn in klinische studies in relatie tot de effectiviteit en veiligheid van antihypertensiva. Daarnaast zou uit vervolgonderzoek moeten blijken dat de populatie die geïncludeerd is ook daadwerkelijk representatief is voor de totale populatie. Verder onderzoek zou moeten uitwijzen of observationeel, cohort onderzoek waarbij gebruikt wordt gemaakt van databases beter geschikt is dan gecontroleerde, gerandomiseerde studies voor het inzichtelijk krijgen van de effectiviteit van geneesmiddelen in relatie tot de therapietrouw. 
166 
Dankwoord 


\section{Dankwoord}

Het dankwoord. Het meest gelezen hoofdstuk van het proefschrift. Wellicht omdat het door de lezers als herkenbaar wordt beschouwd, of juist om er zeker van te zijn dat de promovendus niemand is vergeten te noemen...

Heel veel mensen hebben op de een of andere manier bijgedragen aan de totstandkoming van dit proefschrift. In de eerste plaats wil ik de patiënten die hebben deelgenomen aan de verschillende onderzoeken bedanken. Zonder hen was dit onderzoek niet mogelijk geweest.

Mijn promotores prof. P.W. de Leeuw en prof.dr. C. Neef. Beste Peter, bij onze eerste kennismaking vroeg je me of ik ervaring had met het schrijven van artikelen. Een beetje wel dacht ik...De kunst om een inleiding bondig te beschrijven heeft me door de jaren heen wel wat hoofdbrekens bezorgd (waarom dan niet een inleiding in één zin?). Dank voor je ondersteuning en het uitgebreid meedenken met onderzoeksvragen, maar ook voor de juiste benadering van problemen waar ik niet zo snel mee verder kwam.

Beste Kees, nadat je in Maastricht was begonnen als hoogleraar sloot je wat later bij het promotieteam aan. Bedankt voor je ondersteuning en het leggen van de contacten met onze Duitse collegae. Hopelijk kunnen we in de toekomst het onderzoek met de 'smart blister' nog verder vormgeven.

Mijn copromotores dr. P-H.M. van der Kuy en dr. W.J. Verberk. Beste Hugo, we kennen elkaar (al) sinds dat ik in Maastricht ging werken, eerst als projectapotheker en later als ziekenhuisapotheker in opleiding. Ik was degene die interesse had in onderzoek en jij had nog wel wat ideeën. Vaak op dat moment niet al te gestructureerd en onderbouwd, maar zoals later bleek wel innovatief. We zijn eerst begonnen met onderzoek naar het effect van implementatie van een electronisch voorschrijfsysteem op de medicatieveiligheid. Net één week voordat we de ZonMw subsidie wilden indienen bleek dat onze collegae het jaar ervoor exact hetzelfde onderzoek ingediend en toegewezen hadden gekregen. Hoe groot de teleurstelling op dat moment, was jij degene die nog wat contacten had met het HOMERUS team. En zo geschiedde...Beste Hugo, dank voor je tomeloze inzet om dit traject succesvol af te ronden, voor je kritische en vooruitziende blik, voor je bereidwilligheid om op ieder moment van de dag te overleggen, voor je bijdrage aan de systematische review, het benaderen van openbare apothekers en de organisatie rondom het promotietraject. Ik heb het als bijzonder leerzaam ervaren om met je samen te werken.

Beste Willem, jij was de HOMERUS promovendus van het eerste uur. Jouw bereidwilligheid om mij in de HOMERUS trein te laten stappen heeft ervoor gezorgd dat ik ook direct aan de slag kon. Met een populatie waarvan we initieel dachten, daar kunnen we weinig mee, is het toch gelukt om een aantal mysteries te ontrafelen. Ik heb heel veel van je geleerd gedurende het promotietraject. Ook al werd het contact 
na de eerste jaren minder, je hebt altijd een duidelijke rol in de onderzoeken gehad. Heel veel dank voor je ondersteuning.

Drs.ir. A.G.H. Kessels, beste Fons, jouw statistische kennis en kunde over onderzoeken hebben me zeker gevormd. Het was altijd erg leerzaam om regelmatig met jou na te denken over de methodologie en analyse van data. Daarnaast zijn jouw programmeerkwaliteiten onmisbaar voor het onderzoek gebleken. Heel veel dank voor je ondersteuning.

Dr. A.A. Kroon, beste Bram, bedankt voor jouw bijdrage in de HOMERUS studie. Zonder de inclusie van de Maastrichtse populatie, waar jij de grootste bijdrage in hebt geleverd, hadden de vervolgonderzoeken niet plaatsgevonden.

Mw. dr. P.J. Nelemans, beste Patty, het was een genoegen deelgenoot te zijn van jouw expertise op therapietrouwgebied. Jouw kritische blik was zeer waardevol. Ik vind het een eer dat je deel wilde nemen aan de beoordelingscommissie.

Frederique Menger, jouw hulp bij het onderzoek met de apotheekdata kwam als geroepen. Een onderzoek waarvoor we al twee jaar een onderzoeksstudent konden gebruiken, alleen niemand die reageerde. Gelukkig heb jij een deel van het onderzoek voor jouw rekening kunnen nemen en is het een fraai artikel geworden. Heel erg bedankt voor jouw bijdrage.

Mw. dr. C.C. Gispen, beste Christine, en dr. P.G.M. de Mol, beste Peter, bedankt voor jullie bijdrage aan het CBG onderzoek. Christine, jij hebt het mogelijk gemaakt dat we dit onderzoek hebben kunnen uitvoeren. Dank voor jullie ondersteuning en kritische blik op het manuscript.

Alle openbare apothekers in de regio Maastricht en daarbuiten wil ik bedanken voor de medewerking bij alle onderzoeken in dit proefschrift.

De paranimfen, Rogier van der Zanden en Erwin Vasbinder. Wat fijn om jullie straks naast me te hebben staan. We gaan er een mooie dag van maken!

Beste Rogier, we kennen elkaar al sinds de middelbare school. Daarna dezelfde studie, straatgenoten en nu beiden ziekenhuisapotheker. De cheese-onion, six-pack, PSV (in Enschede viel het doelpunt altijd 1 seconde eerder dan in Maastricht), zitmaaier, het mountainbiken in februari bij -3 zonder fatsoenlijke kleding zijn een van de vele mooie herinneringen. Hopelijk gaan er nog vele komen.

Beste Erwin, en weer een ziekenhuisapotheker die therapietrouwonderzoek doet. Afgaande op je kritische blik en spontaniteit gaat je dit zeker lukken.

Lieve vrienden, ondanks dat we met $z$ 'n allen erg druk zijn, blijkt bij iedere gelegenheid maar weer dat de contacten 'alive and kicking' zijn. Het is prachtig om te horen waar iedereen mee bezig is en wat er nog gaat komen. 
De secretariaten van de afdeling Klinische Farmacie en Toxicologie en Interne Geneeskunde van het Universitair Medisch Centrum Maastricht, beste dames, bedankt voor het regelen van de benodigde formulieren voor het College van Decanen, het maken van afspraken en waarschijnlijk nog een heleboel zaken die achter de schermen hebben plaatsgevonden en waarvan ik geen weet heb.

Tiny Wouters, fantastisch hoe je in rap tempo de layout hebt kunnen verzorgen van het proefschrift. Het is prachtig geworden. Heel veel dank hiervoor.

Karin van der Zanden, bedankt voor het ontwerp van het proefschrift. Het is (wederom) prachtig geworden.

De manuscriptcommissie, prof.dr. Struijker Boudier, prof.dr. Crijns, prof.dr. Leufkens, mw. dr. Nelemans en mw. prof.dr. Sturkenboom bedankt voor het bestuderen en beoordelen van dit proefschrift.

De (oud-)collegae van de ziekenhuisapotheek van het Universitair Medisch Centrum Maastricht, het Sint Jans Gasthuis, Weert en het UMC St. Radboud, Nijmegen, beste allen, bedankt voor jullie interesse in mijn onderzoek.

Drs. E.L.M. Hardy, beste Eugene, dank voor je betrokkenheid en interesse in de afgelopen jaren. De wijncursus gaat nu echt een keer gevolgd worden.

Mijn schoonfamilie, Peter, Annie, Jasper en Nicky. Ik heb het met jullie getroffen. Dank voor jullie warmte en interesse.

Pa, ma en mijn broers Dignar en Emiel, Linda, Tijn en Mila. Lieve pa en ma, jullie hebben de basis gelegd voor mijn ontwikkeling. Ik kan me voorstellen dat het voor jullie niet altijd eenvoudig was om mijn promotietraject te ontrafelen. Toch hebben jullie altijd heel erg veel belangstelling getoond. Heel erg bedankt voor jullie warmte, belangstelling en onvoorwaardelijke liefde en steun. Lieve Dignar en Emiel, als jongste van de drie ben ik niet de economie ingegaan. De relatie zorg-economie begint echter steeds meer vorm te krijgen. Jullie kritische blik heeft me mede gevormd zoals ik nu ben. Heel erg bedankt voor jullie belangstelling en steun. Lieve Linda, Tijn en Mila, wat fijn dat jullie weer in Nederland wonen. Zo kunnen de kids weer samen optrekken.

En lieve Lonneke, onze geschiedenis gaat al heel wat jaren terug. Wat heb ik het getroffen met jou, en er gaat nog een hele mooie tijd komen samen met Joep en Fleur. Zonder jou had ik dit traject niet kunnen afronden. Destijds bedankte je me voor het bewaken van de vrije tijd. Jij hebt me nu de tijd gegeven om het af te ronden. Het is af. We krijgen er vrije tijd voor terug. 
172 
Curriculum Vitae 


\section{Curriculum Vitae}

Hein van Onzenoort was born on the $14^{\text {th }}$ of July 1978 in Maarheeze, the Netherlands. After obtaining his secondary school diploma at the Philips van Horne Scholengemeenschap, Weert in 1997, he started studying Pharmaceutical Sciences at the University of Utrecht. In 2001 he obtained his Master's degree and in 2003 he graduated as a pharmaceutical doctor. Subsequently, he started working at the department of clinical pharmacy and toxicology of the Maastricht University Medical Centre in Maastricht, where he also began his residency in hospital pharmacy in 2004 and his PhD thesis in 2005. In 2008 he registered as hospital pharmacist and started working at the pharmacy department of the St. Jans Gasthuis in Weert and the internal medicine department of the Maastricht University Medical Centre in Maastricht. Since July 2009 he has been working as hospital pharmacist at the clinical pharmacy department of the Radboud University Nijmegen Medical Centre, Nijmegen. Hein is married to Lonneke and is father of Joep and Fleur. 
